Portland State University

PDXScholar

Fall 9-26-2014

\title{
Out of the Way and Out of Place: An Interpretative Phenomenological Analysis of the Experiences of Social Interactions of Bisexually Attracted Young People
}

A. Del Quest

Portland State University

Follow this and additional works at: https://pdxscholar.library.pdx.edu/open_access_etds Let us know how access to this document benefits you.

\section{Recommended Citation}

Quest, A. Del, "Out of the Way and Out of Place: An Interpretative Phenomenological Analysis of the Experiences of Social Interactions of Bisexually Attracted Young People" (2014). Dissertations and Theses. Paper 2002.

https://doi.org/10.15760/etd.2001

This Dissertation is brought to you for free and open access. It has been accepted for inclusion in Dissertations and Theses by an authorized administrator of PDXScholar. Please contact us if we can make this document more accessible: pdxscholar@pdx.edu. 
Out of the Way and Out of Place: An Interpretative Phenomenological Analysis of the Experiences of Social Interactions of Bisexually Attracted Young People

by

A. Del Quest

A dissertation submitted in partial fulfillment of the requirements for the degree of

Doctor of Philosophy

in

Social Work and Social Research

Dissertation Committee:

Ben Anderson-Nathe, Chair

Tom Keller

Jim Nash

Sally McWilliams

Portland State University

2014 
(C) 2014 A. Del Quest 


\begin{abstract}
Research addressing the concerns of bisexually attracted youth has markedly increased in the past few years, yet remains limited in comparison to that addressing the issues of lesbian and gay youth (Brewster \& Moradi, 2010). Those few studies treating bisexual participants as distinct from lesbian and gay participants have findings indicating that some youth who identify as bisexual experience higher rates of depression, pregnancy, substance abuse, suicidal ideations, and suicide attempts compared to their lesbian and gay peers (Kennedy \& Fisher, 2010; Lewis, Derlega, Brown, Rose, \& Henson, 2009; Saewyc, Homma, Skay, Bearinger, Resnick, \& Reis, 2009). Most commonly, however, research studies examine all lesbian, gay, bisexual, transgender, and queer participants as one group, and little is known about the ways in which these distinct groups differ. Biphobia, defined as the aversion felt toward bisexuality and bisexuals as a social group or as individuals, contributes to barriers in addressing this gap.

The primary objective of this study was to gain an understanding of how the participants recalled their social interactions and how they made sense of them. In depth, semi-structured interviews were conducted with ten young people who were bisexually attracted when they were of high school age. Results were analyzed and discussed using an Interpretative Phenomenological Analysis (IPA) approach. Analyses of these accounts revealed the ways these young people made sense of feeling dismissed, isolated, invisible, and unsafe in their environments and the ways they used their observations to control future interactions. The participants discussed their experiences with coming out
\end{abstract}


to family members and friends and the strain of choosing to hide their attractions to more than one gender.

These findings indicate the need for services offering specific supports and interventions for bisexually attracted youth. Social workers, youth workers, and educators can best serve this population by acknowledging the uniqueness of their experiences.

Future research, focused on group specific concerns, could close the existing gap in the knowledge base. 


\section{Dedication}

This is dedicated to each of the participants who shared their stories so generously and to everyone who knows normal is a unicorn.

It is also dedicated to my two blue-eyed Irish angels:

Patric Ailcy Tempest Hatton: you taught me to be who I was no matter what and to always work to make the world a better place. I still miss you every day, Mom, and I wish you could see how your kid turned out.

Milissa Marmon: My dearest wife, you gave me the greatest gift of all - belief in who I could become. Thank you for carrying me through this. We're living the dream, baby! 


\section{Acknowledgements}

There are so many people who have a hand in the creation of a dissertation - it is impossible to mention everyone who owns a piece of this one. Friends and family carried me through the dark days. How smart was I to choose each of you? I have been blessed with such incredible mentors along the way: teachers who took the time to really work with me; writers who gave me feedback (even when I didn't want it); and young people who took a chance and shared their "stuff" with me. I cannot mention each of you by name. I would surely leave someone out and that would make me feel horrible. Suffice it to say I carry your gifts with me and share them with others.

Ben - I don't have the words to tell you how much your guidance, mentorship, brilliance, example, humor, and friendship mean to me. You and I both know I would not have made it to this day without you. That gift I will continue to pay forward since I can never pay you back.

To my dedicated committee members - thank you just seems so inadequate to convey my appreciation for your patience, encouragement, commitment, and willingness to read all those drafts. Please know you have each made me a better teacher and mentor to my students by your example.

And my "panions" - thanks for the car rides, coffees, lunches, laughs, distractions, cheers, tears, puppies, pockets, squirrels, and koping. Where would I be without each of you? I have been truly blessed. 
Table of Contents

Abstract..................................................................... i

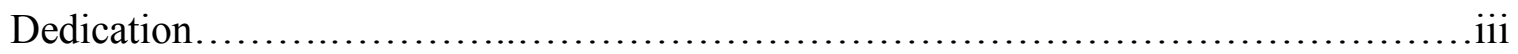

Acknowledgements....................................................... iv

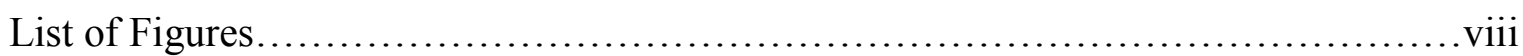

\section{Chapter One}

Introduction.............................................................. 1

Background......................................................... 4

Purpose of the study...................................................... 6

Relevance to social work and implications for practice........................... 7

Chapter Two: Literature review and theoretical foundation

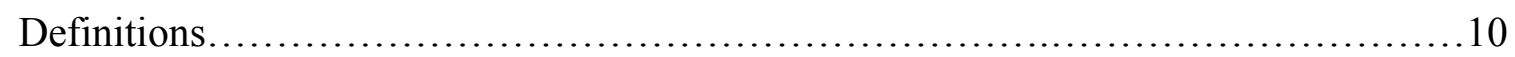

Theoretical foundation...................................................... 11

Overview of literature.................................................... 16

Research Questions......................................................... 30

Chapter Three: Methodology

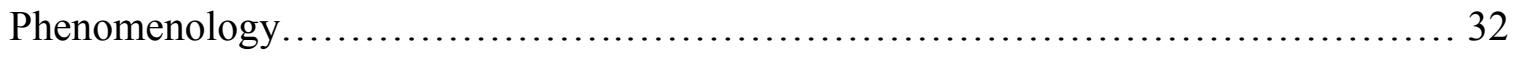

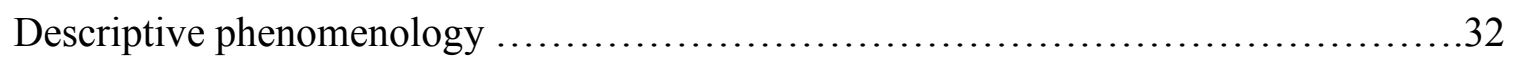

Hermeneutic/Interpretative phenomenology................................. 37

Interpretative phenomenological analysis................................... 42

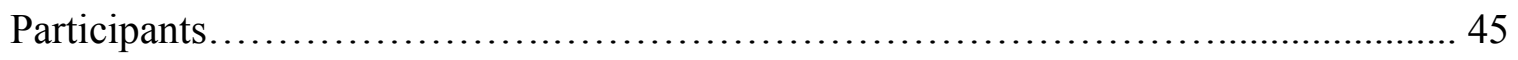

Primary data collection..................................................50

Interview Process.......................................................... 51

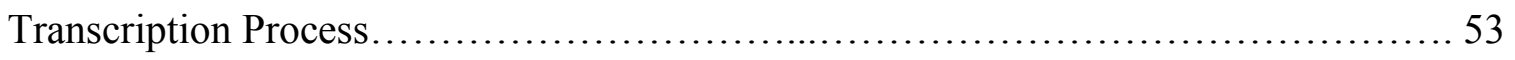


SOCIAL INTERACTIONS vi

Researcher positionality...................................................... 54

Ethical considerations..................................................... 56

Chapter Four: Analysis

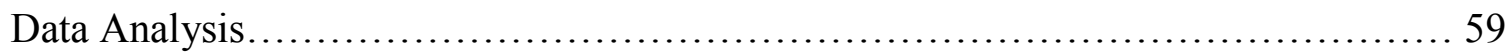

Evaluation of Validity.................................................... 67

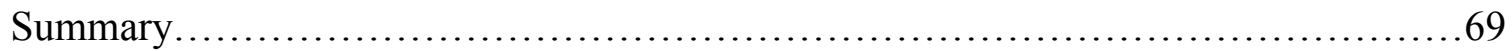

Chapter Five: Findings

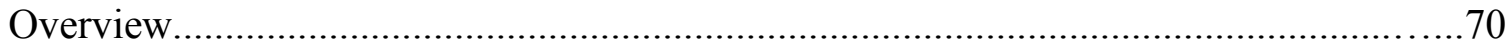

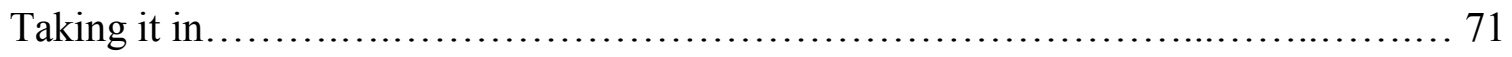

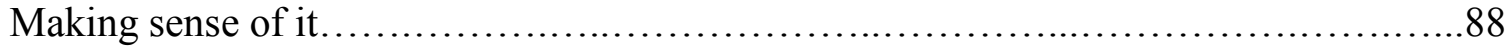

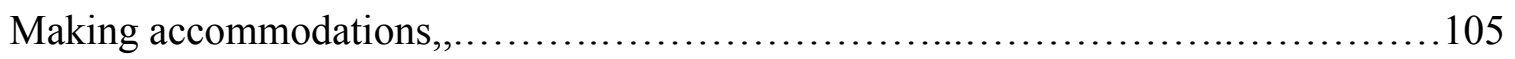

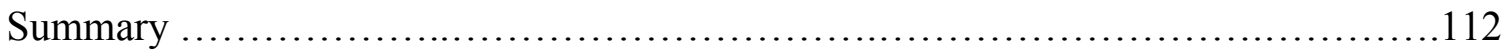

Chapter Six: Implications

Limitations............................................................ 120

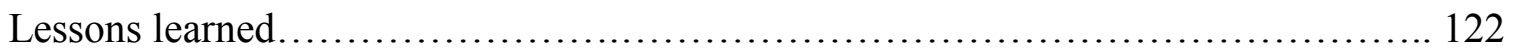

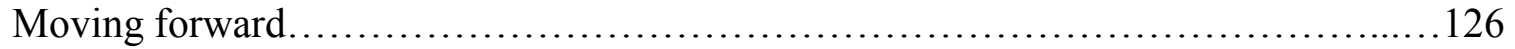

Research implications................................................. 127

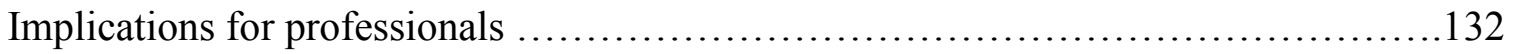

Closing reflections........................................................... 134

References.......................................................... 137

Appendix A: Consent for participation............................................ 154

Appendix B: Interview guide............................................ 156 
Appendix C: Disclosure statement........................................ 158

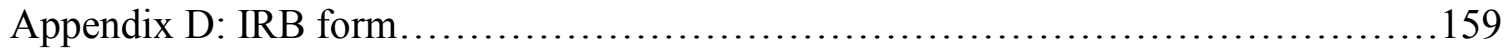

Appendix E: Screening Protocol........................................... 162

Appendix F: Recruitment Flyer............................................... 163

Appendix G: Participant bios.............................................. 164 


\section{List of Figures}

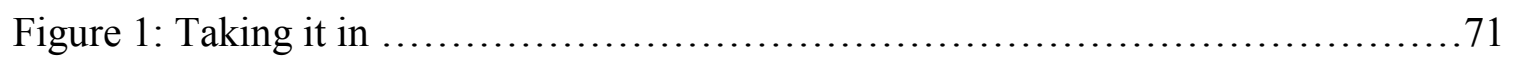

Figure 2: Making sense of it............................................. 88

Figure 3: Making accommodations........................................ 106 


\section{Chapter One: Introduction}

The past decade has been a time of change for many lesbian, gay, bisexual, trans*, and queer (LGBTQ) people in the United States. The social environments of young people experiencing same- and multiple-sex attractions are apt to be more accepting than in previous generations. Debates around issues such as same-sex marriage and federal benefits for married gay couples foster conversations and increase the visibility of some types of relationships. However, included in these discussions is an assumption of a binary categorization of sexual identity - gay/lesbian or straight. And, while the changes in legal union options for some gay men and lesbians are encouraging for some, this persistent binary assumption results in little consideration being given to the spectrum of relationship types for bisexual, trans*, and queer people, perpetuating the invisibility of bisexual men and women and limiting the discussion of the full range of relationship possibilities.

Biphobia (or binegativity) is defined as the aversion felt toward bisexuality and bisexuals as a social group or as individuals. This aversion contributes to the invisibility of bisexuality and remains a barrier in addressing it (Elia, 2010). Research addressing concerns of bisexually attracted people has increased markedly in the past few years, yet remains limited in the social science fields in comparison to the growing attention paid to identity issues in lesbian and gay populations (Brewster \& Moradi, 2010). Elia (2010) argued that little recognition of bisexuality as a valid and legitimate sexual identity may constitute one possible reason for this lack of attention: "often it is difficult... to believe and accept that it is possible for individuals...to genuinely have a stable sexual identity that includes sexual attractions/contact and/or romantic feelings for both members of the 
same sex and the other sex" (p. 454). Several prevailing myths regarding bisexual young people are discussed in more detail in Chapter Five as they impacted some participants' interactions. Two examples of myths heard by these young people were the belief that bisexual attractions are transitional and lead to a gay or lesbian identity (Burleson, 2005) and that those who are bisexually attracted are promiscuous.

While the focus of the current study was solely on the experiences of bisexually attracted young people, some attention to the issues faced by LGBTQ young people are addressed in the literature review. This discussion is offered as a context for the experiences of the participants in social interactions when others were aware of their "gay side." As identified above, the binary categorization of sexual identity has also resulted in a perpetuation of the invisibility of bisexuals in the academic literature and in research studies. Another limitation resulting from the reliance on the binary categorization is inconsistency in measurement approaches in research studies. This limitation is addressed in the next section.

Some researchers have struggled to find consistent ways to conceptualize the categories of gay, lesbian, and bisexual, resulting in questions about whether samples of sexual minorities in one study are comparable to samples in other studies (e.g., Austin, Conron, Patel, \& Freedner, 2007; Saewyc, 2011; Savin-Williams, 2005). Shifts in how individuals choose to label (or not label) themselves add to the challenges experienced by researchers (Russell, Clarke, \& Clary, 2009). While use of some labels such as "gay" and "lesbian" remained stable over the past couple of decades, more recent use of terms such 
as "queer" or "fluid" (Savin-Williams, 2005) have been added as more accurate choices, with "gay" and "lesbian" viewed as increasingly out of date.

The challenge created by the inconsistent labeling manifests, for some studies, in how to phrase recruitment materials to capture the attention of intended participants, how to compare studies across disciplines because inconsistent ways of labeling and identifying lead to questions about similarity of studies, and a clear and consistent way to describe the population of interest in the current study. I chose the term bisexually attracted $^{1}$ youth (or young people/person) to indicate participants who were not exclusively heterosexual or exclusively gay/lesbian in their attractions. Friedman and colleagues (2004) indicated the importance of allowing the aim of the study to determine how sexual identity is measured. I contend that our social interactions are initiated and maintained based on how we portray ourselves to others - the self we put forward; for this reason, the proposed study relied on the young person's self-identification of sexual attractions.

A dichotomous separation of sexuality into homosexuality and heterosexuality, as generally accepted by the dominant American culture, reinforces the assumption that all people fit into one of those categories. This categorization effectively omits bisexuality from consideration as a valid identity (Bradford, 2004). According to McLean (2001), the

\footnotetext{
${ }^{1}$ For the purposes of clarity, the term "bisexually attracted" was used in this dissertation to indicate someone who is not exclusively gay/lesbian or heterosexual. Terms chosen by people to identify their sexuality vary widely and it is not within the scope of this document to address each one or how (or if) people choose to label themselves. For the purposes of this study, the term bisexually attracted accurately reflected my intention as researcher to include participants in the sample who experienced attraction to both males and females while they were in high school, regardless of whether they told others about their attractions, claimed this as an identity, or disclosed this identity to anyone.
} 
most pervasive impact of a binary definition of sexual orientation is the reinforcement of the invisibility of bisexuals (p. 110), which has the effect on young people struggling to make sense of their attractions of creating a feeling of not belonging anywhere, of being stuck in the middle of two worlds with little support from either. Existing literature perpetuates this invisibalization through this process when it presents studies which examine the lives of LGBTQ youth as an aggregate of all youth who self-label as lesbian, gay, bisexual, trans*, or queer/questioning, with little attention to the differences among the groups. Only a few of the multiple articles supporting this study examined data from bisexual participants separately from their gay or lesbian peers. The little data that does exist indicates that youth who identify as bisexual experience higher rates of depression, pregnancy, substance abuse, high risk sexual behaviors, suicidal ideations, and suicide attempts compared to gay and lesbian peers (Kennedy \& Fisher, 2010; Lewis, Derlega, Brown, Rose, \& Henson, 2009; Saewyc, Homma, Skay, Bearinger, Resnick, \& Reis, 2009). These findings suggest that youth who identify as bisexual may not benefit from supports available to their gay and lesbian peers, making it important to understand their needs more fully in order to adequately support them.

The following sections describe the background and purpose of the study. They also describe the study's relevance for social work in terms of practitioners providing services to bisexually attracted youth, as well as implications for future research.

\section{Background}

Learning to engage in social interactions is continuous and influenced by previous experiences. Each experience a young person has influences future interactions and 
shapes how he or she chooses to engage in subsequent ones. Most young people rely on available role models, societal images that resonate, and peer relationships (Glover, Galliher, \& Lamere, 2009; Morrow, 2004) to provide them with examples of ways to interact. While LGBTQ youth face many of the same challenges that come with social relationships, they also manage stressors such as stigmatization and the potential of parent/family rejection based on their sexual identity, potentially leaving them to navigate the transition to young adulthood with few positive role models (Detrie \& Lease, 2007; Saewyc, et al., 2006; Wright \& Perry, 2006). Increasingly, there are role models for these youth but they are often difficult for youth to identify. Supportive relationships and social connectedness to peers and family have been identified in several studies (e.g., Davis, Saltzburg, \& Locke, 2009; Difulvio, 2011; McNicholas, 2002) as important factors in fostering resiliency for these youth, helping them navigate some of the additional stressors they may face as a result of heterosexist and homophobia-related stigma. Focusing on the positive aspects of LGBTQ youths' interactions with others allows educators and service providers to identify ways to increase the sense of connectedness these youth feel to peers and family members and to support new connections (Detrie \& Lease, 2007).

Over the past decade, research has increased examining those factors which may indicate the risk of negative outcomes (e.g. victimization, stigmatization, family or peer rejection) as well as those factors functioning in a protective way (e.g. support from peers and family, connectedness to school and community) in the lives of LGBTQ young people. This research suggested that these youth tend to have higher rates of some 
negative outcomes compared to their heterosexual peers (Robinson \& Espelage, 2011). Recent studies (e.g., Espelage, Aragon, Birkett, \& Koenig, 2008; Russell \& Seif, 2010) indicate bisexual youth may be at even greater risk of some of the negative outcomes mentioned above. However, many of these studies were designed from a deficits orientation, focusing on negative outcomes, high-risk behaviors, and the challenges faced by LGBTQ youth. They largely failed to incorporate strengths, coping strategies, support networks, and other factors that hold the potential to improve the lives of LGBTQ youth (e.g., Hatzenbuehler, 2011; Kaminski, et al., 2010; Needham \& Austin, 2010). Studies focused on assets youth utilize while navigating their lives offer the opportunity to inform the ways support is offered.

\section{Purpose of the Study}

Gaining an understanding about the experiences of bisexually attracted young people's social interactions with their peers during their high school years was the purpose of the current study. Understanding and nurturing those factors that support youth in seeking out positive interactions with peers could help bisexually attracted youth manage experiences of stigmatization based on their attractions (Detrie \& Lease, 2007). Other scholars have shown that positive peer relationships, those in which a young person feels a sense of safety and experiences support when discussing sexuality-related topics, are a protective factor for some youth. Those youth who experience positive relationships are more likely to complete high school (LaFromboise \& Lewis, 2008), feel a sense of social connectedness (Detrie \& Lease, 2007), and experience a sense of belonging (Brendtro, Brokenleg, \& VanBockern, 2002), all factors in keeping young people 
engaged in education and in reducing self-harming behaviors (Detrie \& Lease, 2007). A better understanding of peer relationships among bisexual youth and their social circles can help both correct the unhealthy or damaging interactions and cultivate the healthy ones.

\section{Relevance to Social Work and Implications for Practice}

Not all LGBTQ young people experience school and school age years in the same way and the focus of this study was to examine the range of experiences had by the participants. While many bisexual youth are reporting higher rates of self-harming behaviors, substance use, suicidal ideation and attempts, many more do not have this experience. Practitioners and researchers need a clearer understanding of how these youth see these experiences. What do they think about their social interactions with their peers? Are their experiences of the social world of high school as punishing as existing (largely deficit-based) research suggests? Are the needs of all LGBTQ youth the same? Or are the experiences of youth who do not identify as exclusively heterosexual or gay/lesbian different in significant ways, meaning that the one size fits all approach to working with this population will not be effective for them?

Despite many positive changes in school environments over the past decade (Savin-Williams, 2005), school settings continue to be a source of struggles for some LGBTQ youth. Many schools have added Gay-Straight Alliances (GSAs) to provide a space for LGBTQ students to interact with each other in a safe setting. While these groups are open to all students, they can seem exclusionary to bisexually attracted youth because the name Gay - Straight Alliance implies the group is exclusive to those who 
identify as gay or straight. Research on the effectiveness of these groups indicates that LGBTQ youth in schools having a GSA report less substance abuse, fewer missed days of school due to fear of victimization, and the ability to identify a teacher or staff member they believe to be supportive (Heck, Flentje, \& Cochran, 2011). A limitation of these findings in terms of their applicability to bisexual youth is that it is difficult to know if GSAs provide a sense of safety to bisexual youth in the same ways they do for gay and lesbian youth because the experiences of bisexual youth have not been examined separately from their gay and lesbian peers. Additionally, some bisexual youth report feeling they are not part of any group - gay and lesbian peers tell them to choose and straight peers tell them they are too gay (McLean, 2001).

Schools can be supportive environments; however, more frequently schools are experienced by LGBTQ youth as physically and psychologically unsafe (Kennedy \& Fisher, 2010). School staff can be trained to understand that much of the risk for selfharming behaviors among LGBTQ youth stems from responses to negative interactions with peers, family, and society and not from inherent problems related to identification as a LGBTQ (Kennedy \& Fisher, 2010). Social workers, bound by the Code of Ethics to intervene in instances of violence or harassment against others, are ideally placed to improve school climates. School social workers can be instrumental in interrupting the marginality and isolation experienced by bisexual students and can be supportive of students by validating bisexuality as a healthy and natural identity.

Social work researchers have the opportunity to interrupt the deficits-based orientation which dominates the academic literature. Conducting research that focuses 
only on risk behaviors and negative outcomes supports the prevailing picture of the struggling gay teen. Conducting research perpetuating the silencing of some voices and the privileging of others reinforces stereotypes. It was important that this study focus solely on the experiences of this group in light of the prevailing invisibility of bisexually attracted people in the existing literature. The current study intended to explore the range of experiences had by the participants and to give voice to the young people who shared their stories with the hopes of gaining a fuller understanding of the lived experiences of bisexually attracted youth. 
SOCIAL INTERACTIONS

\section{Chapter Two: Literature Review and Theoretical Foundation}

All young people have stories uniquely their own, experiences only they can describe, and skills at navigating their lives that would work for no one but them. As a clinician working with this population, I learned that to be most effective in providing them with support and resources, it was necessary to first listen to how they understood these experiences. This chapter begins with a description of the study's theoretical foundations followed by a literature review. This review of the literature focuses on factors related to the aspects of social connectedness, identity development, and how young people develop a sense of self that is healthy and well-adjusted within the context of their lives.

\section{Definitions}

I present the following definitions of several of the concepts in this chapter in the interest of providing clarity. Each of the following is a feature of some of the experiences of the participants and will be addressed in more detail. The definitions presented here are those I relied on for this study.

Binegativity. Klesse's (2011) definition of this term is the one most referenced in recent literature on bisexuality: "Binegativity works through a broad set of oppressive practices, which include forms of violence (interpersonal, legal, institutional), discrimination (social, cultural, legal), as well as epistemic erasure and denigration through negative representations" (p. 234). As Cox, Bimbi, and Parsons (2013) found, binegative attitudes exist in several environments with which bisexually attracted people are involved, including families, peers, schools, and among therapists and counselors: 
"Binegativity is a complex area of study with important implications for the well-being of a stigmatized group in our society who face discrimination from heterosexuals and gay men and lesbians. Binegativity is particularly insidious phenomenon due to its pervasiveness" (p. 224).

Homonormativity. The concept of homonormativity mirrors heteronormativity in that exclusion of those who do not conform to a set of stereotypes has become accepted. The enforcement of these stereotypes is a strategy intended to gain rights for a cultural group (Cover, 2013) through the adherence to those representations of queerness that are deemed acceptable by broader society, including a binary classification of sexual attractions. This concept manifested in the study as a sense of being excluded from the gay and lesbian community and the participants experienced it as a dismissal of their attractions.

Monosexism. Monosexism is the assumption that a stable sexual identity includes sexual attraction/contact/romantic feelings for just one sex/gender (Dworkin, 2001). This is evident in several of the themes and will be explained more fully.

\section{Theoretical foundation}

The theories relied on in this study are symbolic interactionism, social constructionism, and sexual minority stress. The following section presents a description of each, along with a rationale for its choice as a basis for this study.

Symbolic interactionism. Symbolic interactionism is rooted in social psychology and theorizes that people's interpretations of their worlds are the basis for how they construct that world. According to this theory, each person structures their external world 
through interpretations and this perception of their world influences behaviors. Symbolic interactionism is based on the belief that people should be regarded in the context of their environment and that behaviors adapt to the dynamic nature of this environment (Benzies, 2001). "Symbolic interactionism provides a theoretical perspective of studying how individuals interpret objects and other people in their lives and how this process of interpretation leads to behavior in specific situations" (Benzies, p. 544). An individual's behaviors are constantly changing depending on how they interpret their world. Habits arise through interpretation, which in turn further influences behaviors.

There are three main tenets of the theory. The first is that people's interactions with others are based on the meanings they attach to their experiences. This meaning resides in the behavior people direct toward an object rather than in the object itself. In this study, the object is language young people use in interactions. The second tenet is that the meanings attached to experiences are influenced by previous interactions. Meaning emerged for the study's participants out of the way others defined objects and the agreed upon meanings of these objects in their environments. Interactions were influenced by how meaning emerged in previous engagements with others. According to Blumer (1969), imagining the reactions others will have to them influences the sense of self people derive from interactions. The third tenet states that meanings are affected by interpretations of interactions. People play an active role in shaping their future through this process of interpreting meaning. New meanings are formed through the interpretation of stimuli and people form new ways to respond based on these interpretations. Thus, it is impossible to find an ultimate truth. People attach meaning to the communications they 
have with others "within the context in which the interaction takes place" (Rogers, 2010, p. 93).

Symbolic interactionism is included as part of the theoretical foundation of the current study because of the attention on the influence of communication in context. A focus of the study was the influence previous interactions had on how the participants chose to engage in future interactions. The integration of messages taken in during an interaction was evident in the way the participants filtered future incoming and outgoing messages as a result of their experiences in social interactions. The current study drew on this understanding suggesting that bisexually attracted young people modify how they engage with others based on their interpretations of previous social interactions.

Social constructionism. This theory is similar to symbolic interactionism in that it acknowledges that each person perceives the world in a unique way and asserts that people construct their reality based on their experiences. People's perceptions of their interactions reflect their culture, history, language, and experiences as well as how these things have impacted their interpretations. The focus is on the process of how people make sense of their interactions and create their realities with social constructionism. Attention to multiple realities provides a solid theoretical foundation for the current study because the participants' unique experiences are the focus of interest.

Social constructionism differs in that it is more interested in what happened within and among people during an interaction and not as concerned with the outcome of the interaction. The theory provides a basis for deconstruction, which is especially useful for this study. Deconstruction is the examination of how one group's reality has become 
accepted, allowing for the reinforcement of the group's power over social values and beliefs. A focus of the study's analysis was to consider the participants' experiences in the context of a heteronormative culture and explore how enculturation into it impacted the participants. Heterosexual relationships have acquired the power to shape beliefs and dictate behaviors in the dominant American culture. This reality has become the right way to do things. Using the theory as a framework in which to view the participants' interactions helped to identify the common ground among them and what helped them make sense of their world.

The proposed study, with a focus on the experiences of the participants, relies heavily on this theory because of these basic tenets. The participants were asked to describe their experiences and how they made sense of those experiences from their place in the world. Social constructionism provides a theoretical basis for my expectation that the participants will have constructed their reality based on previous experiences and that their future engagement with (or avoidance of) similar interactions may be determined by these experiences.

Sexual Minority Stress. Meyer (2003) conceptualizes sexual minority stress as an extension of social stress theory, and suggests that environmental conditions may impact some individuals who belong to stigmatized groups such as LGBTQ people. Experiences of discrimination and prejudice can have negative impacts on mental and physical health (Balsam \& Mohr, 2007; DiPlacido, 1998). Sexual minority stress is more than daily hassles - it includes externally stressful events (threats of violence, verbal or physical violence) and the anticipation of such events (Lewis et al., 2009). Those who 
have experienced a stressful event (e.g. victimized at school) anticipate it occurring again, becoming vigilant in hopes of warding off the next experience (Meyer, 2003). Participants of this study who experienced incidents of sexuality-related stress talked about the changes that occurred in their feelings of safety and the steps they took to place themselves in more comfortable situations.

Sexual minority stress can manifest through the social psychological internalization of negative societal attitudes, the psychological pressures associated with maintaining a concealed identity, and even internal conflicts resulting from discordant beliefs (Wright \& Perry, 2006). Results of a study by Teasdale and Bradley-Engen (2010) showed that identity-related stressors are more negatively received than other types of stressors, resulting in differential mental health outcomes. The concept of buffering supports the belief that it is possible for youth to withstand a single instance of a stressor, depending on his or her coping skills, but several stressful events increase the possibility that serious mental health outcomes will occur (Cohen \& Wills, 1985). Developing a positive identity in a climate of social stigma requires resiliency (Morrow, 2004).

The sexual minority stress model guided my analysis because the experience of stress impacted how the participants engaged in and experienced social interactions. Linking sexual minority stress with symbolic interactionism, I anticipated the stress of negative social interactions would impact the participants' sense of self and how they chose to interact with peers and may influence how they would seek support from family members. As shown above, experiencing a sense of social connectedness can support a young person in many ways. This sense of connectedness may, however, be interrupted if 
a young person also has experiences of sexuality-related stress. The ability to use the experiences to determine when or if to engage with someone is a potential benefit of this stress. A young person learns quickly that a negative experience with a certain person could be indicative of future conflicts, making social interactions with that person not worth the effort. Bandura (1997) described this process of integrating experiences and developing self-efficacy in social learning theory.

The matching theory of social support posits that support will be most beneficial when it specifically addresses the stressors at hand (Cohen \& Wills, 1985). Youths' perception that they are not able to cope with situations gives rise to feelings of stress linked closely to feelings of helplessness. Youth can also experience a loss of self-esteem if they perceive their inability to cope with the situation to be based on an internal cause rather than an external one. Negative psychological states such as depression and anxiety can arise out of a lack of positive social relationships (Hall-Lande, Eisenberg, Christenson, \& Neumark-Sztainer, 2007). A LGBTQ youth can avoid negative experiences that could increase the chances of physical or mental health problems (Ueno, 2005) through involvement with inclusive social groups that can provide positive support.

\section{Overview of literature}

The following review of the literature includes those studies focused on the specific experiences and issues of bisexually attracted or identified people; it presents the existing literature on the importance of peer and family support for young people; it addresses the gap that exists in the coming out literature as it relates to bisexuals; and it 
explores the ways research is beginning to address the influence of the imposition of binary classifications.

The majority of the studies reviewed here aggregate all LGBTQ young people in one homogenous group. The lack of specific attention to, and the underrepresentation of, bisexual youth in some LGBTQ research has been referred to as the "silent B" (PalottaChiarolli, 2006). While it is not within the scope of this review to examine all LGBTQ research, it is possible to explore how the grouping of bisexually attracted people into the same group as lesbian, gay, and transgender people perpetuates the assumption that all people with attractions other than exclusively heterosexual have the same experiences. Saewyc and colleagues (2007) hypothesized that population-based studies may not accurately represent the experiences of bisexuals when outcomes are presented as an aggregate of all LGBTQ participants. For example, several studies of suicidal behaviors among LGBTQ youth suggest that bisexual youth are at greater risk for suicidal ideation and attempts compared to their gay and lesbian peers (Hatzenbuehler, 2011; Hershberger, Pilkington, \& D’Augelli, 1997). The following section addresses how existing studies have aggregated findings of all LGBTQ youth and some of the potential implications of this aggregation.

Gaps in the literature related to bisexual identity. The scant attention paid to the lives of bisexually attracted individuals adds to the invisibility of bisexuality in American culture. Primary value is placed on heterosexual relationships and monogamy, with bisexuals erroneously perceived as promiscuous because of attraction to more than one gender (Callis, 2009) and unwillingness/inability to commit to a single relationship 
(Kleese, 2011). Even the most current research seems to present bisexuality and bisexual young people in one of four ways (Pallotta-Chiarolli, 2006): underrepresentation (p. 81), where the samples claim to be inclusive of bisexual participants, yet the outcomes and recommendations offered are not specifically designed for bisexual young people; misrepresentation (p. 82) of young bisexual men as risky or dangerous as partners and AIDS-carriers and young bisexual women as transitioning to a lesbian identity or "drunkon-a-date" bisexuals; outdated representation (p. 82), which insists on the categorization of identity as gay, lesbian, or bisexual at a time when more young people are choosing other labels such as queer or to not label themselves at all; and a homogenized representation (p. 83) that is not reflective of the diversity of young people.

Given that the majority of empirical literature regarding bisexuality and the experiences of this group was built on study data collected from samples with typically very few bisexually identified participants, the reliability of these findings must be questioned. Do observed differences in suicidality and other high-risk behaviors indicate something else - a measurement issue or a conceptual issue in how studies are designed or is "bisexuality an indicator of a broad disposition to sensation seeking or risk-taking?" (Russell, 2011, p. 435).

Development of an individual sense of self. Peer relationships gain importance as young people begin transitioning from reliance on family relationships as the primary source of emotional support (Morrow, 2004). Bisexually attracted young people facing this transition may experience challenges in their peer relationships that their heterosexual and gay/lesbian counterparts do not, such as rejection by those peers who 
are not accepting of their sexual identity (Morrow, 2004). A young person who experiences sexuality-related stigmatization may use that experience as a cue to modify how they interact with others, how they present themselves, and may choose to be silent about their sexual identity in order to be with others (Sadowski, Chow, \& Scanlon, 2009). Those young people who get the message from their gay and lesbian peers that they are not accepted because of their attractions may choose to take one of these actions in order to fit in. Some bisexually attracted young people may need to hide their emerging sexual identity from parents or family members, may experience violence at school related to that identity, and may anticipate rejection from friends or family if their sexual identity becomes known.

At a time when they are learning how to date, they may need to also learn to hide who they date, with enormous social and emotional costs (McLean, 2001). The effort required to conceal one part of their attractions could impact a young person's ability or willingness to engage in future interactions. Over the past decade, there has been a decreasing stigma placed on lesbian and gay relationships, making social climates more welcoming for these young people. The climate for those who are multiply attracted is still challenging, and myths abound describing them as promiscuous, attention-seeking, and simply transitioning to being gay (Alaire \& Gaudet, 2013; Callis, 2013; Kleese, 2011).

Identity development narratives. I chose to include the following discussion about the development of non-heterosexual identities despite the fact that the current study focused on attractions and not identity. I focused on attractions rather than identity 
because I made an assumption that the participants were more likely to have been aware of their attractions during their high school years and less likely to have chosen an identity label. In fact, several of the participants agreed to participate in the study because of this distinction. I included the narratives described below because they are relevant in the context of the environments of the participants. Independent of the added challenges with identity development and bisexuality, the process of developing a non-heterosexual identity is sometimes guided by one of two master narratives (Cohler \& Hammack, 2007): stories available to youth with non-heterosexual attractions. These two narratives, struggle and success and emancipation are described in the following section.

Struggle and success. This narrative describes a process by which young people "struggle" with the challenges of accepting a sexual identity other than "normal" and the "success" of surviving these struggles and "coming out" as a part of the gay/lesbian community. It emerged out of early research depicting the challenge of developing a positive LGBTQ identity in a heterosexist society (Cohler \& Hammack, 2007). The concept of sexual minority stress (Lewis, et al., 2009) has been correlated with suicidal ideation and behavior (D'Augelli et al., 2001; Remafedi, French, Story, Resnick, \& Blum, 1998), substance abuse (Huba et al., 2000; Orenstein, 2001), and other mental health problems (D'Augelli, 2002) and provides support for this narrative, reinforcing as normative the image of the "struggling gay youth" (Cohler \& Hammack, 2007; DeCrescenzo, 1994; Rofes, 1983).

This narrative continues to serve as grounding for research and education on issues related to LGBTQ youth, with these young people viewed as victims of 
internalized homophobia resulting in mental health concerns such as anxiety, depression, and suicidal ideation. According to McDermott and colleagues (2008), sexuality may become an aspect of stress and uncertainty, and young LGBTQ people must find ways to "invent and sustain" (p. 818) adult LGBTQ identities within overwhelming heterosexual norms. These authors add that LGBTQ young people are confronted with additional challenges of creating identities within discourses of compulsory heterosexual and gender normative adulthood and the accompanying risk of homophobia, sexuality related violence, and social isolation. This narrative also suggests success despite the struggle and considers the primary developmental task of the LGBTQ youth to be one of overcoming the challenges, developing a positive sense of identity despite experiences of homophobia and heterosexism, and coming out as a member of the gay/lesbian community (Cohler \& Hammack, 2007; Savin-Williams, 1998).

Emancipation. The narrative of emancipation, which emerged as a result of shifts in cultural influences, recognizes that the development of a minority sexual identity is not the same for each youth, is directly influenced by life-course and the resources (internal and external) of each individual (Hammack, Thompson, \& Pilecki, 2009), and suggests that the rigid categories of sexual identity no longer resonate with contemporary young people (Savin-Williams, 2005). Russell and colleagues (2009) acknowledge a shift in how LGBTQ youth label themselves and point to findings from a large study (California Preventing School Harassment, 2003, 2004, 2005) indicating that many LGBTQ youth chose to not label themselves at all, raising the issue of similarity of findings across studies if sexual identity was measured in different ways. 
Additionally, this narrative is tied to recognition of cultural shifts over the past two decades. These shifts provided some youth in urban areas with more open and accepting environments and suggested that obstacles such as stigmatization and homophobia influence the development of LGBTQ youth to a lesser degree (Cohler \& Hammack, 2007). It recognizes the increasing fluidity of identification among youth with same-sex attraction and complicates the science of research with this population, acknowledging the changes in how youth choose to (or choose not to) label themselves (Russell et al., 2009).

These two narratives hold important implications for youth becoming aware of both other- and same-sex attractions, but neither directly addresses these implications. The struggle and success narrative suggests that all youth with same-sex attractions are automatically faced with lives filled with stigmatization, rejection, depression, and suicidality. These messages of inescapable doom are countered with the message that, with adequate resiliency, these obstacles can be overcome (Hammack, Thompson, \& Pilecki, 2009). The emancipation narrative presents youth with the idea that the choice of a sexual identity other than heterosexual is no longer concerning and if they are facing victimization or other negative outcomes, there is something wrong with them.

While acceptance has increased for gay and lesbian youth in some parts of the United States, this acceptance has not extended to those who are bisexually attracted. Additionally, many who are bisexually attracted remain invisible because of the dominant culture's reliance on a binary classification of sexuality (Bradford, 2011). Many youth may benefit from engaging with the emancipation narrative and feel acceptance from 
peers and family. However, the struggle and success narrative more closely matches the experiences of many others who face homo/biphobia, lack of support from peers and families, heightened stress, and lack of access to examples of bisexual adults (PallottaChiarolli, 2009). This lack of access to adult role models, a consequence of invisibility, may reinforce young people's sense of isolation and contribute to their caution in claiming a bisexual identity (Bradford, 2004). Several of the participants of this study shared experiences of feeling isolated and a need for adult role models; these are described in Chapter Five. Many young people are met with assumptions about their sexuality based on the gender of their current partner, with bisexuality never being considered as a possibility.

How these narratives fit with bisexual young people is unknown. Assuming that there are only two master narratives is dismissive of all the other narratives with which young people engage as they navigate their experiences. Perhaps the narratives of bisexual young people show a much different process which could change how researchers and academics approach future studies and program design.

Development of a sense of self in context. Life course approach. Societal changes since the 1980s have significantly altered the social climate for many LGBTQ youth. While some argue that the same-sex marriage debate has caused an increase in stigma-related stress (Rostosky, Riggle, Horne, \& Miller, 2009), the impact of these changes cannot be overlooked. While there are increased representations of gay and lesbian people in popular culture, there are still few examples of those who are bisexual. What messages do young people experiencing bisexual attractions take from this? How 
do they find themselves similar to or different from the representations available to them? Examining identity development from a life course perspective allows for specific attention to be paid to the unique characteristics of the context in which a young person is developing a bisexual identity, and provide that young person with support.

Expanding on the two narratives described above, the life course approach considers the context in which a young person develops as well as a recognition that the narratives have shifted to accommodate social changes (Cohler \& Hammack, 2007). The approach calls into question the notion of "normal" adolescent development and suggests the most normative feature of development is the context in which it occurs. Cohler and Hammack (2007) suggest "divergence in conceptual accounts of gay adolescent identity development emerges from a failure to fully acknowledge the salience of contextincluding cohort, geographic location, and the larger social-historical context of development - in understanding the relationship between identity and lived experience" (p. 48). They further suggest that accounts of LGBTQ youth overcoming obstacles and coping with minority stress, made more widely available due to internet access, have led to changes in the ways LGBTQ youth are able to create their life stories.

Some bisexually attracted young people may experience isolation from their families and heterosexual peers, and schools, churches, or communities because of the context in which they develop. They may fear stigmatization from both heterosexual and gay/lesbian peers because of stereotypes and may also experience discrimination from gay and lesbian peers or adults based on a bisexual identification. Drawing on symbolic interactionism and social constructionism, experiencing stigmatization and discrimination 
may lead bisexual young people to not disclose their identity to anyone (Sheets \& Mohr, 2009) or to experience the coming out process in ways different from those of their gay and lesbian peers. "In effect, they learn to hide twice: once from the mainstream society that rewards the establishment of heterosexuality but also from the gay and lesbian community where announcements of bisexuality may be met with suspicion or distrust" (McLean, 2001, p. 113). From a social constructionist perspective, bisexually attracted young people are influenced by their multiple realities as they make decisions about social interactions and how to engage with others. In the following section, the importance of peer relationships and social connectedness to a young person's sense of self and healthy development is discussed.

Peer Relationships. Developing social relationships with peers is a human process and the importance of peer relationships to the well-being of LGBTQ young people has been well-documented in the social sciences literature (e.g., Cohen \& Wills, 1985; DiFulvio, 2011; Doty, Willoughby, Lindahl, \& Malik, 2010). This section examines how social relationships influence a young person's sense of self and can impact social interactions.

School is an integral part of most young people's lives (Morrow, 2004) and during high school, for better or worse, peer group relationships influence how a young person develops new social skills and behaviors (Poteat, Espelage, \& Koenig, 2009). A sense of connectedness to school is critical to supporting a young person remaining in school, getting good grades, and achieving successful completion (LaFromboise \& Lewis, 2008). Although the climate of many schools has changed over the past decade, 
becoming safer and less toxic for LGBTQ youth, many others continue to be environments in which these youth experience sexuality-related violence, harassment, and stigmatization (Goodenow, Szalacha, \& Westheimer, 2006). Studies examining the school environment and the impact it has on a young person and strategies for supporting LGBTQ young people while at school have looked closely at the effectiveness of antibullying curricula (Merrell, Gueldner, Ross \& Isava, 2008) and gay-straight alliances (GSAs) (Kosciw, Greytak, Bartkiewicz, Boesen, \& Palmer, 2012; Griffin et al., 2004; Heck, Flentje, \& Cochran, 2011).

Gay-Straight Alliances (GSA). GSAs are school-based, student-led clubs with a goal of improving the school climate for LGBTQ students (Heck, et al., 2011). They were initially formed to provide LGBTQ youth with a safe place within the school environment and to increase opportunities for social support (Savin-Williams, 2005). Kosciw and colleagues (2012) examined the school experiences of LGBTQ students in a national sample of 8,584 students between the ages of 13 and 20. Students were recruited for participation in the study through outreach to organizations providing services to this population and social networking sites such as Facebook ${ }^{\circledR}$. This study examined the effectiveness of these groups and found that LGBTQ students in schools with GSAs missed fewer days of school due to feeling unsafe in the school, reported fewer incidences of harassment or victimization, and experienced more opportunities for students to educate the school community about LGBTQ issues compared to those schools that did not have a GSA. The study conducted by Heck and colleagues (2011) reported similar findings which supported the effectiveness of having a GSA in schools 
for improving students' sense of safety in, and connectedness to, their school. A limitation to these studies is a lack of direct attention to bisexual participants and their experiences with the group. Given this lack of information on how bisexual young people experience GSAs, the question must be asked whether the groups are effective for, or even of interest to, students who are not exclusively straight or exclusively gay/lesbian. Saewyc (2011) and Israel (2010), respectively, report findings from studies indicating that bisexual youth have lower levels of protective factors useful in managing violence and harassment in their school environments and that they experience less school connectedness than do their non-bisexual peers. These findings indicate the need for a clearer understanding of what bisexual youth consider to be most important to them for increasing their feelings of connectedness to peers and the school community.

Social connectedness and support. A sense of connectedness to peers, family members, and school/community environments has been shown to act as a resiliency factor for all youth (Brendtro, Brokenleg, \& van Bockern, 1990) and especially for LGBTQ youth (Detrie \& Lease, 2007). This connectedness builds on social support by including a sense of belonging to the social world, and the importance of fitting in with others. A focus on self in relation to others impacts a young person's self-esteem and, potentially, psychological outcomes. According to Savin-Williams (2005), making connections with a family of choice is one example of a positive coping skill related to connectedness. This strategy is less available to bisexual youth if they find themselves excluded from both a gay and lesbian peer group and a heterosexual peer group. Saewyc and colleagues (2009) found bisexual youth experienced a sense of connectedness to a 
significantly lesser degree compared to peers, as well as fewer protective factors.

Understanding how bisexual youth experience social connectedness and looking more closely at the role connectedness plays in the lives of bisexual youth has implications for practice with this population.

Peer support. While the importance of family connectedness to a LGBQ young person's development is clear (Eisenberg, Ackard, \& Resnick, 2007), young people naturally begin to rely more on peers and there is a link between the support received from peers and a young person's well-being (Sheets \& Mohr, 2009). Social support, which consists of both specific support behaviors a person receives and the person's perception of that support, provides young people with emotional and instrumental support (Detrie \& Lease, 2007). This type of support has been shown to buffer against anti-gay victimization (Goodenow et al., 2006), substance abuse (Espelage et al., 2008), and depression (Teasdale \& Bradley-Engen, 2010). LGBTQ youth may rely more heavily on friend networks for sexuality-specific support depending on the level of family acceptance they experience (Detrie \& Lease, 2007). However, friend networks might be less accessible to these youth given the rejection some bisexually attracted youth experience from gay and lesbian peers. According to Cohen and Wills (1985), "social support could be related to overall well-being because it provides positive affect, a sense of predictability and stability in one's life situation, [and] a recognition of self-worth" (p. 311). It is positively related to higher levels of self-esteem and more positive health behaviors and those with social support have been shown to engage in lower levels of problem behaviors. The concept of social support is integral to this study because those 
studies examining the concept have grouped all LGBTQ youth together and much less is known about how rejection impacts bisexually attracted youth specifically. Detrie and Lease (2007) made the argument that utilizing social support is a resiliency factor and should be nurtured in LGBTQ young people. A useful extension of these studies would be to explore how bisexually attracted youth seek support in environments where they experience rejection from both heterosexual and gay/lesbian peers. According to Sheets and Mohr (2009), the negative effects of an unwelcoming social environment can be counterbalanced by the young person's perception of social support.

\section{Summary}

Research examining many aspects of the lives of LGBTQ youth has increased substantially over the past decade. These studies have made clear that young people who identify as LGBTQ have protective factors and needs for supports and interventions that are different from those of heterosexual young people. Research has also begun to identify concerns unique to bisexual youth and has suggested the need for studies focusing solely on these young people in an effort to inform how services can be designed and implemented to be most effective. Other studies have evaluated the effectiveness of interventions and suggested ways to improve them as well as offered a clear path for future research.

However, as highlighted in this review of the existing literature, few previous studies have examined the lives of bisexuals as a group distinct from their gay and lesbian peers, making it difficult to know if or how their experiences are similar. Little is currently known about whether bisexual youth experience differences in terms of the 
developmental process, how supports such as GSAs are experienced by bisexual youth, or whether factors such as social connectedness and minority stress are experienced in a similar way.

\section{Research Questions}

This study intended to go beyond existing understandings of how sexual identity impacts bisexual youth development and wellness by bringing the lived experiences of these youth to light. My hope was that by providing a rich and detailed description of what social interactions are like and the meaning the youth take from them, adults who interact with these youth regularly will have more knowledge about how best to support them. To gain access to this information, the study was guided by the following questions: 1) How do young adults who were bisexually attracted in high school recall experiencing social interactions (with peers, teachers, school environments)? and 2) How do these young adults understand and make sense of these social interactions, both then and now?

The study adds to the literature with these stories of the unique experiences of bisexually attracted young people. While it is not possible to gain an understanding of the experiences of all bisexual young people within the limited scope of the study, it is possible to gain a deeper understanding of the experiences of a few individuals and present these in a way that informs future studies. 


\section{Chapter Three: Methodology}

In this chapter, I present the philosophical grounding for my study, a short statement about the steps taken in data collection and analysis, and how I evaluated the validity of my findings and interpretations. I also address ethical issues I considered prior to beginning the study and how these concerns were addressed.

The grounding for this study is an epistemological stance that recognizes the power of words, and a belief that experiences are "soaked through with language" (van Manen, 1990, p. 38). My intention was to gain an understanding of the social experiences of bisexually attracted young people. I employed a phenomenological approach in hopes of learning more about how "world is lived and experienced" (Finlay, 2011, p. 3) by the young people who participated. Stories describing in detail the social experiences of bisexually attracted young people in high school offer a rich and resonant source of information for those who work as educators and therapists with this population.

This study sought an understanding of how bisexually attracted young people described their experiences of social interactions while in high school. New information will be available for those who work with youth through this effort to understand how these experiences were similar or different among the participants and different from gay and lesbian youth. Such an understanding is important because bisexually attracted youth have experiences that set them apart from their gay/lesbian and straight peers. It was necessary to use a methodology that supported the gathering of stories from participants which could then be presented to practitioners and educators in order to gain an understanding of how the experiences differed. This study employed interpretative 
phenomenological analysis (IPA) as the methodology because it allowed for deep and careful attention to the words shared by participants; it allowed space for descriptions of experiences to unfold in a natural way; and it situated the perspective of the participants in the context of their worlds (Smith, Flowers, and Larkin, 2009). This chapter begins with a presentation of the philosophical roots of phenomenology, followed by an explanation of how IPA builds upon these roots.

\section{Phenomenology}

Phenomenology is a methodology rooted in philosophy; it developed into what it is today through the works of Edmund Husserl and those who followed him, building upon his theoretical foundations for the science of phenomenology (van Manen, 1990). This section provides a brief presentation of the philosophical underpinnings of phenomenological philosophy and research and a description of how the methodology can be used to increase understanding of a range of human experience.

\section{Descriptive phenomenology}

Husserl, an Austrian-German philosopher, is credited as the founder of modern phenomenology (Finlay, 2011). His numerous works, including books, lectures, and manuscripts, presented his conceptualization of phenomenology (Husserl, 1900-01, 1913), carved out new pathways in mid-century philosophy, and provided a foundation for phenomenological research methodology. His vision was for a philosophy of the study of the universal essence of things, meaning that if experience were examined critically, objectively, and rigorously enough, that examination would reveal a core 
essence of a phenomenon, such that everyone would experience that phenomenon in the same way (Husserl, 1970).

It was of primary importance to examine experience from a place unconcerned with an interpretation of the person's understanding of the experience, according to Husserl (1970). He considered it most useful to see the experience in a prereflective state, or from our immersion in our everyday existence which Husserl called the "natural attitude." Husserl developed the human science aspects of phenomenology into a descriptive method of research (van Manen, 1990) with the goal of getting to a description of things "in terms of their essential concepts, the essences which make themselves known in intuition" (Husserl, 1970, p. 249).

Advocating for a pure descriptive approach to phenomenology, these components were central to Husserl's thinking of the understanding of experience: an understanding of intentionality (defined as the connection of a person to his/her world and the idea that we are not consciously aware of the connection in the moment - awareness comes with reflection upon experience); the practice of bracketing (defined as the necessary suspension of one's own beliefs about the world in order to be open to the beliefs of others); and essences (defined by Husserl as the "whatness" of things) (van Manen, 1990). With phenomenology, Husserl believed it possible to describe the essence of discrete phenomena. It must "describe what is given to us in immediate experience without being obstructed by pre-conceptions" (van Manen, 1990, p 184). With descriptive phenomenology, the aim of the researcher is to identify and describe the essence of a phenomenon. The researchers' descriptions stay close to what the participant 
gives them, making few interpretive assumptions. Husserl believed there was great value in the lived experience of the human world, and, while his intention was to "bring out the full richness of our subjectivity as ways of discovering the world" (Finlay, 2011, p. 45), he still believed it was possible to identify an essence of an experience. Described briefly above, the technique of bracketing, central to the researcher's ability to get to "the things themselves," is more clearly defined in the following section.

Bracketing. In order to see the "things themselves," Husserl encouraged researchers to set aside all previous knowledge, or overcome expectations, of the phenomenon being studied through the practice of bracketing. Bracketing is part of a reductive attitude, which allows the phenomenologist to remain constantly aware of how her or his understanding of the phenomenon might be distorted by a previous experience and offers a rigorous, systematic way of identifying essences (Finlay, 2011). As first articulated by Husserl, bracketing is a process requiring the researcher to set aside the natural world and the world of interpretation in order to see the essence of the phenomenon. He saw the procedure of bracketing as essential to moving away from the "natural attitude", or everyday experience, to the "phenomenological attitude," which involves examining our perceptions of objects, in order to encounter "things as they are in themselves" free from preconceptions (Finlay, 2011, p. 44).

The notion of putting one's understanding of an experience in brackets meant simply to remove it temporarily from the consciousness of the researcher. Far from simple, bracketing is a demanding process requiring the researcher to reflect on the phenomenon being studied with curiosity and openness. Husserl defined several steps in 
reduction: the epoché of the natural sciences, the epoché of the natural attitude, the transcendental reduction, and the eidetic reduction. Husserl's idea of the epoché draws much debate and criticism from researchers.

The first epoché is a difficult step because it requires the researcher to set aside any previous scientific knowledge and understandings such as that our mind and body are separate or that depression is a 'real' phenomenon (Finlay, 2011). The second epoché "brackets the reality of the natural, taken-for-granted lifeworld" (Finlay, 2011, p. 47) and focuses on how the "lifeworld presents itself" and the subjective processes through which perceptions, emotions, and beliefs are presented (p. 48). Lifeworld was described by Husserl as the "world of immediate experience" or the world as it is experienced in the "natural attitude" (1970, p. 103). Husserl seemed to claim with this step that it is possible to separate oneself from subjective experience. The researcher attempts to get to a fundamental meaning or essence of what appears in one's consciousness, "without which a phenomenon could not present itself as it is" (Finlay, p 48) in the eidetic reduction. One view is that, by performing the act of setting oneself aside from one's own subjective experiences, one can truly observe the phenomenon of interest from a totally objective perspective (Dahlberg, Dahlberg, \& Nystrom, 2008). The other view is that it is impossible for researchers to separate themselves so completely and the epoché is merely a hypothetical notion (Dahlberg, et al., 2008).

Several philosophers who built on Husserl's work moved beyond his conceptualization of bracketing. In contrast to Husserl's notion that the researcher must remain isolated from the participant's experience, Giorgi's scientific phenomenological 
reduction describes a process where "the researcher aims to be fully present to the participants and to what is being described" (Finlay, 2011, p. 75) and what is bracketed is previous theoretical or scientific understandings. Giorgi was concerned with creating an account of a particular phenomenon that focused on the commonalities. Another adaptation of the practice of bracketing came from Dahlberg and her colleagues (2008) when they drew on their experience with horses to introduce the concept of bridling.

Bridling. Dahlberg and colleagues (2008) used the term bridling instead of bracketing to describe an "open discovering way of being" and suggested that researchers should develop a "capacity to be surprised and sensitive to the unpredicted and unexpected" (p. 98). Bridling, as described by Dahlberg et al., combined the meaning of bracketing (with its restraining of our personal beliefs and assumptions), and the idea that researchers should be disciplined in their interactions with the phenomena in an effort to slow their interpretations. This term resonated with me because, having years of riding experience, I related to the interplay between horse and rider that a bridle offers. While there is some control for the person holding the reins, the act of riding is a cooperative one with the horse having an equal, if not greater, level of control than the rider. It was my intention to strive for cooperative interviews that offered participants some control over the way the interview was conducted, and the stories they shared.

These researchers emphasized the importance of recognizing that no researcher comes to a phenomenological study free of her or his own history with the chosen topic. As a result of this history, and in the interest of maintaining an open attitude and allowing the phenomenon to appear naturally, some method of restraining pre-suppositions must 
be applied in an effort to restrict bias. Dahlberg et al.'s conceptualization of bridling as a method of holding onto and directing presuppositions rather than denying them entirely was a useful concept for this study. When a researcher practices bridling, he or she keeps an active and alert attitude of waiting for the phenomenon to show itself and taking care to not come too quickly to an understanding (Dahlberg, et al., 2008).

Phenomenological attitude. As described by Husserl, the phenomenological attitude involved the researcher stepping outside of his or her everyday experiences and practicing an inward look at their perceptions of those everyday experiences in an attempt at objectivity (Smith, Flowers, \& Larkin, 2009). In contrast, Finlay described a more humanistic approach to the phenomenological attitude, which allows for the researcher to experience an openness to the research. This approach allows researchers to accept what the participant tells them as truth as they understand it. Part of this acceptance is also acceptance of their socio-cultural background, "taking seriously our respect of difference and diversity" (Finlay \& Evans, 2009, p. 37). Through the use of empathy and curiosity, phenomenological researchers attempt to get a feel for what the participant's lived experience is like, while at the same time maintaining enough distance so that he or she can remain critically analytical.

\section{Hermeneutic/Interpretative Phenomenology}

While descriptive phenomenology is the foundation upon which other traditions are built, it is only one tradition. Philosophers such as Heidegger, Gadamer, and Giorgi carried it forward, expanding, modifying, and sometimes contradicting Husserl's original 
positions, and other threads of phenomenology continue to emerge. This section presents the work of a few of these philosophers and describes their work as it supports this study. Hermeneutics, the theory and practice of interpretation, developed beyond its roots as a method for the interpretation of biblical texts into wider application for interpretation of historical and literary documents at the turn of the nineteenth century (Smith, Flowers, \& Larkin, 2009). Its use as an analytical approach by other disciplines, such as health psychology, interested in the interaction between people and their environment, relied on the work of those philosophers who argued that it is not possible to separate the meaning of a text from the person who created it. In descriptive phenomenology, the aim is to bracket out presuppositions about the phenomenon being studied and present the essence as it is given. This Husserlian stance makes clear that there is an essence and holds that this essence can be viewed free from outside influence. An interpretative or hermeneutic approach, in contrast, argues it is useful to acknowledge "our embeddedness in the world of language and social relationships" (Finlay, 2011, p. 11). Philosophers such as Heidegger and Gadamer viewed interpretation as inevitable and already a part of an experience, focusing on what meaning a person takes from that experience. The following section presents these philosophers as they related to and departed from Husserl.

Heidegger. As a student of Husserl, Heidegger built upon what he learned and moved phenomenology toward an understanding of what it means to be (Finlay, 2011). Shifting phenomenology from a purely descriptive stance into a hermeneutic one, Heidegger focused on the concept of Being. Heidegger's concept of human existence as 
Dasein or "being-in-the-world" (Finlay, 2011) emphasizes humans' immersion in the world surrounding them. Central to this concept is the awareness that self cannot be separated from the world, departing from Husserl's assertion that it is possible to look at experiences of others free from the influences of previous experiences. Heidegger believed it necessary to recognize that we are always "in the world" and that our activities and understandings of the meanings of things can only be understood in context to our relationship with the world (Smith, Flowers, \& Larkin, p. 18).

Humans' involvement with time is also central to Heidegger's thinking: we are present in the moment or activity with which we are engaged while also looking into the future and envisioning the completion of that activity (Finlay, 2011). Heidegger's later work showed his shift in thinking about philosophy as closer to poetry than to science and emphasized the power of language. Heidegger considered language, thinking, and being to be one (van Manen, 1990, p. 38) and only through language could being-in-theworld be understood. An implication of this is that all human interactions are interpretations, making it necessary to examine the ways these interactions are socially constructed. Intersubjectivity, the relational and overlapping nature of how we engage with our world, is a central concept of Heidegger's work.

Heidegger described a "hermeneutic circle," which "moves between question and answer." The researcher starts with a pre-understanding and "moves on to being open to discovering something" (Finlay, 2011, p. 53). Through a process of openness to reinterpreting an initial understanding, revising this understanding, and then challenging the new interpretation, one comes to a deeper understanding of a phenomenon. Heidegger's 
awareness that all understanding of lived engagement with the world could only be accessed through interpretation and, thus, relies on language influenced hermeneutic phenomenology.

Gadamer. Gadamer built on Heidegger's work, focusing on the hermeneutic process and stressing the notion that all understandings are situated in historical and cultural context. Furthermore, Gadamer (1997) stated: “And who would deny that there are real factors conditioning human life, such as hunger, love, labor, and domination, which are not themselves real language or speaking, but which for their part furnish the space within which our speaking to each other and listening to each other can take place" (p. 28). He added the idea that it is not possible for the interpreter of a text to be separate from the meaning, that the reader belongs to the text, and that the history of the interpreter must be as much a part of the interpretation as is the history of the creator of the text (van Manen, 1990).

This idea is critical for the interpretative approach of the current study because of the relational nature of the phenomenon studied. The youth who participated shared experiences rooted in a lived world; I collected these stories from a place influenced by my experiences with my lived world; and readers of the accounts created from these stories will be taking them in while rooted in the context of their lived worlds. According to Gadamer, researchers must maintain an open mind and look beyond normal horizons in order to learn something new (Finlay, 2011). The following sections define the concepts of lifeworld and lived experience and their relevance to the current study.

\section{Lifeworld}


The concept of lifeworld, described by Husserl (1970) as "the world of immediate experiences" (p. 103), is that location where we engage with our environment in the natural state before reflecting on the meaning of our experiences. For example, I have several lifeworlds, including my home lifeworld and my work lifeworld, and each has very different experiential qualities. This central focus on the lifeworld of the participant is at the core of phenomenological inquiry and requires openness to the participants' experiences (Denzin \& Lincoln, 2005). An awareness of lifeworld was important for this study because it was my intention to gain an understanding of how the participants lived their experiences.

\section{Lived experience}

Lived experience refers to the prereflective encounters (those mundane experiences which are given little thought such as noticing the sound of footsteps or the touch of a breeze) with a particular phenomenon in a person's lifeworld. Smith and colleagues (2009) use the example of walking down a lane, having a minimal level of awareness of the experience of walking down the lane, and in these encounters can be found the essence of the person's experience. In this example, the authors refer to catching glimpses of trees, hearing the chattering of birds, and not attending to those stimuli. In contrast, reflected experience is influenced by factors such as consequences from previous encounters, and cultural or social mores, no longer reflecting the essence of the experience. For example, asking participants to describe how they lived a social interaction may yield a clearer description of the encounter, undiluted by time and successive encounters. And, from the lived experience description, it may be possible to 
draw an idea of its fundamental nature (van Manen, 1990) and thus create a phenomenological description.

Van Manen (1990) presents four different components central to lived experience: temporal experience (how time is lived); spatial experience (how distance and space are lived); corporeal experience (how physical body is lived); and relational experience (lived experience through relationships). Considering the phenomenon of social interactions of bisexually attracted young people when they were in high school with the breadth of how it is experienced in these four dimensions increases understanding of that experience. These components, especially the relational one, are of great importance to the proposed study. Everyone exists in the world differently. Each person describes experiences using different language. Finding those descriptions that may be common across the experiences of the participants, and that resonate with me as the researcher, depends on my ability to be attentive to van Manen's central components. As Dahlberg and Dahlberg (2003) put it, "our very own behavior, our personal actions and our individual ways of being are all a result of our own personal room in the world, which can be described as one's own entry to a common and shared world" (p. 39). The following section describes interpretative phenomenological analysis (IPA) and how it draws upon the hermeneutic approach.

\section{Interpretative Phenomenological Analysis}

Interpretative phenomenological analysis (IPA) is a specific hermeneutic approach committed to exploring how people make sense of experiences in their lives (Smith, et al., 2009). Extending the work of Heidegger and Gadamer, this approach 
makes an explicit commitment to person-in-environment and not just phenomenon-asexperienced (Finlay, 2011). The methodology has seen increased application in the field of health psychology over the past decade, due in part to its concern with examining human experience in detail (Smith et al., 2009). Epistemologically, researchers using IPA engage in a reflective focus on participants' lived experiences and how they make sense of them (Smith et al., 2009). This study drew on Heidegger's focus on language while also drawing on Gadamer's centering of context while intentionally seeking an understanding of the participants' perspectives. IPA research is phenomenological in its attention to a particular experience, with a hermeneutic approach to the analysis of the text of interviews. According to Smith (2004), "The participant is trying to make sense of their personal and social world; the researcher is trying to make sense of the participant trying to make sense of their personal and social world" (p. 40). The researcher works to understand the experience of the participant, listening to the stories through the filter of his or her own experiences. Parts of a story may resonate more than others, depending on how the researcher has experienced similar situations in his or her life. An important component of IPA is the ability to separate the strands of what is participant experience from that which is researcher experience, and then present a description of the experience as accurately as possible with minimal filtering.

A researcher using IPA must keep two aims in mind. The first is to gain an understanding of the participant's world and then to describe what that world is like. There exists in IPA a "double hermeneutic" (Smith \& Osborn, 2003) involving the researcher making sense of the participant who is trying to make sense of the 
phenomenon (Smith et al., 2009). A researcher is never able to access the exact experience had by a participant because of the influence of his or her perceptions. The objective in IPA, then, is to obtain a description which gets as "close to the participant's view as is possible" (Larkin, Watts, \& Clifton, 2006, p. 104) while recognizing that the process is inevitably interpretative. The second aim is to create an interpretative account expressing how the participant made sense of the experience and what it means to him or her. These aims draw directly on the work of Heidegger, who believed phenomenological inquiry to be an interpretative process, and Gadamer, who recognized the complex relationship between the person and the phenomena. In contrast to bracketing as it was practiced by Husserl and Giorgi, which encourages the researcher to seek the essence of a phenomenon in participant accounts, IPA encourages a detailed analysis of the divergence of accounts (Smith et al., 2009). Smith et al. (2009), in their application of IPA, recommend that the researcher engage with the participant rather than with bracketing, and the role of bracketing is seen as a way of "acknowledging evolving preconceptions, hunches, and theoretical predilections while engaging the hermeneutic circle where fore-structures are continually modified" (Finlay, 2011, p. 79).

There are three core concepts of an IPA approach: the phenomenological component which seeks the participants' understanding, the interpretative component which considers cultural and physical environments as they attempt to make sense of the experience, and the renewed insight gained by the researcher. The phenomenological component was important for this study because it sought to examine the participants' experiences as they expressed them. In the analysis, I considered the context of each 
participant as it influenced their recounting of social experiences. It was also my intention to consider my interpretations as they related to existing literature. In this way, the study had the potential to fill a gap in knowledge about the lived experiences of bisexually attracted young people. These components provided a solid foundation for exploring social interactions and the lived experiences of bisexually attracted young people and what meaning they made of these experiences.

\section{Participants}

I was attentive to the potential impacts of the intersectionality of race, gender, and sexual orientation during recruitment. I anticipated that each participant would have experienced a range of social phenomena including stigmatization, connectedness, and more, in unique ways based on a multitude of factors. One of the advantages of the proposed methodology was the ability to accept each account in terms of how young people themselves articulated their social location as it related to race, class, gender, and sexuality. Inclusion criteria only specified demographic information related to age and sexual attractions, not race, class, and gender, because I hoped to allow space for participants to name (or not name) intersections among those identities and experiences as they emerged. None of the participants directly identified class or race distinctions during their interviews. I was attentive to those experiences that seemed to have been influenced in some way by class or social locations. An example of this was the ability of several of the participants to attend private, religiously-based high schools.

Sampling criteria were kept intentionally quite open and without presuppositions of the potential impacts of race, gender, or other factors. Despite my awareness of the 
importance of examining the intersectionalities of these factors, for the purposes of the proposed study, participants were selected on the basis of what access they could grant to the phenomena of interest in the study, so they could "represent a perspective, rather than a population" (Smith et al., 2009, p. 49).

Letters of invitation and recruitment flyers were sent to LGBTQ groups at several universities and agencies providing support and other services to LGBTQ youth and young adults in the Pacific Northwest. The invitation letters described the study, extended an offer to meet with faculty advisors or agency staff members to answer questions, and requested assistance with recruitment of participants. The recruitment flyers also briefly described the nature of the study, the criteria for participants, and included my contact information (See Appendix F). When someone indicated interest in participating in the study, he or she was required to complete a screening tool that asked for age and a response to a question about sexual attractions. As presented in the literature review, a universal way of measuring or ascertaining sexual identity and sexual orientation does not yet exist. I focused only on the participants' stated attractions with the following question: "Which of the following best describes your sexual identity during high school? a) $100 \%$ heterosexual (only attracted to people of the opposite sex); b) mostly heterosexual (attracted to both but mostly opposite sex); c) bisexual (equally attracted to both sexes); d) mostly gay/lesbian (attracted to both but mostly same sex); e) 100\% gay/lesbian (only attracted to same sex); and f) not sure or none of the above. Focusing on participants' sexual attractions while they were of high school age ensured that the sample included only those who had experiences with the phenomenon of interest. 
Several participants raised concerns about this terminology, stating it was limiting in terms of how they viewed their choices. Their primary concern was that it was not inclusive of trans* attractions. We discussed these concerns and they were invited to choose the option that felt most correct for them. I assured those who questioned the terminology that the complexities of their attractions would be explored during the interviews and they would not be asked to label or identify themselves at any point in the process. I made a deliberate choice to rely on participants' self-report of sexual attractions in framing the screening tool this way.

Gaining access to rich descriptions of the experiences of interest for this study required involving participants who met the following criteria: male/female/transgender young people of any ethnicity between the ages of 18 and 24 who identified their sexual attractions as something other than exclusively heterosexual or exclusively gay/lesbian while they were in high school. The criteria for inclusion or exclusion was based on a social constructionist viewpoint that posits that a person actively interprets his or her attractions through a "continual, recursive interaction between oneself and one's environment” (Horowitz \& Newcomb, 2001, p. 10). I chose the age range of 18-24 because I believed subjects would have self-awareness about their sexual attractions, were still close enough to high school age to have clear recall of events that occurred during that time, and they might be open to discussing their attractions. Exclusion criteria included those potential subjects who were outside the age range of 18-24, if they identified as exclusively heterosexual or gay/lesbian during high school, if they could not 
recall events that happened during high school age years, or if they were concerned about being "outed."

The participants were not asked to identify their gender at any point in the study. One participant identified herself as female at screening through choice of pronouns and a clear statement of choice of name. However, at the time of the interview, he identified as male and asked that I refer to him with male pronouns. I assured him I would respect that request throughout the interview and the rest of the study. He shared with me that gender is fluid for him and that he generally resists choosing a gender. Numerous attempts were made to recruit additional male participants. As a result of these efforts, several males initially agreed to participate but did not respond to efforts to schedule interviews. I looked to the literature for some possible reasons for fewer males agreeing to participate in the study. I was not able to find any studies which identified reasons why few men might be interested in participating in a study of this type. Some possible reasons might be the prevalence of the myths attributed to male bisexuals, which include their status as HIV carriers (Meyer, 2003) and that males who claim to be bisexual are really gay and have not, or will not, come out of the closet (Savin-Williams, 2005). This stigma and the discounting of the possibility of bisexual attractions for males may explain why some males might have been hesitant to talk with someone they did not know about their attractions.

While school attendance was not a focus of this study, each participant talked about their school experiences during the interviews and it was a factor on which the participants varied from each other. Amelia, CS, and Emily all went to private Catholic 
high schools in large metropolitan areas. Aythn, Brittany, TD, and Kylie went to large public high schools in metropolitan areas. Kina was unschooled: a term she used to explain that she was homeschooled but not in a structured way. Jane homeschooled part of the time and went to a charter school part of the time (while she said it was not specifically a Christian school, she did say the area in which the school was located was a part of town where many Christians lived and the school had the reputation of being supportive of their religion). Emerald attended an alternative school that was part of the public school system in the town where she lived. Though all participants lived in the Pacific Northwest at the time of their interviews, they attended high school in other states (Nevada, Utah, California, and Washington). Seven of the interviews took place in person and three were conducted by phone due to my geographic relocation near the end of the data collection phase. More detailed biographies of each of the participants are provided in Appendix G.

Process of obtaining informed consent. Once a young person expressed interest in participating, the study was fully explained and he or she was asked to sign a consent form (See Appendix A). This consent form explained in detail the benefits of participation (\$20 one-time payment, in the form of a gift card, and the opportunity to share experiences), the potential risks (discomfort at recalling painful events, possibility of being "outed" by participating in study, and embarrassment at sharing intimate stories with the researcher), and how the information would be collected, stored, and potentially distributed. Each participant was informed of his or her right to discontinue participation 
in the project at any time, for any reason, and of the ability to deny use of any of the information shared in any journal articles, presentations, or the dissertation.

\section{Primary Data Collection}

Semi-structured, in-depth interviews are one of the best ways to obtain the types of rich descriptions of experiences desired for this study. Interviews allowed participants to share stories, thoughts, and feelings about the phenomenon and were the primary method of data collection. Young people meeting the inclusion criteria were invited to participate in one interview lasting from 60-120 minutes. Each participant was asked to choose a place for the interview where she or he felt comfortable sharing the details of experiences openly. Interview sites included an office in the referring agency, private conference rooms at a research office, a study room in a local coffee shop, and in a study room of a local university. Three of the interviews were conducted by phone and in each

of these cases, the participants were offered the option of video chatting or talking on the phone. These participants signed consents and mailed them to me prior to the interviews. I scheduled the interview when I received the signed consents, and explained the ways in which I would ensure their confidentiality in the phone interview process. I conducted these interviews from my private office. During the consent process, I informed the participants of the benefits to them being in a quiet, private place during our interviews and each assured me they could find such a place from which to call me. Since the interviews were conducted by phone, I am not able to say whether other people were present during the call, but it was quiet in the background. Each interview was digitally recorded and the audio recorder was stored in a locked desk drawer when not in use. The 
recordings were transcribed verbatim by the researcher and were shared with my advisor during data analysis. All study materials, including files containing contact information and signed consents, were kept in locked file drawers.

\section{Interview Process}

I spent time prior to the beginning of each interview noting my thoughts about the participant, my reactions to prior interviews, and any other thoughts so I would be more attentive during our conversation and in order to keep my pre-suppositions of the topic bridled.

At the beginning of each interview, I explained my role as interviewer and their rights as participants. I believed it was necessary as the interviewer to create a space which allowed the participant to share experiences freely. Each interview began with a few minutes of conversation intended to put the participant at ease and build a sense of trust. I explained the purpose of the study again and answered any questions that had come up since the screening. I asked the participant to give verbal consent again prior to beginning the interview. Each participant was asked to begin the interview by telling a story from high school they had interpreted at the time to be influenced by their attractions to more than one gender. I asked follow up questions to things they said and when the participants seemed to run out of things to talk about, some prompts (See Appendix B) were used to encourage them to tell of another experience.

I spent a great deal of time preparing for the first interview because I only practiced this type of interviewing a few times in preparation for the study. Prior to the first interview, I took time to reflect on the practice interviews, review the questions and 
prompts, and clear my mind of any preconceived ideas I had about how the interview might go. I used a journal as part of this reflection process as writing is a tactic that works for me in terms of clearing my mind. Each time I prepared for subsequent interviews, I took several minutes to free-write in a journal my thoughts about how the previous interviews might impact the way I conducted the upcoming one. I concentrated on putting aside all thoughts of previous interviews and any assumptions I was beginning to form about the social interactions of the participants, and I made a few notes about my goals for the present conversation. Both processing and prepping for interviews took place with each interview. My intention with this reflective process was to help me be open to the uniqueness of the stories the participant might share and remind me of those things I would like to attend to (examples of this include asking one question at a time, listening for places in the participants' stories where it seemed like they had a clearer memory of something, and asking them to say more).

As the participants told their stories, I made a few notes about things they said on which I wanted to follow up. I asked additional questions in order to gather more details about their experiences. I followed this process until the participant seemed to run out of things to say. When I noticed this, I asked if there were other things they wanted to share. We continued the interview if they had other things to tell me and I wrapped it up when they told me they were out of stories.

At the conclusion of each interview, I took time to make notes about the process. These notes included my thoughts about places in the interview where I could have followed up on a comment or asked a probing question to elicit a more descriptive 
answer. I reflected on things such as the interview space and whether the participant had seemed at ease, concerns about distractions such as noise outside the room where the interview took place, and if I thought the participant experienced any part of the process as particularly positive or supportive. My comfort as an interviewer and the way I engaged in the process with each participant was different every time. I felt this was an important part of the process because it was my hope to improve as an interviewer with each interview. When I felt more comfortable, the participants seemed more able to be share more openly. I was able to see the specific things I wanted to do better when I looked back to these notes prior to the next interview.

\section{Transcription process}

Each interview was transcribed verbatim from audio recordings of the interviews. I typed each of the transcripts as soon after the interviews as possible. It took an average of about a week to complete the transcription. As I am not a professional transcriptionist, this was a lengthy and time-intensive part of the process. There were advantages to doing my own transcription, which included the ability to recall what a participant said if the audio did not capture a comment, and the opportunity to remember pieces of the interview beyond the words such as body language and facial expressions. Where I recalled these non-verbals, I noted them in the transcript. These notes were useful to me during the analysis when things like changes in eye contact or body posture indicated something in the story was not captured by the words they spoke. While IPA analysis typically centers on the text, noting these non-verbals enhanced my understanding of the complexity of the things the participants were telling me. 
I interviewed three participants by phone, which limited my ability to make note of facial expressions or body language in the transcripts. I was, however, able to capture sighs and silences or pauses after a question or an emotional comment by the participant. I asked for clarification about what the silence or sigh meant when I heard these during the call, in order to capture the complexity of the story.

I read through the document following transcription and corrected any misspellings or formatting mistakes. Once the document was completed, I printed a copy because I always saw things in this copy that I missed when I was reading the computer file. I highlighted or circled any mistakes during the first reading of the printed copies and made notes in the margins at those places where I had a question about the accuracy of the transcription. I went back to the audio file and listened again to the interview while reading the transcript. During this process, I focused on the places where I had questions about the accuracy of the transcription; this allowed me to check those and make any necessary changes.

\section{Researcher positionality}

The study was motivated by several factors. The first motivation came from my own experience in high school. I cannot deny that I experienced high school as a time of torment and an unending quest to be invisible. Like this study's participants, I experienced attractions to both male and female peers. Also like some of the participants, I could share these attractions in very limited ways. I could talk about my "gay side" with my gay peers but I could not share the "straight side" with them for fear of being rejected 
for not being gay enough. The experiences I had with learning to anticipate reactions and control interactions left me with little sense of safety.

The safety I did have was because of a mother ahead of her time. I believe she saw who I was becoming and she gave me clear, direct guidance about the way the world worked in my small, conservative hometown. She let me know, in equally clear terms, that I could only be who I was and to hold on to that in spite of the opposition I would face. My awareness of how my experiences impacted my social life had some bearing on choosing to do this study. I did see something of my experiences in the experiences of some participants, and I saw experiences that differed from mine. As I moved through the analysis of the data, I paid close attention to those details that especially resonated or felt particularly foreign and sought participant feedback or peer debriefing for clarity regarding my interpretations.

The second factor leading to my interest in this study was a preliminary analysis I did of a large data set collected from youth in Oregon regarding their health behaviors. My findings were disturbing in that they all pointed to higher risk behaviors and poorer outcomes for youth who identified themselves as "bisexual" or "unsure" compared to their heterosexual and gay/lesbian peers. I am cautious of the findings because of some limitations in data collection, but they did raise a question about studies that treat all LGBTQ youth as though they are the same. Some practitioners and researchers assume interventions created for gay and lesbian youth will be effective for any youth who does not identify as heterosexual. Additionally, I noticed an invisibility I had missed before. Gay/Straight Alliances, offered as solutions to negative school environments, suddenly 
became perpetuating agents of the silencing of bisexual voices. Once I noticed the invisibility, I was aware that other gaps existed and I became curious about how young people who are bisexually attracted view these gaps, how they understand themselves in interaction with the gaps, and how they make sense of the fact that they are often ignored at worst and lumped together under the larger LGBTQ umbrella at best.

I approached this study as a therapist, social worker, student, and researcher. I am also a woman of incredible privilege. I am safe to identify as queer in my community. I have not always enjoyed this privilege and I am keenly aware of the opportunity I have to use my position to bring attention to the experiences of youth who do not always feel safe. I am also aware my experiences shaped how I conducted the study and I attended to the impact as best I could throughout the study process with the practices of bridling and reflection mentioned earlier in this section.

\section{Ethical Considerations}

Asking young people to recount experiences of high school social interactions presents potential risk for discomfort and emotional upset. All efforts were taken to minimize this risk and guidelines provided by the Institutional Review Board (IRB) at Portland State University were closely followed. The purpose of the study and the study process was explained to potential participants in detail and all participants were provided with contact information for the researcher and the IRB should they have questions or concerns during the study process. Additionally, I provided each participant with contact information for several people who could provide support services if the need arose. An informed consent form outlining all potential risks and benefits was fully explained to 
each potential participant and a copy of the signed form was provided to each participant prior to interview. I clearly described how information collected in the interviews would be used, how the data would be stored, and how the participant could remove his or her information from the study should they change their mind about participating in the study.

\section{Summary}

I was drawn to a phenomenological framing of this study for two reasons. The first motivation was to allow for the possibility of hearing from young people who may not have been offered an opportunity to tell their story. There is a transformative power in reflecting on an experience (Finlay, 2011) that may provide the participants with a new understanding of what they have lived. The second motivation was more selfish. I gain new perspectives on my own experiences from every person with whom I interact and I gain understanding of these interactions through the process of telling the story. A phenomenological approach to my dissertation attended to each part of my identity and allowed me to support new learning with skills I already possess. As Finlay (2011) states, "Surely, as therapists, we have a professional obligation to transform our research into practice and share it more widely" (p. 257). This study was a step toward meeting this obligation. 


\section{Chapter Four: Analysis}

This study used an Interpretative Phenomenological Analysis (IPA) (Smith, et al., 2009) approach and the analysis followed the steps outlined by Smith and colleagues. According to these authors, the essence of the analytical process in an IPA study lies in its focus, which “directs our analytic attention towards our participants' attempts to make sense of their experiences" (Smith et al., 2009, p. 79). Like hermeneutic approaches, it allows for a close examination of the interviews. As with idiographic approaches, it locates the interpretation of these texts in the experiences of the participants, affording privilege to their voices in the context of their lives. The theoretical foundations and epistemological groundings for this study were explained in Chapter Three; this chapter builds on that epistemology and outlines the particular steps in the analysis, providing an explanation of how themes were identified, named, and grouped in order to present a clear picture of how the participants experienced and made sense of their social interactions.

Previous research studies have grouped gay, lesbian, and bisexual participants as one in an effort to increase the power of the sample. Since this grouping does not allow researchers to differentiate youth who identified themselves as bisexual from their gay and lesbian peers, it is difficult to determine how, or if, the experiences of bisexually attracted people are different. I chose IPA for this study because of my belief that the voices of bisexually attracted young people are crucial to the development of a clearer understanding of the unique experiences of this group. My use of the theories described in Chapter Two is grounded in my belief in the importance of language in determining 
how people engage in social interactions. I considered the impact of context and previous interactions on how the participants might choose which stories they shared in the interviews as I conducted the analysis.

Research studies use various recruitment strategies as they seek to include participants who are bisexually attracted. Often the number of bisexuals who participate in research studies is small, especially when recruitment strategies are directed at all sexual minorities. I contend that an unintended consequence of the practice is an assumption that the needs and experiences of all LGBTQ participants are relatively similar. There certainly are similarities; however, there are also a number of differences such as where they find support, whom they can look to as role models, and a more difficult process of explaining their attractions. These differences can only be understood through learning more about the experiences from those who have them. The experience of the bisexual participant is often lost in the social work literature related to LGBTQ people, and youth in particular. My intentions in this analysis were to allow the voices of the participants to come through, to allow the young people who told me of their experiences to explain how things were for them.

\section{Data Analysis}

There is no one way to do phenomenological analysis. As a novice researcher, I relied on the steps outlined by several others (Barritt, et al., 1984; Dahlberg et al., 2008; Smith et al., 2009) as a guide. While it was enticing to have an opportunity to engage with the process in a way that maintained creativity, privileged participant voice, and 
held to rigorous standards, I needed more structure in order to manage the vast amounts of data collected through the interviews and relied on the steps outlined below.

Analysis in IPA Studies. There is great flexibility in IPA in working with data, with the analytical focus always on "our participants' attempts to make sense of their experiences" (Smith et al., 2009, p. 79). Attention is given to what is distinct about each participant, balanced against the commonalities among the group of participants. There are two aims in analyzing data in an IPA study. The first is to try to understand and describe what the world of the participant is "like" (Larkin et al., 2006). My goal in the first stage of analysis was to simply "get as 'close' to the participant's view as is possible" (Larkin et al., 2006, p. 104). The second aim was interpretative and intended to provide a "critical and conceptual commentary" (Larkin et al, 2006, p. 104) on how the participants made sense of their experiences.

Analysis in IPA differs from other qualitative approaches in that it focuses on the participants' process of making sense of their experiences as much as it does on the experiences themselves. Undertaking a process of working with the descriptions taken from the interviews with the goal of understanding the data on their own terms is one approach to analysis. I engaged in an informal process of analysis during each interview when I noticed pieces of the discussion that seemed to be of greater importance to the participant. Cues, such as an increased rate of speech or a change in tone of voice, a change in eye contact, increased hand gestures, or sitting back in their chair, alerted me to a change in the participant's feelings about particular topics. During each interview, I 
made notes of these particular instances so I could refer back to them during transcription.

I used bridling, as suggested by Dahlberg and colleagues (2008), to help keep my pre-conceptions in check and focus my attention on the participants' descriptions. The process was an "iterative and inductive cycle" (Smith et al., 2009) involving several readings of each transcript, identification of themes, creation of a framework in which to explore the relationships between themes, consultation with my advisor, participant feedback, and the development of a short summary describing the themes. The following section presents a description of the process involved with each step in the analysis.

Analysis of experiences. I began the analysis of each transcript by reading it through without making any notes. I then read the transcript a second time and underlined passages in the text that seemed to contain something that was meaningful to the participant. I paid attention in subsequent readings for those times when a participant's words "flew up like sparks" (Barritt, et al., 1984) from the text, and I pulled this piece into a working file of meaning units. These meaning units were chunks of text that held a comment or passage that spoke clearly about a particular aspect of an experience the participant was trying to describe. These varied in length and were typically a sentence or two. A new working file was created for each participant. These files remained separate while each transcript was read several times. During this phase, I made notes in the transcripts such as comments about participants' choice of phrasing, where I had a question about the intent of their comment, or where they created a powerful image of a piece of their experience. 
Identification of emergent themes. I created a working file from each transcript, and compared them across all participants. During the comparison, I made note of similar meaning units and combined them, maintaining each participant's particular phrasing. Those meaning units unique to one participant were also added to this file. Meaning units that seemed to identify a similar experience were merged, becoming the beginning list of themes through this comparison process. These themes were typically much shorter phrases that captured the meaning of the participants' comments in a few words. In naming themes, I attempted to capture the essence of the participants' meaning, on both the linguistic level and a more interpretive level. Themes were differentiated from each other by examining the context of the participant's story, and how the participant phrased what they told me. This was an iterative process with theme names moving back and forth from my words to participant words and from individual participants to the group of participants.

I engaged in a process of imaginative variation in order to explore all possible meanings of a theme. This process involved examining the phenomenon in order to include only essential features (Beech, 1999) as the participants described them. This part of the process clarified my thinking about some of the themes so I was sure the theme was something unique to the experience of bisexually attracted young people. Those themes presented in the next chapter all describe parts of an experience that, while unique for each participant, also hold common threads and meaning across all participants.

Dialogue with the data. While it is one of the roles of an IPA researcher to "attempt to make sense of the participant trying to make sense of what is happening to 
them," (Smith et al., 2009, p. 3), I engaged with the interpretation phase too quickly. I realized this after several attempts to match participant words from the text with the themes as I named them. In response to this realization, I journaled about what I thought I was seeing and then set aside my interpretations so I could take a fresh look at the participants' actual words. This fresh reading of the transcripts allowed the themes to emerge as the participants named them, free of my influence. These themes became part of the structure of the experience in the final description and are described as part of this whole. As part of this step, I created summaries of each interview and sent an email to each participant that included their summary and a request for their feedback on my interpretations.

Building summaries. I wrote summaries for each participant once I was confident I understood the participant experiences as fully as possible. These summaries provided me with a sense of the overall experience of social interactions. A picture of how the participant made sense of their interactions and how they managed their interactions came through in the stories they told me. I remembered the interview clearly when I read the transcripts and reflected on participants' body language and tone of voice as they told me the stories. The non-verbals of the participants as they shared their experiences became part of my interpretation because of the way these things supported, or were incongruent with, the words they chose. I referred to these non-verbals in the summaries when I wanted to check on one of those moments of incongruence. It was important to me that the participants understand how I decided on the interpretations so they could let me know if I was on track with what they were feeling. The summaries attempted to 
present the participants with a clear picture of my thoughts through the use of pieces of text and notations about how the participant told the story.

Member checking. An important piece of the analysis process was to provide each participant with a summary of my interpretations of their interview and ask for their feedback. I asked each participant at the end of the interview, if s/he was willing to read the summaries in order to ensure I was accurately representing what was shared with me. All of the participants agreed and provided me with an email address they anticipated would be good for one year. These addresses were kept with the screening and consent forms.

I wrote summaries that collected the thoughts of each participant, pulled some chunks of text as illustration, and sent these to the participants for checking of my assumptions. I sent each of the participants a summary; six responded to my emails. Of the six who responded, five agreed with my interpretations and naming of themes and said they felt they were represented accurately. One participant disagreed with my terming as confusion what she had called ambivalence or not really being interested in relationships and dating. She indicated that she had not felt confused and had made a conscious choice to not think about that particular side of herself. This change was incorporated back into my interpretations to better reflect her intentions.

I sent a second email to those participants who did not respond to the first email. None of these participants responded. One of the reasons for this might be that nearly a year had passed since the initial interviews of some participants; given this much time 
since our last contact, email addresses may have changed and participants may no longer have had interest in further participation.

Developing a structure. The structure of the experience (van Manen, 1990) created by these stories highlights the unique ways these participants experienced their social interactions in the context of feeling attractions to more than one gender. Distilling the stories shared by these young people into the themes that form the structure of the experience was an interesting and daunting process. It was important to me to tell the stories of the participants in such a way that other readers would get a sense of what tied the stories together and the implications of the stories themselves. The participants shared stories of their experiences with me, knowing that I might not understand them. It was clear that some of the interactions they described were influenced by their anticipation of discrimination or negative reactions. As I discuss the themes more fully in the following chapter, these interactions will be more clearly described.

Organizing study materials. I began this step by making a list that contained all the small phrases I commented on in the first few readings of the transcripts. This list contained more than fifty terms. I created a table from this list that contained all the initial themes and participant names. I used this table to explore those themes that were common or similar across the participants. I also looked at themes that seemed to use different words for a concept that was the same between two or more participants. An example of this was Amelia's comment about "not fitting" at school and Jane's comment about being "out of place" at her school and the way they each talked about this experience of being different from their peers. Those words or phrases that seemed to be 
indicative of a like concept were combined and I noted the particular phrasing used by each participant. This table contained about twenty-five themes at the end of this process. I then examined each of these themes across the participants in order to see those places where several of the participants had talked about the particular concept as part of their experience. This table provided the overarching themes that described the structure of the experience.

Seeking supervision. I consulted with my advisor at each step and sought, and incorporated, his feedback regarding the themes as they are named, as well as the design of the overall structure. I considered the feedback I received from the participants to be an additional layer of supervision, as their responses were carefully considered and used to strengthen the final analysis.

Developing a narrative. This part of the process was also iterative. Chapter Five presents a description of the constituent elements of the experience. The themes and structure evolved, and were strengthened by the process of writing this description.

Reflecting on the process. This step, while stated as the final one, was something I did consistently throughout the entire study. This was part of the process of preparing for interviews and for debriefing after interviews. I drew on my theoretical foundations as part of this reflection, noting those places where the meanings participants made of an experience influenced their future engagement in social interactions. Many of the theme names reflect this influence and I address the links to theory in the theme description in the next chapter. In the final analysis, reflecting on the overall process strengthened the way the stories of these ten young people are shared. 


\section{Evaluation of validity}

Evaluating validity in qualitative research is an important part of the process and Smith et al. (2009) describe two methods that are applicable to qualitative methods. For this study, I relied on one of the models they describe. The model (Yardley, 2008) presents four broad principles qualitative researchers can use to assess the quality of their study. These principles are described in the following paragraphs.

Sensitivity to context is the first principle and requires the researcher to pay careful attention to the context in which the participant was situated, the existing literature, and the information gathered in the interviews. This principle was carried into the analysis, requiring me to pay close attention to how each participant's account unfolded and what could be learned from it. This principle was important for the study because the context in which the participants experienced the phenomenon was a large part of what was being studied. Using verbatim extracts from the interviews gave the participants a voice in the analysis, providing the reader with the opportunity to check my interpretations.

A second principle was commitment and rigor. Commitment on my part to the process of data collection and analysis meant that each interview needed to be conducted well and that the needs of the participants needed to be carefully considered and met, especially in terms of making them comfortable with the process of sharing their experiences with. Careful recruitment of participants, interviews of a consistent and high quality, and a commitment to the analysis were needed for this principle. As markers of 
rigor, I have presented examples in Chapter Five of the ways the participants' experiences differed and were similar.

Transparency and coherence is the third principle important in an IPA study. Transparency refers to a clear description of all the steps taken in the research process when the study is written up. This was achieved in this study by the presentation of the steps taken in the recruitment process and the steps of the analysis. Transparency was important for this study as a way of ensuring that the voices of the participants were represented accurately. The most important check of whether I achieved transparency was through the use of member checking. Each participant was given the opportunity to read a summary of my analysis of his or her interview, and offer feedback about my interpretations. Coherence refers to how the themes hang together and if the argument presented is logical. To ensure this, I met regularly with my advisor to debrief.

The final principle important in IPA studies is impact and importance. As Smith and colleagues (2009) put it, the final evaluation of validity is whether the reader finds something interesting or useful in the report. The presentation of the findings "needs to be plausible and persuasive in terms of the evidence presented to support the claims made and the writing needs to be bold and confident in presenting the interpretation of that unfolding evidence trail" (Finlay, 2011, p. 142). A first measure of assessing whether my findings have validity was to invite participants to read parts of the initial report and provide feedback. A second measure of assessment relied on input from my advisor and other committee members. 
In addition to attending to the principles described above, I kept a reflexive journal recording my thoughts about each aspect of the study. This journal acted as a record which could be available for others to examine my process. Reflexivity is the awareness that "all knowledge is affected by the social conditions under which it is produced; it is grounded in both the social location and the social biography of the observer and the observed" (Mann \& Kelley, 1997, p. 392). An important part of establishing trustworthiness is examining how the researcher's position or social location impacts the research process (Lietz, Langer, \& Furman, 2006). As it is not possible to fully understand the lived experience of the participants, reflexivity encourages the researcher to strive to capture the connections and be aware of how subject and object influence each other (Finlay, 2002).

\section{Summary}

Chapter Four outlined the steps taken in the analysis process. I explained how themes were identified, named, and grouped in order to present a description of the elements of the participants' experiences. This analysis attended to both unique and common features of each participant's story. I developed a summary about what I interpreted from the interviews and sent it to each participant as a way of checking my assumptions. This member checking allowed me to trust my interpretations and incorporate the participants' feedback into the final narrative. In Chapter Five, I present the themes that emerged during the analysis which describe my fundamental framework for understanding the participants' experiences. 


\section{Chapter Five: Findings}

This chapter presents the features of participants' experiences with others in social interactions and describes the ways participants made sense of these experiences. Each feature contains several themes and variations which are described in detail.

The theoretical underpinnings explain how the participants took in information from their interactions. Symbolic interactionism theorizes that people's interpretations of their interactions with others are part of a dynamic process, shaping future interactions (Robbins, Chatterjee, \& Canda, 2006) and describes how previous interactions with others, and the meaning they attached to those exchanges, influence future exchanges.

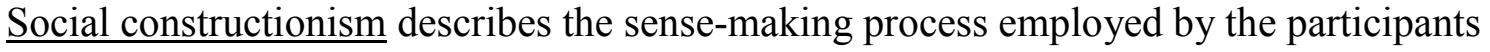
as they interacted with others in their social environments. Sexual minority stress suggests that exposure to sexuality related violence, personally or vicariously, prepares someone to anticipate future negative interactions. Although the themes and variations matched in some ways with these theories, in other ways they did not. Examples of this include the variations of assumptions from gays and lesbians, explaining, and conditional acceptance. I will describe how these variations did and did not match with the theories in the following sections.

\section{Overview}

The three main features I present in this chapter describe participants' experiences with others in social interactions. Participants integrated observations of their social interactions and previous experiences into an understanding of their relationships with others. They modified their behaviors as a result of their interpretations. The way 
participants interpreted the messages they got from their experiences was influenced by environmental factors such as whether an experience happened at school, home, or in a church setting, and who was involved in the interaction. The young person's context was an important factor in how social interactions unfolded. Short biographies, presented in Appendix G, describe participants' backgrounds and offer a description of their social location. It is important to note that participants thought some of their interactions were influenced by their bisexual attractions; however, they understood some experiences as having to do only with their "gay side." They interpreted that their attractions to someone of the same gender created resistance from others. Given the nature of the interviews, it is not possible to know how previous interactions influenced how participants made sense of the experiences they shared with me.

During the analysis, it became clear there were three main features of meaningmaking for these participants, with each feature holding themes and variations describing the participants' experiences. These themes and variations were closely related in how participants incorporated the messages into their interactions. Some of the experiences resulted only in a change in the participants' awareness, while other experiences resulted in changes to how they chose to interact with others in future interactions.

\section{Taking it in}

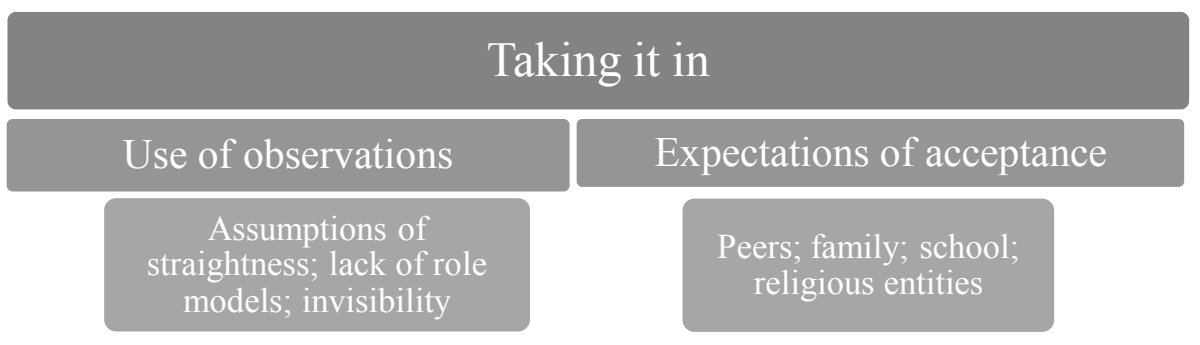

Figure 1 
The feature taking it in describes how participants gleaned information from their social interactions. This feature presents how participants gained an awareness of what others thought about them and their attractions to more than one gender. Participants became aware of what others thought through the use of observations. They held expectations of acceptance from peers, parents and family, and those in the community such as school leaders and church members based on previous interactions. The participants interacted with others in such a way that they could manage and integrate messages from their interactions into their understanding of themselves. The following themes - use of observations and expectations of acceptance - illustrate how participants took meaning from the messages received during social interactions.

Use of observations. Participants used the meaning they took from previous interactions with family, peers, teachers, and school environments to shape future social interactions as part of the dynamic development of an identity. Symbolic interactionism suggests that people share significant symbols (shared meaning) created during interactions with each other (Robbins et al., 2012). Having integrated symbols of how LGBTQ people are viewed and treated, the young people were attentive to those instances when peers and teachers engaged differently in social interactions. The use of observations is about those moments when the participants relied on knowledge gained from previous interactions to make sense of what was happening in a current situation. Several of the participants shared experiences of observing the behaviors of others, which they then incorporated into an awareness of what to expect from future interactions. The 
following two stories illustrate how the participants learned to make use of what they observed in the interactions of those around them.

Jane shared a story of being in class when a teacher made fun of one of her male classmates because he spoke effeminately. She watched as her peers laughed along with the teacher and the boy ran from the room. She took from this interchange that school in general, and this teacher in particular, were not safe. “...you know your English teacher thinks that gay people are to be made fun of and you just basically know...that's not the best place to go." Jane's knowledge from previous school experiences, where most teachers acted more positively towards LGBTQ students, caused her to struggle with this new message. As she shared the story about her teacher's ridicule of a classmate, Jane's tone of voice indicated a sense of disappointment. Her disappointment in how the teacher treated the student impacted how she anticipated future interactions with teachers. It is understandable that Jane would internalize this interaction and anticipate future encounters with others in this environment when her story is explored from a sexual minority stress standpoint. Jane believed she would need to be more guarded with this teacher and her peers based on this observation even though the act of stigmatization was not directed at her.

Amelia shared several stories of trying to engage in discussions with her teachers about LGBTQ issues and being frustrated by their reliance on the teachings of their church: "...the teacher would just step back and say "well, this is what the Catholic Church teaches"... and it wasn't like a conversation." She learned from her parents to raise questions when she encountered what she considered to be rigid and biased 
thinking. Amelia approached these conversations in the classrooms carefully: "I found myself defending (LGBTQ relationships) more strongly because there was a very finite answer...I found myself...just playing devil's advocate." She understood her attractions to both females and males would be problematic for her peers and teachers and she engaged in these discussions without outing herself. The knowledge she took from social encounters, such as those between her parents and their friends, prior to attending this school was that even controversial topics could be discussed. The power of the symbols in this Catholic classroom necessitated an adjustment on her part. This refusal to discuss the issue in a deeper way, as well as her peers' refusal to engage in the discussion at all, indicated to Amelia that she was not able to trust her teachers or peers. She became disengaged in the classroom, listening to music rather than listening to what the teacher was saying and she stopped participating in class discussions: "...I just ignored the whole class... because after a few conversations, I no longer had any interest in what the teacher had to say..."

Assumption of straightness. Participants held an assumption of their own straightness based on previous attractions. They also understood others held the same assumptions about them because of their previous behaviors. From a sexual minority stress perspective, this assumption may arise out of the hetero/ homonormative binaries and the fact that the participants had other sex attractions. It is also explained by social constructionism in that, drawing on the visible examples of relationships available to them, participants became convinced that since they had other sex attractions in addition 
to their same sex ones, they could doubt the same sex ones and believe themselves to be straight.

These young people described this experience in two ways. One was the realization that others made this assumption about them:

Straight is the default in our society so everyone just assumes that you're straight until you say you're gay. And so, even though I knew that my parents weren't homophobic, I still think that they, maybe they didn't assume that I was straight, but they certainly didn't assume that I wasn't straight. And so just telling them that I was maybe different than they thought that I was and telling them that I was different than they were was nerve-wracking. (Kina)

This awareness of the assumptions of others added to their anxiety when participants considered outing themselves to family members. Kina thought at length about what she would tell her parents about her attractions when she began to date a girl. She dated boys and talked about her crushes on them with both parents and she knew their assumptions were that she was straight. After she dated her first girlfriend for a short time, she knew she needed to tell her parents and worried about their reactions to the change. Her anxiety about outing herself came from having to tell them she was different than they thought and an awareness they might not understand her attractions to males and females.

The other way participants described the assumption of straightness related to how they thought about themselves. They were often confused by their attractions to someone of the same sex when they had been in a relationship with an other-sex person. 
Emily shared a story about her first attraction to a female peer. She was caught off guard when she realized she was attracted to her best friend in the same way she was to the males she dated. Her confusion started when she felt her heart racing, her hands sweating, and her face flushing when she was with her female friend. She experienced the same physical reactions when she was with her boyfriend and she did not know how to reconcile the reactions she felt. "I've slept with a guy...I can't be bisexual. I slept with a guy and did just fine." This assumption of their own straightness was a result, in large part, of the heteronormative nature of all the environments with which these participants interacted and was related to their attempts to understand their attractions without examples to which they could compare their feelings. Kina had a similar reaction when she met her first girlfriend. Since she had only dated males prior to meeting her girlfriend: "I just assumed that I was straight, even though I'd been attracted to women because I was so surrounded by straightness." She did not know anyone who was gay or lesbian, so she assumed she would marry a man and have children because those were the relationships she observed in her family and community.

Lack of role models. It was difficult for the participants to know if the attractions they felt were genuine because they did not have someone with whom to discuss their attractions. Sexual minority stress would suggest that this lack of visible examples results from stigmatization and the adjustments people make in their behaviors when they experience discrimination. Those who had a negative interaction related to their bisexual attractions might be less likely to share their feelings with others. 
Several participants questioned their feelings of attraction and were clear that they thought they might have been less confused had role models, who were also bisexually attracted, been available to them. A belief they were the only ones in their social environments experiencing attractions to more than one gender was an outcome of the questioning with which participants engaged. Several participants noticed this lack of role models during observations of their peers; they saw how peers accessed information and made use of examples around them. A struggle some participants had with making sense of their attractions to more than one gender resulted from this lack of examples. TD described it in this way:

It took me so long to come to terms with my bisexuality not because I thought it was bad or it was wrong but because I didn't have anyone to discuss it with. I didn't have anyone to tell me whether or not you were really bisexual if you felt differently about men than you did about women. I didn't know anyone who was a successful bi adult.... I knew gay... it was just more confusing than helpful to only have gay men to talk to. I didn't even know any lesbians for a long time. I felt like there was this roadmap for people and I just didn't have that.

When TD experienced attractions to women as different from the attractions she felt for men, she wondered if she actually felt the ones for women or if she was feeling something else. I found it interesting she doubted the attractions she felt for women but not men and it did not seem to occur to her that she could question the attractions she felt for men. I wondered if her doubt about the legitimacy of her attractions would have been different had more examples of all types of relationships been available to her. 
...I realized I felt very differently about women than men. And it's funny, when I first started noticing the differences, I thought they were different differences than I think they are now...but because I just saw men with women and I was attracted to boys at the time, I didn't look beyond that. And I would notice things about other women that other girls didn't notice about other girls but I didn't think too much about it...(TD).

Kina's efforts to process her attractions to males after being attracted to females was another example of the importance of having others to look to for models of interactions. She was caught off guard when she developed a crush on a male while she was in a relationship with a female. "I remember it totally confusing me because...then I just didn't know how to identify...it was confusing to be attracted to multiple genders."

Invisibility. A ramification of the lack of role models was that participants felt a level of invisibility in most social interactions. Some participants discussed the impacts of their school curricula in general, and sexuality education programs in specific, that did not address their needs or recognize their existence and the invisibility they felt as a result of this omission. TD recognized that some of her confusion about her attractions would have been eased with the addition of relevant content in her sex education classes: “...there was some mention of "some men like men and some women like women"...and as a young teen I didn't perceive this lack of information as something that kept me from coming to terms with my sexuality but now (sighs)..." While there has been an improvement in how gay and lesbian topics are presented in classes such as sex education in high schools, little content has been added that specifically addresses bisexuality. 
When teachers talked about gay and lesbian topics, but not bisexual topics, participants interpreted this to mean they were not significant and they would have to figure things out on their own. TD described her experience with representation in the classroom: "it's the same concept as representation in the media...those hidden messages you get whether they're intentional or not... just that you're not...significant...that you don't need to be taught to be safe..."

The feelings of invisibility and not having anyone to discuss their attractions with left them with increased stress about their social interactions, resulting in participants creating a reality that they were outsiders in their social worlds. An example of this was Jane's comment:

...it made me question myself. Maybe I am just going "oh, ok... girls are cute” and I can just move on without thinking any more than that but when I realized that that wasn't the case, I had that distinct feeling of removed again from the general population that I knew and it was just hard to deal with.

Use of observations illustrates how participants took messages from their interactions with others and used the information to make sense of what they experienced. The variations on this theme of assumptions of straightness, lack of role models, and feelings of invisibility address how participants made sense of what they were feeling. When they did not have any one to which to compare themselves, they struggled more to understand what they were feeling. It was not easy to make sense of their attractions when no one else they knew felt the same way. 
Expectations of acceptance. Young people are exposed to numerous examples of the dominant American culture's notion of family through movies, textbooks, and television. From these examples, many youth form expectations of what their parents should provide them in terms of support and acceptance. Interactions with peers, teachers, and church members provided the participants with a sense of what to expect from others. Participants developed an expectation of what others should provide in terms of acceptance based on the knowledge gained from their interactions. In this section I describe the participants' expectations of parental, peer, school, and religious entities' acceptance which, while similar, were experienced in distinct ways.

Parental acceptance. The most frequently available images of "family" and "parents" for young people in the dominant American culture are those showing some variation of a father and mother and children who all show love and support for each other. Parents and children learn to expect these types of relationships as a result. The expectations about family relationships for youth who are gay/lesbian or bisexual are much different, however. Viewed through the lens of symbolic interactionism, the participants and their parents were working with symbols of "family" that were not always reflective of their relationships. Essentially, neither parents nor children were prepared by previous interactions to manage the uniqueness of their experiences. When participants anticipated certain behaviors going into an interaction, they were often caught offguard by something unexpected and needed to reevaluate their thinking.

The stories shared most often by the participants were those involving interactions with family members, centering on discussions about acceptance. Those stories offering 
insight into how parents and other family members might react to a disclosure about their bisexual attractions had the greatest influence. I had not anticipated this reliance on their family interactions. As I reflected on this during the analysis, it became clear that my anticipation of how participants would view family relationships had been shaped by my own family experiences. I assumed these youth would be intent on building a family of choice early on, as I had done. After this realization, I went back to the transcripts and reread them while bracketing my assumptions about family. This reflection clarified my perceptions about the family relationships the participants were describing and solidified my understanding of their expectations of acceptance.

Some participants watched their parents interact with people who were gay or lesbian and integrated this into their understanding of how they might react to a disclosure. For example, Emily's mother had gay employees and never made antiLGBTQ remarks. She hoped her mother would be supportive, but she was not completely sure. Amelia's parents often left her with a gay couple when they had to go out of town and had many other gay friends. Their interactions with others let Amelia know they would be supportive of her if she came out. CS had two gay uncles and knew from her mother's support of them that she would be supportive. She still hesitated to come out, however, because of being attracted to both males and females. She knew her mother would understand her lesbian attractions, but she was unsure of how she would feel about attractions to males and females. None of the participants had knowledge of their parents' understanding of bisexuality. They had to make sense of a change in their understanding of the meaning of the primary caregiver relationship when they received a message from 
a parent or caregiver indicating something other than acceptance. Some of the participants reacted to the discomfort created by the change in meaning by engaging in self-protective measures. One example of these measures was buffering.

Buffering was a coping mechanism participants used as a protective measure to shield themselves from future negative interactions (Cohen \& Wills, 1985). They employed buffering tactics to avoid interactions they anticipated would not be supportive; they chose to not tell parents and caregivers about their same-sex attractions if they thought they might not be receptive. Kylie protected himself by leaving home. He was uncomfortable with his parents' "passive ignore-ance" - which he described as their choice to ignore the issue by not talking to him about it and dismissing him when he brought it up. CS anticipated negative reactions from extended family and protected herself from this by not telling anyone: 'I guess the issue was more I wasn't worried about my immediate family but by telling them it opens up to the rest of our acquaintances and family and that would be something I was nervous about."

Participants' feelings of uncertainty in their relationships with parents and caregivers illustrated the power of these messages of acceptance. They shared stories about anxiety as they considered telling their families about their attractions and guilt when they did not disclose their attractions sooner. CS talked about her decision to come out to her mother: “...I don't know why I was nervous...I never doubted that I would have the support of my parents...I felt guilty that it took so long...I didn't mean to hurt them by thinking I had been hiding this from them." 
$\mathrm{CS}$, Kina, and Emerald all received supportive reactions when they outed themselves, resulting in a sense of relief because each had anticipated a negative response from their parents.

Peer acceptance. The anticipation of peer acceptance differed from that of family members because participants understood peer relationships to be more transitory than family ones. Participants knew what to expect from peers if they disclosed their bisexual attractions because they understood the rules of what was acceptable to others in the school environment. The tenuous nature of peer relationships described by this group indicated they often anticipated peers to be less accepting, and more stigmatizing, of their multiple attractions. This anticipation resulted in the participants making great efforts to buffer themselves in these interactions.

Amelia shared an example of this when she described how she handled the difficult transition from a public middle school to a conservative Catholic high school. She anticipated that the environment of the new school would be conservative and she held back from outing herself to peers at her new school: "I had to branch out and meet new people and when you're meeting new people you tend to leave out certain things so (sharing her attractions) never came up." She protected herself by not dating anyone in high school, unsure of how to go about approaching someone and anticipating a negative reaction. She learned from her observations of incidents that happened to others that the community might judge her. She integrated this understanding into how she engaged with peers: "I never had any specific bad experiences but I wasn't going to put myself out there for the community to pass judgment on." 
She spent much of her time in class listening to her peers' reactions to different topics and matching their messages with knowledge she already held about peers in this setting: “...maybe it made me more skeptical of other people and who you could not necessarily trust...I was just skeptical of other peoples' beliefs and how that might affect me and in turn trying to steer away from those individuals. "

Another example of how participants protected themselves in interactions with their peers is Kina's consideration, based on her integration of knowledge from previous interactions, of how others would react when they asked her a specific question about her sexual attractions: “... a lot of the time in conversations, I would purposely...use gender neutral terms...because I didn't want to be questioned about my sexuality... and anticipating those conversations which I find tiring and trying to avoid them impacted some of my social choices. ” Kina's management of conversations was not unique. Several of the participants talked about how they learned to steer conversations away from certain topics in order to avoid having to explain their attractions.

Acceptance at school. Most of the participants spoke about their school experiences as being true to what they anticipated. From their previous interactions with the school environment, they had symbols of what the experience would entail. I was interested in their stories about experiences with education and the school environment because of the time participants spent with school-aged peers and engaged in school activities of some sort. Most participants described strong connections to their educational environments because of friendships with peers and a few teachers. Emily experienced her years in high school as positive; school was a place where she had good 
friends and supportive teachers. Brittany felt comfortable in school but experienced it as a dangerous place for her brother who was frequently beaten up by peers for being gay. Aythn, Emerald, and Kylie shared their experiences of school environments as lacking safety or "punishing" and "brutal"; they managed these feelings by finding places within the school that were more welcoming or provided a space that felt safe.

TD took control of those interactions where she anticipated feeling unsafe or discounted by not outing herself. She explained her decision-making process by sharing a story about a classmate: “...he was speaking about a mutual friend who was out as bi and said that he believed bisexuality didn't really exist and that bi women are...attention seeking and kind of slutty..." She did not feel like telling him about her attractions after his comment.

Acceptance from religious entities. Participants differed in their involvement with churches and religious schools: several went to Catholic high schools, two lived with Christian caregivers, and one was heavily involved in a Christian church. Those who attended church or religiously-based schools formed expectations of acceptance from fellow church members and teachers based on interactions with these people. Their anticipation of acceptance and love from other church members held tremendous power and influenced their interactions in their environments. In the process of making sense of their attractions, participants became aware of several powerful symbols in their churches and schools. Many religions, such as the Catholic Church some participants attended and the evangelical Christian church to which Brittany's foster mother belonged, oppose same-sex relationships, and many have an official stance on same-sex marriage 
(Bornstein \& Miller, 2009). Participants anticipated being excluded from this community if they outed themselves based on their awareness of their church's stance on gay issues and observations of previous interactions with other church members. Within the context of an environment where they initially anticipated being accepted, the negative messages they received about those who were LGBTQ caused them to doubt their place within the religious organization. Brittany experienced negative messages from her foster mother and those with whom she went to church: "Going to church with them was hard because they're telling you one thing... and being the way I was... and feeling like I was wrong in the church's eyes was something I struggled with." Much of the previous research on Christian involvement focuses on how LGBTQ individuals internalize the negative messages they receive from fellow church-goers (Lapinski \& McKirnan, 2013). Participants of this study, however, had questions that focused on the teachings of the church and the beliefs of other church members.

Jane described having close relationships with members of her church, which she experienced as supportive. These relationships became important for her to hold on when her mother passed away, as attending church activities was something she and her mother had done together. "...I did want to try to be part of church. My mom took me to church when I was a kid and it was something that tied me to (her). "Much of Jane's confusion about the dual attractions she experienced stemmed from her understanding of the church's teachings on same-sex attractions. She interpreted the messages she got from these teachings as meaning she would be forced to decide between being true to herself in terms of her attractions and continuing to be involved with the church: “... am I going to 
have to hide something about me in order to be able to participate in this? And starting to think about that question was challenging. That was big. " Youth leaders talked with her about potential leadership roles in the youth groups and told her how important she was to these groups. These positive messages were negated when the leader explained the requirements for group leaders:

...she set up this list of qualifications and I don't remember all of them but one of them that stuck out to me was...you can't be gay. At the time I was like well, then that won't work for me...that can't work for me because I don't fit their expectations of what to be.

Jane interpreted what the youth group leader said to mean they would reject her if they knew about her attractions. She knew if she was open about her attractions, she would need to make a choice about attending this church: “...I knew if I was going to be open about...my preferences...then I would have to be willing to turn things down sometimes...to sacrifice being myself...to turn away things to be me."

While Jane was the only participant to share a story related to an experience with a church, other participants shared experiences of marginalization or discrimination in the religiously-based high schools they attended or from Christian caregivers. Amelia occasionally challenged teachers in her Catholic school on LGBTQ issues and learned to anticipate responses such as "well, this is what the church teaches and this is what the Catholic Church says..." She learned from these responses that her teachers were unwilling to explore these topics more deeply, and her peers were unwilling to engage with the topics at all. As a result she felt "... a lot of insecurity in how people would react 
- it definitely wasn't allowed in our school...you couldn't be in a same-sex relationship or you would be asked to leave..." I asked her about this perception and whether it came from specific incidents or conversations and she related a story of two teachers who were fired for attending a gay pride parade in another town. "It was definitely an unspoken thing of it is not allowed and then it was backed up by teachers being asked to leave because of being a bad influence on students..."

In the preceding section, I described the feature taking it in and the themes use of observations and expectations of acceptance. The use of observations illustrated how participants managed the messages they got from their interactions with others. The experiences with assumptions of straightness, lack of role models, and invisibility were included as variations on the use of observations theme because they described a unique aspect. The theme expectations of acceptance was included because it described how participants received messages about interactions with peers, parents, school environments, and religious settings. The participants held unique expectations for each group mentioned and each of the variations were similar in some aspects. In the next section, I describe a second feature of the experience of social interactions that emerged from these interviews.

\section{Making sense of it}

\section{Making sense of it}

\begin{tabular}{|c|c|} 
Coping with assumptions & Being misunderstood \\
\hline Myths about bisexuals; & Explaining; not \\
seeking a sense of safety; \\
assumptions from gays and \\
lesbians
\end{tabular}

Figure 2 
Making sense of it describes how participants considered and attempted to make sense of what happened during an interaction. Participants' interpretations of their interactions were influenced by previous interactions, social locations, and the context in which a message was received. Messages were also interpreted with the awareness that others were making assumptions about them because of their attractions to more than one gender. These young people realized their interactions were influenced by others' lack of understanding of their attractions. There are two themes in this feature. The first is coping with assumptions, which includes the variations myths about bisexuals, seeking a sense of safety, and assumptions from gay/lesbians. The second theme in this feature is being misunderstood, which includes the variations explaining, not fitting, anxiety about coming out, and isolation.

Coping with assumptions. Each participant made sense of interactions in a specific context influenced by social location, history, culture, and interpretations of previous interactions. Participants' ability to cope with the assumptions of others was influenced by their understandings of the experiences of other LGBTQ people, myths others believed about bisexuals, and what they could anticipate as part of this group. During our interviews, each of the participants shared comments they heard from others about assumptions peers made about bisexuals. A comment Emily made illustrated the overarching stereotype succinctly: "Bi girls are slutty. Bi boys are fags. End of story." This stereotype was the basis for several of the other assumptions peers made about these participants. 
Myths about bisexuals. One of the myths participants shared was that females who felt attractions for people of different genders were in a phase, doing it for the benefit of a male, or attention-seeking; and that males attracted to multiple genders were really gay and reluctant to come out. Kina talked about her experiences with sharing her attractions with others and the impact the assumptions of others had on how she engaged in interactions:

...people assume that bisexual women are really straight girls who want to be special and sexy and fun so they call themselves bi. It's associated with being an attention seeker or being a slut, which is a pretty offensive term to use. I really found out if I said I was bisexual, people did not assume I had genuine attraction towards women or that my attractions towards women were as serious as my attractions towards men...There's this weird thing that if you're dating a girl, people assume you're a lesbian but if you say you're bisexual, people assume you're straight. I found it very devalidating. When sexual orientation would come up, I'd be very afraid to answer people's questions because there would be assumptions that I couldn't control.

Emily shared her frustration with the reactions of her male friends: “...it's okay to be a phase for girls because that's hot but not for guys... anytime you say you're bi...the first response you get is "ooh, can we watch?"...It was like, "really guys?" The stereotypes others held about bisexual females also impacted TD's relationships in high school: “...one thing that made it difficult to trust other people with my sexual orientation 
SOCIAL INTERACTIONS

in high school was the fact that so often when my male friends found out I was bi their first thought was threesome."

McLean (2008) raised questions about the impact stereotypes such as these have on bisexuals and the ways the stereotypes are internalized. Several of the participants talked at length about the assumptions people made about bisexuals and how their awareness of these assumptions impacted their social interactions. While gay and lesbian attractions and relationships have gained legitimacy in the past few years, bisexual attractions continue to be viewed negatively and are often misunderstood as a result of homonormativity and an expectation of monosexism. The young people interviewed for this study articulated several pervasive, negative myths about bisexuals, and bisexuality as an identity, that influenced the ways they made sense of their attractions. One common expression of the experience was that they did not perceive themselves to have the characteristics described by the stereotypes. The dissonance created by this generated self-reflection in the participants. For the most part, the young people were able to make sense of the message and not take it on, but this frequently took some time and work. The upshot is they often had a more difficult time making sense of their interactions because they could not reconcile what others thought about them.

Phase. The temporary status applied to bisexuality, and the prevailing stereotype that bisexuals are just on their way to being gay, is one consequence of monosexism (Alarie \& Gaudet, 2013) and the dominant American culture's adherence to monogamy. Those participants who worked to understand having attractions to more than one gender integrated the message that they needed to be concerned about the reactions of others. 
Emily made a decision to not share her attractions with her mother because of the dismissive way she reacted when Emily told her about a bisexual friend:

... and she said, "Oh, really? She's going through that phase?" and I remember that and that's one of those things... every time I think about telling her I'm like, maybe not...I mean I know she wouldn't be trying to hurt me and I don't know why it's hurtful...I think it goes back to the every girl's just two drinks from being bi...in a way it softens the blow for us in having to come out but in another way undermines the whole coming out process.

She also discussed the decision adults made when working with youth in a LGBT center to focus their attention on the gay and lesbian youth: “...we're going to focus on the gay kids...because it might be a phase for the bi kids and they can pass for now." Kylie stopped talking with his grandmother because of the question she asked him every time they talked:

When I told her I was attracted to males and females she went the "are you sure" way but then after that she started trying to fix me...every single time I talked to her she'd be like "are you through with this phase?" I stopped talking to her long before I stopped talking to my parents because it's a lot easier to handle silent ignore-ance than it is to handle aggressive intolerance.

Participants interpreted these messages as dismissive of their feelings, adding to their sense of invisibility. After listening to these participants talk about the changes they made in order to feel more accepted in their environments, I began to question whether a transition from a bisexual identity to a gay or lesbian one is a natural part of maturation 
or if the shift is just one more choice made in an effort to feel legitimized, seen, and not dismissed.

Sexualization by males. I included this experience as part of the myths because those participants who experienced it believed it resulted from the myth that females were expressing bisexual attractions to draw the male gaze. This conceptualization of female bisexual attractions allowed males to assume females would also be open to fulfilling other males' fantasies such as three-ways and a willingness to perform for them. In a study conducted on the influences of psychosocial factors such as sexual prejudice on the body image of bisexual women, Chmielewski and Yost (2013) addressed the eroticization of bisexually attracted women by some men, and the impacts this can have on the women who experience it. Their findings presented new information about the influence of sexist and biphobic attitudes on bisexual women. The participants in their study addressed the isolation and prejudice they experienced in the LG communities and the impact these experiences had on their overall wellbeing, similar to experiences of some of the participants in this study. For example, Kina recounted instances of being "creeped on" and having men "invite themselves into my relationship in a way they never would with a straight couple." She illustrated her experience with this story: "Recently at a party I was dancing and kissing my girlfriend and when we looked up, there was a circle of men around us who were watching us. They were not being discreet at all and it was really creepy."

Others talked about making drastic changes to how they engaged in social activities in order to avoid being considered objects of pleasure by their male 
acquaintances. Interactions with males, those they considered friends and those they did not know, changed as soon as the men learned of their dual attractions. Not only did they need to navigate objectification by males because they were female, they needed to do so from a place of being sexualized because of their attractions to other women.

Emily and TD felt degraded by male friends' reactions when they came out and decided to not come out to others in order to avoid these reactions. They adapted how they engaged in interactions as a result of these experiences, resisting the cultural conceptualization of women as objects to be enjoyed by men (McLean, 2008). TD decided to remain closeted in high school because of the reactions she got when she told a male friend about her attractions: “...in my experience that was not about...enjoying both sides of my sexuality, it was about pleasing the guy. Because, of course, they were never interested in guy guy girl..." Emily's male friends had similar reactions: "Cool! Can we watch?" and "Can we have a threesome?" These messages left both women feeling as though their relationships with female partners were devalued or dismissed.

The encounters resulted in the participants learning to modify their behaviors and being much less demonstrative when they were in public with a female partner. They changed their public activities because they interpreted the messages they received to mean they were the ones who needed to make the changes in order to avoid the unwanted attention of the males in their social environments. They became aware that acting on their affections with a female partner in public would be viewed as something being done for the benefit of males or to draw attention from males. This need to hide affection, not dance in public, not hold hands, or kiss a girlfriend in public, was draining and daunting 
and angering. They chose to make these changes in order to be more comfortable in their lives and wound up feeling isolated and dismissed.

Deviant sexuality. Another common myth participants described was the belief that bisexuality is a deviant sexuality (Israel \& Mohr, 2004). This myth supports an assumption that bisexuals are non-monogamous (Rust, 2000) and open to engaging in threesomes (Christina, 1995). It includes the assumptions that bisexual women are considered trendy, that women's claims to be bisexual are done with the intention of drawing the male gaze, and that women are doing it for attention. These assumptions allow others to dismiss claims of bisexual attractions as legitimate (Callis, 2013). Kina talked at length about her experiences when she outed herself to others and the impact their reactions had on her willingness to share with others:

...it can be really exhausting to need to explain over and over again. But then if I didn't explain, I knew that people would be assuming untrue things about me and putting me in boxes I didn't want to be put in.

For males, discounting the legitimacy of a bisexual identity supports a prevailing assumption that they are really gay and not willing to come out for fear of losing their straight privilege (Bower, 2002; Ochs, 1996). Much of the literature about bisexual males notes the most common stereotype applied to bisexual men is that they are "...considered dangerous... and will bring HIV/AIDS to the unsuspecting straight community" (Callis, 2013, p. 84). Kylie talked about the reaction of his high school classmates when he began dating a female peer: “...oh so you're NOT gay...” and noted that some behaviors of his peers, such as avoiding him in the locker room, changed while he was dating a female. 
From a sexual minority stress standpoint, Kylie's experiences with his peers contributed to his sense of isolation and not being safe in his school.

Choice. The participants understood from their interactions that others believed it was possible for them to make a choice about their attractions and they should use this choice to make things easier for themselves. The concept of choice both referred to the way others assumed the participants could make decisions both about their attractions and about whether to pass in order to avoid discrimination. Emily's experience with a youth worker at a LGBTQ youth center in her hometown is one example of this message: “...if you're bisexual they tend to say "well, if your parents don't accept it, just don't tell them....bring your boyfriend home and if you're dating a girl then don't tell them "...it's more like it's your problem..." The young people heard from gay and lesbian peers that they should choose attraction to one gender. Kylie shared: “...even amongst the LGBT community, gays and lesbians are saying pick a side...that's how they're presenting. And so even within your own peer group, you don't have the support that a "normal" gay or lesbian might have..."

The participants shared experiences of being told by adults, usually service providers, they should choose to pass until a time when they were out of high school or away from parents if they were experiencing negative reactions to their attractions. Choosing to pass, for these participants, meant not disclosing their same-sex attractions and, instead, foregrounding their relationships with other-sex partners. Participants described frustration and feelings of being dismissed as impacts of being told to "pass for now." 
TD told about encountering an “....attitude that I don't experience as much oppression as the rest of the community because I have the option of being with a partner of the opposite sex because I find them attractive but it's not like I can just suppress that part of my identity..." from her gay and lesbian friends. Her reaction to this message was one of dismay and frustration at being dismissed by a community of the very people to which she believed she should be able to look for support.

Seeking a sense of safety. The sexual minority stress model explains the impact experiences of vicarious violence can have on those who experience it. Though none of the young people shared examples of violence directed at them, they did share experiences of sexuality related violence directed at peers. Participants developed a sense that they were, themselves, in tenuous social situations based on their attractions when they witnessed these acts of violence experienced by others. Aythn shared a story of an event she witnessed that had lasting impacts on her sense of safety and the degree to which she shared her attractions with others. On arriving at school one morning, she noticed that someone had painted anti-gay slurs and Bible passages on the school walls in red paint. She was so frightened by this she left school for the day because she did not feel safe:

I just felt really scared. We came to school one day... and our main hallway was spray painted with a verse from the Bible - the one man shall not lay with manthey just had...the passage spray painted repeatedly across the hallways, the lockers, the doors, in dripping red. I wanted to go home. I wanted to run. 
Other participants managed a desire for a sense of safety by finding those places in their environments that provided it. Kylie spoke about his experience in school: " $I$ never felt physically at risk but it was certainly emotionally abusive to everybody who did not fit the straight white male..." His desire to avoid the verbal abuse prompted him to seek a safe haven. He found it in his school library where he formed a close bond with the librarian. She enforced clearly stated anti-discrimination policies in her library and offered Kylie a sense of safety. He valued the time he was able to spend in the library, choosing to volunteer in order to be able to be there more frequently. His relationship with this librarian left a deep impression and he talked about her with respect and gratitude for what she provided him.

Emerald found safety in band. She illustrated her unique relationship with her bandmates: "I was out as "not straight" in high school and one of the guys in band said, "You're not straight? Then you're a lesbian." So, after that no one called me by my name, they called me "the lesbian." But it was okay, you know? It was band family." While she did not feel comfortable being referred to that way, she accepted it because it made her feel like part of the group. Despite finding the label stigmatizing, she appreciated the support she felt in this environment.

Assumptions from gay men and lesbians. Bisexually attracted people often experience discrimination from those in the gay and lesbian community. As McLean (2008) stated: "Although these attitudes are not necessarily held by all gay men and lesbians, there is an understanding among many bisexuals that bisexuality occupies a problematic position within the gay and lesbian community - and that the gay and lesbian 
community is a place that can be unfriendly, and unwelcoming, to bisexual men and women" (p. 69). Participants of this study took several messages from their interactions with gay men and lesbian peers. The primary message the participants heard was that their situations were easier than those for gay men and lesbians because of their ability to pass and avoid discrimination.

Emily expressed frustration with LGBTQ community center workers where she volunteered who told her “...if your parents don't accept it...just bring your boyfriend home and don't tell them you are dating a girl..." To her it seemed they were saying “...it's your problem... and (it wasn't) like they were doing it actively but it was like "we're going to focus our resources on helping the gay kids"..." She saw these workers as triaging the needs of the gay youth ahead of those of bisexual youth, which she interpreted as dismissive of her needs. "I felt dismissed within the community especially when they looked out for the gay kids a little bit better. And the bisexual kid is more likely to have to bring (problems) to their attention..."

Previous research on concealing a stigmatized identity such as minority sexual orientation shows some benefits to the act of passing (Newheiser \& Barreto, 2014). These authors also argued that hiding a stigmatized identity has tremendous costs and examined the costs to young people of choosing to pass in order to have the illusion of safety. They showed these costs, in terms of interpersonal interactions, to include a reduced sense of belonging and social acceptance. The young people in this study experienced similar reactions, suggesting that passing was not a reasonable solution to anticipated marginalization. Both social constructionism and the sexual minority stress model 
explain why the participants took steps to create safety in their environments. These theories do not, however, explain the impact experiencing stigmatization from gay and lesbian peers had on these young people. Participants shared their feelings of not having a community and being surprised when they were rejected by gay and lesbian peers. As Kylie said:

...even amongst the LGBT community, gays and lesbians are saying pick a side. Whether they say that is what they're saying or not, that's very much how they're presenting. So even within your own peer group you don't have the support a "normal” gay or lesbian might have...

Participants felt additional stress and confusion as they tried to make sense of their attractions to more than one gender because of the homonormativity they observed in their interactions with gay and lesbian peers. They received clear messages about others' beliefs that attractions to same gender partners was acceptable but attractions to same- and other-gender partners was not. This reinforcement of monosexist notions about sexual attractions added to the confusion some of the participants experienced. They learned to doubt themselves because of these interactions.

Being misunderstood. It became clear to the participants, as they worked to make sense of their interactions, that others would hold some assumptions about them that were not true. Feelings of being misunderstood resulted from their awareness of the assumptions. When people showed a lack of understanding about bisexuality or bisexuals, participants felt the need to explain their attractions in order to be able to interact with others in a less stigmatizing way. Each of the variations in this section relate 
to assumptions the participants knew others were making about them and about bisexuals in general. These assumptions impacted the participants and added to their sense of being dismissed and not fitting. While some of their experiences of stigmatization and discrimination were similar to those of their gay and lesbian peers, these participants recognized they were misunderstood by both straight and gay/lesbian peers.

Several variations of this theme were evident within how participants described this experience of being misunderstood. These variations included a need for explaining attractions, a sense of not fitting in their environments, and anxiety about coming out. The following sections describe each of these variations.

Explaining. Participants understood from previous interactions that others held inaccurate beliefs about them, creating a need to explain their attractions. This need to help others understand what they were feeling in terms of attractions manifested in two ways: frustration with needing to explain and a reluctant engagement in educating others. Taking on the responsibility of teaching someone about their attractions was, in part, a way of managing their interactions and creating a sense of control in their environments.

For some the need to explain these attractions led them to search for words to describe what they were feeling; this effort was often frustrating because they felt a gap in language: “...it's really so much more difficult to overcome barriers when you have a lexical gap...it's not just the experience of being a bi person but being surrounded by people who don't have that vocabulary..." (TD). She described her decision to not label herself when talking with others: 
SOCIAL INTERACTIONS

...I was attracted differently to men and women and I didn't like the term

bisexuality because it goes hand in hand with the whole gender binary thing but pansexuality didn't really describe it well either. And if you make up your own word to go with whatever you want, then no one is going to know what you're talking about.

Explaining to parents was difficult, even when they were accepting and understood gay attractions. This was true of CS's mother who had a gay brother: ...but the way she (tried) to explain it to me was that for them they used to see it as one way or the other and I think it honestly would have been easier if I had come out fully lesbian. That was kind of hard to hear because they didn't understand and I didn't know how to explain it to them... and so it wasn't like they were unsupportive, it was like it didn't make sense to them.

Kina struggled with the decision of whether to explain her attractions to others when she questioned if they were really interested in understanding:

I guess it'd always come down to me having to choose between whether it was worth the effort to explain it in order to have people understand correctly or whether I'd just rather people make assumptions about me... sometimes I would just give up and agree to the terms people were suggesting for me because I didn't have the energy to really explain...So that was always frustrating and a little alienating...

Despite their struggles explaining themselves, it was still important to the participants that their attractions be understood by others; this often meant gauging 
whether the person asking was genuinely interested and basing how much to share on previous responses they received. Kina explained how she decided what information to share with someone who asked her a question about her sexuality:

...it depended on partially on how much energy I had, you know, how many times I'd already been asked that question that week or day and probably depended on how much I thought this person was actually open. You know because sometimes when people ask those questions, they seem genuinely interested. But a lot of the times I didn't feel like they were really going to believe me. So with those people I would normally just not answer or just change the subject...

The struggle with explaining their attractions to others quickly became tiresome for the participants and led them to share less information with peers or family members who were asking questions simply because they did not have the energy to tell someone about it. This growing frustration with the need to explain was only partially explained by the theories used in the study. Participants were not able to make sense of why they needed to explain their attractions and seemed to give up on the hope that others would accept their attractions without questioning them.

Not fitting. A sense of not fitting was another variation on the theme of being misunderstood. An example of this feeling was Jane's experience with her church youth group leader, who suggested she consider being a group leader. From this conversation, she received the message that she could not be open about her attractions and be part of the church because of the church's rejection of LGBTQ people: "I remember thinking, what then?...if I don't fit their expectations, do I fit? " Maintaining her connections to 
some parts of her church community was important despite her awareness that she did not fit with this person's idea of who should be a youth group leader. The sense of not fitting also carried over into her school community and she made a conscious effort to stay out of the way. "It was easier for me to just stay out of the way and out of place instead of trying to make a place for myself and already there was a feeling of...self-consciousness that can be the worst in high school..." Amelia experienced anger and frustration as a result of her outsider status and reacted by detaching: “...it just made me more angry ...this is ridiculous...this is 2011 and we're still debating this issue and it shouldn't even BE an issue and yeah,...I detached myself from school and the community..." Outing themselves to others alleviated some of their feelings of not fitting.

As described in Chapter Two, a sense of connectedness to peers is important for young people and the absence of this sense of connection can result in lack of school success and poor mental health outcomes (Davis, Saltzburg, \& Locke, 2009; Difulvio, 2011; McNicholas, 2002). Some participants of the current study talked about their fears of losing connections if peers could not understand their attractions to more than one gender. The participants made sense of these fears in a context of feeling attractions to more than one gender and understood the loss of connections to peers to be related to these attractions. The experience of this loss, as described by the participants, was an absence of expressions of acceptance and support.

Anxiety about coming out. Feelings of vulnerability intensified as participants contemplated telling others about their attractions. Their anxiety about coming out to others, particularly parents, often started when they witnessed someone else receive a 
response they interpreted as negative. This vicarious experience made them worry about how others might react to them, even though nothing negative had happened specifically to them. Even when parents expressed accepting feelings about LGBTQ people, some participants still created a reality in which they were vulnerable. They took efforts to manage their vulnerability by controlling how and when they came out. Emily told her sister first because she was unsure of her mother's response. She and her sister had a conflicted relationship and she decided, if her sister outed her and her parents had a negative response, she would deny it and claim her sister was just being hateful to her as usual. She knew her mother was accepting of same-sex attracted people but considered her mother to be "a very judgmental woman" and was concerned she would have a "not in my backyard" response to Emily's attractions. She created a plan that would allow her deniability if her mother had a negative reaction. Kina believed her parents to be very open and accepting, but she felt anxious prior to telling them about her attractions because she did not know how to tell them she was "different than they thought (she) was and different from all of them."

In this section, I described the feature of making sense of interactions and the themes of coping with assumptions and being misunderstood. These themes had several variations which illustrated the complex ways these young people made sense of the messages they got during interactions with others. Participants shared several examples of how the assumptions others made of them impacted their social interactions. The young people made clear decisions about when to engage with someone who did not understand them and when to steer clear of potentially painful environments. In the next 
section, I describe how the participants integrated their understandings of interactions and how they made adjustments to their behaviors in an attempt to both make those around them more comfortable and to make themselves feel safer in their environments.

\section{Making accommodations}

\section{Making accommodations}

\section{Conditional acceptance}

\section{Tolerance of abuse}

\section{Figure 3}

The third feature described by participants was making accommodations, which includes the themes conditional acceptance and tolerance of abuse. These young people made adjustments to their behaviors in order to make others more comfortable and in order to maintain some sense of control over their environments. The participants created the way they interacted with their environments based on an understanding of belonging to families, peers groups, school or church environments, and as someone with stigmatized attractions. Each participant made sense of previous interactions and engaged in future interactions within the context of previous learning. The themes presented in this section reflect the participants' sense that they were responsible for someone else's discomfort in their interactions. They made accommodations to their presentation of self in order to put that person at ease. The themes in this feature included an understanding that their acceptance from others was conditional and a tolerance of abuse.

Conditional acceptance. This theme is closely related to participants' expectations for acceptance from others; however, I considered it a theme in this feature because participants made adjustments to their behaviors when they became aware they 
would only be accepted by others if they did not come out about their same-sex or multiple sex attractions. Participants understood from previous interactions that their acceptance from others was conditional: there was a shift in how someone interacted with them once that person learned of the participant's attractions to more than one gender. While they desired acceptance from others in their environments, the sense that parental acceptance was conditional resulted most frequently in accommodations on the part of the participants. They shared stories of watching their parents and caregivers interact with others who were LGBTQ and using these observations to learn what they might expect in interactions with parents/caregivers if they outed themselves. Kylie described his father as anti-gay and was used to hearing him make negative comments. Brittany's foster mother was clear about her dislike of LGBTQ people.

Even those who were sure their parents would accept their attractions hesitated to come out to parents and family members out of fear of losing the relationships. Amelia knew her parents were accepting of LGBTQ people because several of their friends were gay. Emily knew her mother had gay employees who she treated well. CS had gay uncles, so she anticipated her mother would be accepting of her attractions. Emerald knew of her mother's attractions to females despite being married to a male. Yet, each of these participants considered whether to come out because they were not sure if their parents would still be accepting of them. As CS shared: "I don't know why I was nervous...I never doubted I wouldn't have the support of my parents...I just didn't want to add that stress to their live." Based on what they observed, some of the other participants understood their parental relationships to be tenuous and conditional. Participants made 
accommodations for this when they sensed it, often delaying outing themselves and taking other measures to protect themselves.

For example, as Brittany observed her grandmother verbally abuse her brother for being gay, she anticipated the same abuse if she told her grandmother about her attractions to girls. "I remember him being 6 or 7 and wanting to play with my Barbies and she would call him "faggot" and (say) "that's not right!" She'd put him in the corner..." She took from these interactions that she would lose her grandmother's acceptance and she chose to run away from this home rather than come out and open herself to similar abuse.

She later chose to run away from a foster home where she had lived for several years because of how the foster mother reacted to Brittany's relationship with a classmate. She respected this foster mother deeply and came to expect supportive interactions with her because of the positive nature of their previous interactions. This ended when the foster mother took Brittany's cell phone and looked through her text messages, some of which were quite intimate, and shared them with Brittany's foster sisters. She justified this invasion of privacy by saying Brittany was engaging in nonChristian activities and she wanted the other young women in the home to know about it. Brittany had, until that experience, believed her foster mother to be accepting of her. Brittany placed importance on this relationship because she wanted and needed love and acceptance. Abuse from her grandmother and her mother's inability to care for her gave her a message that she was unlovable. The foster mother's message reinforced this understanding and Brittany found she struggled to believe others cared for her as a result. 
...when an adult is saying that something's "wrong" or "that's gross," especially being in foster care, when you want ...to be able to call somebody "Mom"...and then that person is saying these kinds of things about you...it makes it hard because then, you're shameful for being the way that you are...

She believed she would be better off returning to her grandmother, who had abused her, than listening to her foster mother's comments.

TD's experience with her father, who expressed his dislike of her transgender sister, led to an understanding she would be better off not outing herself to him. "He was civil to her but...he said "I am amazed you can be as comfortable as you are around those people"... and for that reason I've never really talked with him about it."

Kylie experienced supportive and accepting relationships with both his father and mother until he outed himself. He interpreted the changes in the way they treated him to their lack of acceptance of his attractions to boys and girls. He related that his father allowed him to have girls in his room without leaving the door open but that he was not allowed to shut the door when he had a male in his room:

He didn't state it but he made it a practice. If I had a guy over and we started to hang out in my room, just watch TV or something...my dad would come by and push the door open...He never did that when I had a female friend over so it was a pretty clear message.

He interpreted this as an obvious expression of his father's displeasure with his attractions to males. His parents' conflicted relationship provided context for how he eventually made the decision to leave home. His parents divorced when he was young 
and he lived most of his life with his father. He described his interactions with his mother as primarily positive, but not close. He chose to come out to his father first because he was unsure how his mother would react based on her beliefs as a Jehovah's Witness and other interactions he had with her. He reasoned that if his father reacted badly, he would not tell his mother, so he could live with her and have one safe place to live. His father's initial reaction was "well, we always sort of thought you might be...(attracted to males and females)." Following this initial reaction, Kylie saw a change in his father's behavior which he interpreted as a reaction to his disclosure: "I noticed a significant increase in the amount of anti-LGBT comments he made (post coming out). My dad prides himself on being an asshole. And it was like I suspected was going to happen..."

Following his disclosure, they went from being verbally loving and supportive to giving him indications they found him unlovable and distasteful, such as his father's antiLGBTQ comments and his mother's religiously-based ones referring to LGBTQ people as sinners. His assumptions about their acceptance of him led him to construct a reality that he would prefer being houseless to staying in a home where he felt ignored and unaccepted. When he made the decision to tell his family he needed to be away from them, he knew was putting his wellbeing in jeopardy. In a letter to each of his parents, he said: "I need time to figure out who I am, without you telling me I'm not what you wanted." At the time of the interview, he had not heard from his parents in more than six months and resided in a youth shelter hundreds of miles from his hometown.

When parents made negative comments about LGBTQ people, these participants believed it was their same-sex attractions, not other-sex ones, that would be problematic, 
based on their interpretation of these messages. Several participants thought at great length about whether to out themselves to parents because of the possibility of this primary relationship being threatened. When they decided that parents would reject them for the attractions, they took steps to hide it or took proactive steps to remove themselves from the relationships. This control manifested in different ways: Kylie and Brittany left home, Aythn chose to stay in an abusive situation because she knew what to expect, Emily told a sister in hopes she would tell their parents, and several others chose to not tell family members because of their uncertainty of how their family members would react.

Examined through the lens of social constructionism, participants' interpretation of the tenuous nature of the relationships with their caregivers is more understandable. The sense of acceptance as conditional influenced the behaviors of these participants in profound ways and they constructed their realities in such a way that they were able to make sense of it. This theory does not explain how participants made sense of this experience, however. The young people were able to accept and adjust to their relationships with their caregivers but were not able to verbalize any understanding of the conditional nature of acceptance.

Tolerance of abuse. A few of the participants experienced incidents of abuse in their homes in addition to vicarious incidents in their social environments. They tolerated interactions that were sometimes punishing in order to maintain their relationships with caregivers and learned to engage in interactions with these family members differently in order to minimize the instances of abuse. I named this theme tolerance of abuse because 
SOCIAL INTERACTIONS

part of making accommodations involved deciding how much abuse they would tolerate. Participants anticipated they would feel vulnerable at times in their social environments and adjusted to this knowledge. However, they struggled when they felt unsafe in their own homes. As I discussed in the previous section, participants made choices in their interactions in order to make others feel more comfortable when they knew it would make some interactions easier. Tolerating the abuse they experienced at the hands of parents and caregivers increased the accommodations they made and required them to accept painful interactions in order to feel some small measure of safety.

The need for a sense of security in their living situations caused both Aythn and Brittany to remain in emotionally and physically abusive homes. The meaning they ascribed to incidents of abuse was that they were deserving of it based on earlier messages they received and they made accommodations accordingly. Aythn's grandfather, who she described as "... a very violent and abusive man ... who told me I wasn't going to amount to anything...," also told her she would be "just like her mother" who was chemically dependent and unable to care for Aythn. She based her decision to continue living with him on previous messages from peers that foster homes might also be abusive: “...as a kid I figured this is the best it'll get. He's abusing me...but I don't want to be in... a foster home where you might...be with parents who don't care." She learned through other interactions that she could gain some positive attention from him by engaging with him on projects he liked doing and she adjusted her behavior accordingly. When she was with him in his workshop, she knew he would not hurt her. The longer term impact of this tenuous sense of safety was a shift in her sense of self that 
led her to believe her safety depended on her engaging with other social interactions from a place of wariness and fear. In the context of her environment, her decision to adopt a "tough girl" persona in hopes classmates would leave her alone, indicates she was buffering in order to protect herself in the only way she knew.

This section described changes participants made to how they talked about their feelings, how they interacted with others, and, occasionally, how they thought about their attractions in order to keep others from being uncomfortable. Rather than expect the other people in their lives to catch up to them, they modified their behaviors. They saw accepting abusive actions from others as necessary and did not seem to consider the long term impacts of these decisions. As the themes in this feature illustrate, making accommodations for the sake of someone else's feelings was often difficult for the participants. Their struggles with the adjustments they made can be seen as a manifestation of sexual minority stress. While these young people were able to buffer against other sexuality-related stressors, the close nature of their family relationships often prevented this protective action.

\section{Summary}

The themes and variations presented in this chapter are closely related to each other in terms of the participants' experiences. Making sense of what they experienced when they had no examples to which they could compare was often difficult. When the participants made accommodations in their behaviors, it was to make someone else more comfortable or to increase their own comfort by avoiding negative interactions. As the themes described above show, making sense of the messages they received in their 
SOCIAL INTERACTIONS

interactions was ongoing. TD shared an illustration of her experiences of trying to make sense of her attractions:

...it's all laid out in a lot of ways for people who are straight. I just felt like there was this roadmap for people and I just didn't have bi adults in my life that I knew and trusted and (there was) the whole attitude that it's just kind of something that women do...experiment ...that I found to be just extremely widespread... when I first tried to come out to my mom in high school...I said "Mom, I'm pretty sure I'm bi" and she said "No, you're not!" (laughs) and she told me a story about (an experience she had in college) and she assumed that because of that experience that it was exactly the same for me and I didn't really know how to respond to that at the time but... (pauses)...I felt like I could have had a much worse reaction to it if I was like less stable in other aspects of my life. I did feel pretty invalidated...to have her generalize about... her daughter because of her own experience...I found myself thinking about it a lot. I mean why would she think that? Because it's not as though with anything that my mother has experienced, it's going to be the same for me.

She interpreted this experience as invalidating and dismissive of her attractions. She attributed her mother's reaction partly to a lack of knowledge about or experience with bisexuals. This led her to make clearer decisions in future interactions about how she engaged with others: “...I wasn't particularly open about it...it's scary to be out there with it and a lot of people don't understand why you would do that. They have this 
SOCIAL INTERACTIONS

attitude of you should just keep it to yourself...but the reason I do it more now... is so they have this broader experience of bi people."

Some participants experienced confusion when they did not have role models to look to for examples. This was most evident when they realized they were experiencing attractions in ways that were very different from their peers and from family members. They questioned whether they were actually having the attractions or if they were making them up. From the perspective of matching theory, had the participants known someone who was bisexually attracted, they might have avoided this questioning.

One of the responses to this confusion was to shut down. Several participants talked about shutting down their sexual interests completely during high school because they could not reconcile the messages they were receiving with who they believed themselves to be. Shutting down resulted in the participants feeling closed off and removed from interactions with others. Trying to make sense of how differently they felt, and how they felt they did not fit in, added to feeling stigmatized and out of place. The interviews seemed to allow them to voice their regret at what they thought they missed by being shut off from others and not dating as much as they would have liked in high school.

Experiences with others' assumptions and a sense of not being understood led to feelings of isolation for some of the participants. Fears of social isolation or an absence of connection, especially from family and friends, are a common experience for some LGBTQ youth (Darby-Mullins \& Murdock, 2007). The sense they were missing out on the support from teachers and those in the gay community was an experience these 
participants described. They interpreted their experiences with gay men and lesbians as being asked to choose a side and, when they did not, they lost support from those peers. As the sexual minority stress model explains, bisexually attracted young people are more vulnerable to negative outcomes like depression and substance abuse without support from either the straight or gay community.

As the participants talked about their experiences of stigma, anxiety, and the need to come out to parents and family members, it became clear they attributed these things to their "gay side," as Emily called it. They understood some of their experiences were due to their attractions to both same- and other-sex people. Several participants railed against the gender/sexuality binaries and envisioned what it would be like to not need to explain anything. They spoke thoughtfully about their struggles with labels and how to explain things like their attractions to trans* people and what they should call themselves then. Several participants shared the search for a clearer label and an easier explanation. They communicated a sense of resignation and acceptance of the current limitations, though, and a few of the participants made conscious efforts to educate those within their social environments in hopes of improving the experiences for others.

Reflecting back on the master narratives discussed in Chapter Two, neither really seems to capture the range of experiences of this group. The emancipation narrative seems to best fit but does not address the complexity of the relationships and interactions in which these young people engage. As that narrative discusses, the development of a sexual identity is influenced by the young person's life course and their internal and external resources. The emancipation narrative ignores the cultural shifts some of these 
youth experienced based on where they lived and the Christian (both Protestant and Catholic) influences in their lives. Larger cultural shifts regarding gay and lesbian issues did not translate to shifts for those who are bisexually attracted.

The struggle and success narrative was not at all a fit for this group. None of the participants were unhappy about their attractions. When they questioned their attractions, it was not because they did not want to have them, it was because they did not understand them in the context of a hetero/homonormative society which offered no examples other than the binaries.

The sexual minority stress model suggests that some LGBTQ people may be impacted by their environmental conditions, including threats of violence and anticipation of future violence. The experience and anticipation of violence related to one's sexual attractions can increase a LGBTQ person's vigilance for the next incident. Those LGBTQ people exposed to stigmatizing environments may experience stressful events resulting in a sense of diminished well-being (Lewis et al., 2009). Some of this study's participants witnessed violence against their friends and peers in school and integrated these messages into an understanding of their own safety. They knew others in their lives were biased towards LGBTQ people and felt strongly that many interactions came from a place of oppression. These young people were aware they were likely to experience discrimination from both heterosexuals and lesbians and gay men because of their bisexual attractions. They identified several myths and assumptions about bisexuals and discussed their realization that biphobia exists in heterosexual and lesbian/gay 
communities. Having this prior knowledge led participants to anticipate how interactions would go and to interpret the messages from the interaction through this awareness.

Chapter Six discusses the implications of these themes for social workers and youth workers, education professionals, service providers, and parents. The participants of this study were most influenced by their relationships with their parents. Future studies should address the impact such disclosures have on parents in hopes of identifying ways to educate parents about non-binary attractions and relationships. 


\section{Chapter Six: Implications}

The previous chapter showed how the young people who participated in this study experienced social interactions in similar and unique ways. Their stories offered insights into the complexities of social interactions for those who are not exclusively heterosexual or gay/lesbian. They identified a need for role models or a roadmap in order to navigate the social responses to their attractions. Participants experienced concern at having to figure out how to maintain family relationships once they came out. These young people worked to make sense of their experiences as best they could in the contexts of their environments. This chapter offers suggestions for researchers, clinicians, and educators based on what participants shared about their experiences and how they managed social interactions.

My efforts to find something new in the social interactions of the participants, specific to bisexually attracted young people, challenged me during the analysis phase. Each participant shared stories of experiences they interpreted as happening in a particular way because of their bisexual attractions, although the content of the interview did not always clearly reflect this. As they shared stories about how interactions happened, the young people most frequently attributed an experience to their same-sex attractions. They understood their interactions happened differently when others believed them to be straight. While the participants clearly saw differences in their interactions based on their "gay side" and "straight side," they did not view themselves in this dichotomous way. They made interpretations of their experiences in the context of both attractions. 
I read interview transcripts numerous times in an effort to find those things that were new to the literature and specific to bisexually attracted youth. The most daunting and consuming part of this process was teasing apart the threads of stories and clearly expressing the participants' intent. Many experiences they shared were similar to those that happen to gay and lesbian young people every day. Yet these participants articulated, as they framed their stories, a belief that some of their experiences happened the way they did because they were attracted to more than one gender. They heard a message they were somehow responsible for the negative things that happened to them because they had the ability to pass - to choose to act straight to avoid discrimination - so if something negative happened to them, it was partly their fault. This experience was described in the variation of assumptions of gays and lesbians. Many of the stories shared by the participants are familiar to those who work with LGBTQ youth and many of the stories are familiar to those who work with women in their experiences of stigmatization and sexualization. I did not anticipate the stories of marginalization from gay and lesbian peers because of my experiences of inclusion in the LGBTQ community. And while I knew many young women experience sexualization by male peers, the experiences Kina and Emily endured were more intrusive than I had anticipated.

Several participants shared that it was new for them to have someone to talk with about their attractions. They expressed this in two ways. They seemed to feel free to express things they had not previously shared. I wondered if part of their comfort came from not knowing me and knowing they would never see me again. The participants had an awareness of the need for new terminology that could describe their attractions 
succinctly so they would not always need to explain them to others. They seemed surprised by my ability to understand what they meant without the need to explain their experiences, as they typically felt compelled to do with those who did not understand their attractions. My understanding was useful in that it put them at ease in telling their stories. I wonder, however, if my assumptions about what they were telling me was one of the reasons I did not access the lived descriptions I hoped for. My therapist's desire to let them know I understood what they were telling me allowed for a kind of short-hand in our conversations. This was problematic because participants' descriptions of interactions were occasionally limited by my indications of understanding. Participants might have shared more detailed stories had I not indicated understanding so quickly.

\section{Limitations}

While this study intended to focus on the participants' descriptions of their experiences, I encountered some difficulty in the analysis partly because of how young people articulated those experiences. They sometimes struggled to clearly articulate how their experiences specifically related to their bisexual attractions. These young people seemed to understand it was their same-sex attractions others reacted to, yet they interpreted the negative experiences in the context of feeling attracted to more than one gender. Experiences such as stigmatization and anti-gay violence impacted the participants as they would gay and lesbian youth. These participants seemed to recognize how their experiences were similar in some ways, yet they also understood they lacked resources that their gay and lesbian peers could access. They interpreted this lack of 
support as an indication they mattered even less than gay and lesbian youth and were not deserving of support.

My involvement in data collection and analysis influenced the interpretations of the interviews because of my own experiences as bisexually attracted. I was aware of my preconceptions of some of the participants' experiences and I attended to my biases during the analysis through the process of journaling. My interviewing may have been influenced by my preconceptions and there may have been instances where my own experiences got in the way of asking a participant for more details about their experiences.

My position as the researcher and an older female may have influenced what participants shared. I did not immediately share my own experiences with attractions to more than one gender and participants may have hesitated to disclose more intimate stories. The participants I interviewed by phone shared more details and I wonder if this resulted from of a sense of anonymity since I could not see them and an inability to read me as older. Also, as the interviewer, I may have influenced participants' responses through the way I framed my questions and follow-ups and through my non-verbal gestures.

My struggle to frame some of the themes was often due to a lack of rich, lived descriptions. The stories shared by the participants were powerful and full of potentially useful information for clinicians, educators, and researchers; however, they were not purely phenomenological. During the interviews, I focused on trying to get participants to offer descriptions about specific moments in the stories they shared. I asked follow-up 
questions about what they remembered about the space they were in or what they heard around them. These attempts were largely unsuccessful for at least two reasons: I was unable to make my questions clear enough and the participants did not recall the details of these experiences. My lack of clarity in phrasing the questions I asked may have resulted from the assumptions I discussed above. When I felt I had a clear picture of the experience the participant was sharing, I did not continue to ask the follow-up questions that might have led to richer descriptions of their lived experiences. During the orientation meeting prior to the interview, I asked the participants to think about experiences they wanted to share. I did not provide them with research questions and it is possible I could have elicited more detailed stories had I interviewed participants a second time. Given what I learned in this study, I will be able to collect richer descriptions in future studies.

\section{Lessons learned}

I spent a great deal of time evaluating the process of the interviews while writing the narrative. Interviewing was both awkward and familiar because of my experience as a therapist. Much of the communication participants and I shared was non-verbal and we each read cues from the other. As I listened to the recordings of the interviews after transcription, I noted those places where non-verbal cues had let me know when a particular story was more meaningful than another. Things like sitting back in their chairs or crossing their arms over their chest alerted me to their discomfort. I did not check in with participants about what cues they might be picking up from me, but I was aware of things like leaning in and nodding my head as they told a story that resonated with me. 
These cues were not available to me with the phone interviews I conducted so I paid more attention to pauses, long silences, or sighs to gain additional insights beyond their verbal responses. I also asked questions if I sensed the retelling of an interaction might be causing a reaction. As I reflected on the interviews, I noticed how much of the interaction between each participant and me was non-verbal. When I listened to the digital recordings, I remembered looks on the faces of the participants, I wondered what my facial expressions had been, and I wondered if my therapist habits (nodding my head in agreement, smiling in encouragement) had been apparent to the participants. So much of what participants shared resonated with me because I recalled my own high school experiences so clearly. I think part of this got in my way in the interview because it allowed a kind of shorthand in communication. I had a symbol for what they were telling me, so I did not follow comments the way I would have had what I was hearing not so clearly echoed some of my own experiences. I made interpretations about what they were saying when it resonated with me. Looking at the interviews through a symbolic interactionist lens, the participants and I began to perform differently with each other based on cues in the conversations.

I set aside some of these interpretations in the analysis process but I wonder how it hampered the interviews. I have considered what the participants might have thought about me. They did not typically meet me for the first time until the interview. Did they have an image in their minds about what a doctoral student researcher asking questions about sexuality would look like? And, if they did, what did they think when someone who probably looks like their grandmother showed up? When the interviews did not go 
as smoothly as I hoped, I wondered if it was because the participant was hesitant to share some information with someone old. It might be my perception/projection, but the interviews with Kina, Jane, and Brittany that I conducted by phone were open and frank about some of their experiences in ways the others had not been. This may have also been due to my increased comfort with interviewing and my lack of ability to rely on nonverbal cues.

In the analysis, I struggled to take it slowly. I tried, at first, to rush through and get to "the" meaning quickly. I focused on the search for a Husselrian essence, attempting to fit the each of the participant's experiences into a definitive structure. As I reflected on the analysis process, however, I came back to the IPA focus on what is unique in the experiences as well as what is similar. Revisiting the transcripts several times provided me with a clearer sense of what was meaningful to each of the participants and to the group. Each reading brought out more of the participants' phrasing and emphasis which focused my interpretations. Through the process of writing and revising, I came to meanings that were so much stronger than my initial thoughts. I learned that many of the stories resonated with me in an unanticipated way, which resulted in me naming themes with my words instead of allowing participant voices to shine through. Going back to their words again and again resulted in the descriptions of the participants' experiences presented in this narrative which are my interpretations of the stories they shared.

The interview process taught me numerous things about the young people and about myself as a researcher. I learned that so much communication comes from nonverbals and does not translate well when trying to pull quotes to use as examples. There 
was an unspoken communication in how the participants told their stories and how I listened to them. As I listened to a story, I found myself nodding, smiling, rolling my eyes, or other cues that would have indicated to the participant I understood the message even when they had not yet finished speaking. I wonder how often this shut down the retelling of an experience, took a story in another direction, or stopped something completely because I indicated I understood something when there might have been more I was missing. These young people had not previously found the chance to tell their stories and they shared with a sense of wonder as though I might shut them down at any moment. Many times they began by saying they had nothing to share and then they got caught up in telling their stories and were surprised by how fast time went. Rarely was a participant unable to think of a story to tell; when it happened, I learned to trust what he or she was saying and move on to another question.

Asking the participants to talk about how they made sense of the things that happened to them during high school offered me the opportunity to gather some insights into how they thought now about their earlier interactions. As Heidegger and Gadamer showed, it could be anticipated that each of the young people understood their experiences differently because of their historical and cultural contexts. It became clear during the analysis that some participants understood the things that had happened to them while others did not. Those who had examined their interactions and made some interpretations of why experiences happened a certain way were able to articulate these experiences more clearly. Each considered their experiences in the context of their environments and articulated the impacts of their particular situations. 
I felt a great responsibility to the participants after hearing their stories. It was clear these experiences had profoundly impacted them and I owed it to them to make sure their voices were heard. I experienced a tension between documenting stories that had previously been silenced and analyzing these stories so they could serve a larger function beyond a mere documentation of individual experiences and recollections. Each participant shared much more than I could present in this dissertation and I struggled with decisions about what pieces to include.

\section{Moving forward}

Bisexually attracted people deal not only with heteronormativity, but also homonormativity, in their daily lives. While the increasing visibility of gay and lesbian families is helpful in terms of providing examples of some of the possibilities, the reinforcement of the monosexual expectation of what a family should be strips those who do not envision the same thing for themselves of any model upon which to fashion their family. Studies designed to privilege voices of bisexual people can aid in determining the myriad ways their experiences differ from those of other LGTQ people. One thing that stood out in what the participants shared is that each felt as though they were being listened to about this topic for the very first time during our interview. While much of what they shared was experienced several years prior to the interview, clearly the participants had thought about these experiences in isolation, having few opportunities to tell anyone what they experienced.

Strict adherence to the gender binary, rooted in a belief in socially constructed ideas of traits, behaviors, and abilities, may be to blame for the lack of advances in the 
acceptance of bisexuality as a legitimate identity (Rubinstein, 2013). Jane and Brittany both troubled this adherence to the gender binary and shared experiences of trying to make sense of it. Jane recalled the conversation she had with a youth group leader who was inviting Jane to become a group leader herself. The group leader explained the things that would exclude Jane from being considered for such a role, and one of the things was being gay. At the time Jane was in a relationship with a trans* male and it made her question what the youth group leader would think about that: "That started me thinking...what would they think of him? What would they think of me being with someone like him? He's a valid person... why would you stop someone from participating in your group because of their sexuality or identity?" She imagined the response she would get if the youth group leader knew about her relationship; this awareness added to her distress and feelings of being separate from this group.

These bisexually attracted young people interacted uniquely with their social environments, and it makes sense to examine them as a distinct group rather than as part of the LGTQ group. This study highlighted how much we still need to learn about the needs for resources, specific educational requirements, and social supports of those who are bisexually attracted. While it is not reasonable to make claims about all people who experience attractions to more than one gender based on this study, it is possible to make some recommendations about future research and practice with this population based on what these participants shared. Qualitative studies such as this are useful for filling gaps in existing knowledge because they privilege the voices of those people who are frequently silenced in larger, quantitative studies. 


\section{Research implications}

This study raised several questions for me that I intend to address in future research. One of these questions is how programs that provide services to LGBTQ youth are currently meeting the needs of bisexually attracted youth and what they can do to expand their services to be more specific about their inclusion. It is clear from the experiences these participants shared that they have unique needs in terms of coming out, marginalization, and family relationships which require different supports and resources than lesbian and gay youth. Based on what participants shared, program materials need to be clear about what services are offered specifically for those who are bisexually attracted. Evaluation studies of programs targeted at LGBTQ youth would allow for those who are currently providing services to examine how they support these youth and then modify and shape interventions to be more useful. Not all youth have the same needs, and not all will benefit from supports provided in the same way.

As I designed the study, it was important to me to be mindful of intersectionality and the complexities of the lives of the youth who participated. Several factors, such as religion, geographical location, and gender, influenced how the young people experienced their high school years. Religion influenced most of the participants in both positive and negative ways; it provided connections to a larger community and it provided them with negative messages about their attractions. The participants came from geographically diverse locations: several Western states and larger urban areas. Most described their communities as close-knit despite their size, which was seen as both positive and negative. Emily described how people helped each other, which gave her a 
sense of security. She also described the isolation of belonging to a small Catholic community in the midst of a predominantly Mormon community. Kylie talked about the large size of his high school and his sense that he was alone in spite of the number of students. Participants' gender impacted many of their experiences. Kylie did not share any interactions similar to the sexualization Kina and Emily described. As maleidentified in high school, Kylie was labeled as gay and not bisexual in spite of his stated attractions to females and males. Class locations impacted Kylie, Aythn, and Brittany in that the insecurity they felt as a result of a limited safety net caused them to make challenging decisions about their living situations. I did not ask participants to talk about how they thought things like social location influenced their experiences so I did not include these factors in the themes. The impact of factors such as gender and social location is clear from the stories they shared and, in future studies, I will question participants more specifically in order to gain a clearer understanding of the experience.

While the deficits orientation of much of the previous research provided insights into the unique needs of LGBTQ people, this focus offered a limited understanding of the lived experiences of this population. Future studies that explore these experiences can add to the existing knowledge. Studies focused on the role of victimization and negative peer relationships in predicting negative health outcomes (Ryan et al., 2010) assessed the impact of parental rejection and health of LGBT youth (Ryan, Huebner, Diaz, \& Sanchez, 2009) and showed associations between rejection and things like drug use, depression, and attempted suicide and provided youth workers and other professionals with recommendations for addressing some of these risk factors. A result of this focus 
was an impression that all LGBTQ youth experienced their lives as painful, and an assumption that being a LGBTQ youth automatically meant being a troubled youth. Little room was allowed for positive experiences and the possibility of LGBTQ youth living well-adjusted lives.

As I listened to the participants in the interviews and analyzed the transcripts, I initially latched onto those stories that were positive, that described supportive and loving interactions. I wanted to put a positive spin on their stories. I wanted to focus on their coping skills and their remarkable ways of facing environments filled with people who questioned them and told them they were sick and sinners. I was hampered by protectiveness, by anger at what they experienced, by familiarity with the dismissal and invisibility, and by a wish to create a world for them in which they would be "normal". These desires got in the way. The participants made it through the painful parts of their interactions with little help from others, and were mostly okay. Yet, one thing stood out in their stories - they understood they navigated their social interactions more easily when they had one person who heard them. They knew they did not make it through on their own. The simple act of listening in an open, non-judgmental way is the best first step for youth workers, social workers, and educators.

Their stories have implications for researchers. It is imperative that future studies examine ways to change the dominant narratives that bisexual youth experience things in the same ways as gay and lesbian youth. Research must focus specifically on the needs of bisexually attracted youth as they experience stigmatization and marginalization in unique ways. Some of their interactions with others are painful and damaging and the fact 
they endure these experiences does not negate the need for change. These participants were clear that their experiences occurred because of social stigma, not because they felt these attractions. Researchers, youth workers, and other professionals who work with this population must take responsibility for changing the environments for these young people.

Another area on which I intend to focus in future studies is gaining a clearer understanding of the needs of bisexually attracted youth in out-of-home care. As Brittany and Aythn shared, the need for a sense of acceptance and love is often so great that young people will remain in unsafe living environments where they know what to expect. Tenuous placements add to feelings of insecurity and might alter how young people express themselves. Research exploring the experiences of all youth in care in terms of sexuality and sexual expression could increase understanding of the unique experiences of these young people. In a future study, I intend to engage more youth in care in a study similar to this one. In order to adequately provide care to these youth, we must better understand the impacts of loss of home and family and safety on their living.

Educational environments were seen as punishing and brutal for most of the participants of this study. It is critical that the inclusiveness and effectiveness of GSAs be studied so they can be refined in a way to offer the most comprehensive support possible. Evaluation studies of these programs have examined the effects on the school climate for all youth but have not examined how they impact bisexually attracted youth. Based on what the participants shared, understanding ways school climates can be made more inclusive of bisexually attracted youth will improve their educational experiences. 
Participants noted a desire to see specific classroom content that reflected their experiences. Research conducted in collaboration with school staff would allow for studies that could actually engage the students and gather accurate, honest data. Work with school staff to see how school environments influence school connectedness and students' sense of safety could add to existing programming.

\section{Implications for professionals}

As a clinician and educator, I was most interested in what the study offered in terms of improving social services for bisexually attracted young people. I described how the young people made accommodations in order to make their environments a bit more tolerable. They learned through their interactions that others would not always accept them. There is strength and resilience in how they integrated this understanding. But there was also a great deal of pain. It should not be enough to recognize the difficulties these young people face; it is imperative that clinicians and educators pay more attention to hearing their experiences with pain and negative interactions. It is also critical to validate the breadth of experiences and not devalue the painful ones by focusing only on the resiliency factors. Participants stated clearly the value they gave to someone who truly listened. Furthermore, after truly listening to them, it was vital that the person work to make sure their experiences were validated. Kylie's experience with his school librarian illustrated the impact of one person who listens and stops stigmatizing behaviors immediately.

Coming out. Coming out was different for these young people than it is for most gay men and lesbians. They knew from their experiences that if they came out as 
bisexual, they were opening themselves up to being dismissed, sexualized, or called liars. If they chose another term they felt fit them more accurately, such as pansexual, they knew they would need to explain the term and their attractions to people who often had little interest in understanding the differences. They also knew from previous interactions that some people would focus on the same-sex part of their attractions and stigmatize them for those feelings. Having parents who were accepting of gay men and lesbians did not guarantee the young person acceptance when they came out. Some parents told them it would be easier for them to understand if they had come out as fully lesbian because they could wrap their head around that. One participant's father was happy when she started dating a girl because then he did not have to worry about her getting hurt or pregnant, and he did not react as positively when she told him she was also dating a boy. It was clear from listening to the stories of these young people that they did not share their attractions to more than one gender with family first. Several of them engaged in a process of practicing - where they told someone close to them and then made determinations about who else to tell based on the reactions of the first person. For Amelia and CS, not telling others in the family was experienced as dishonest and not something with which they were comfortable, but they still struggled with the awareness that they needed to have this difficult conversation with their families.

Participants told diverse stories about their coming out experiences. Each had engaged with (or avoided) the discussion with parents and caregivers out of nervousness and fear of losing their relationships. A common wish among the participants was that they had some examples of how others with bisexual attractions came out to parents. 
Youth workers and educational professionals are well placed to provide these supports to youth and parents by using inclusive language, being aware of stigmatizing behaviors in others and interrupting it, and by including specific content about bisexual attractions and relationships in program materials, educational components, and activities.

Making schools more welcoming and safer. Based on what these participants shared of their school experiences, simply having a GSA was not enough to create a more positive school environment. It is of greatest importance for bisexually attracted young people to know they are seen by teachers and staff and to see their experiences reflected in school curricula and classroom materials. Participants made suggestions for inclusion of safe sex techniques in sex education classes that addressed the needs of all students. They wished for more open dialogue between teachers and students about issues related to bisexuals. They talked with resignation about the invisibility of anything related to bisexuals in curriculum or textbooks. School staff can offer non-judgmental places for youth to share their feelings. Improving school climates for all LGBTQ students can be facilitated by challenging the patterns of heterosexism, sexism, and racism embedded in school policies, practices, and programming. It is important that teachers and school staff understand the effects of these on all students and work to make changes to school policies and curricula.

\section{Closing reflections}

The preceding sections offered several suggestions for ways to improve how bisexually attracted young people live their lives. The simple act of listening was the one participants sought most in their interactions with others. There is so much more we, as 
social workers, youth workers, and educators can do to improve the experiences of bisexually attracted young people. The participants identified a desire for school environments that offer visible representation of all types of attractions, sex education classes that offer information of safe sex practices for every type of relationship, curricula in every course that specifically includes examples of bisexual people in addition to those of gay and lesbians, and services in the community that are inclusive. They felt it would be helpful to have resources to use when they are ready to come out to their parents. Part of their frustration with explaining their attractions was feeling like they did not have a common language to help parents understand that their attractions were normal. The change the participants most wanted to see was acceptance and recognition. This seems like a place to start. 


\section{References}

Aerts, S., van Houtte, M., Dewaele, A., Cox, C., \& Vincke, J. (2012). Sense of belonging in secondary schools: A survey of LGB and heterosexual students in Flanders. Journal of Homosexuality, 59, 90-113. doi:10.1080/00918369.2012.638548

Alarie, M. \& Gaudet, S. (2013). “I don't know is she is bisexual or if she just wants to get attention": Analyzing the various mechanisms through which emerging adults invisibilize bisexuality. Journal of Bisexuality, 13(2), 191-214. doi:10.1080/15299716.2013.780004

Austin, S.B., Conron, K.J., Patel, A., \& Freedner, N. (2007). Making sense of sexual orientation measures: Findings from a cognitive processing study with adolescents on health survey questions. Journal of LGBT Health Research, 3(1), 55-65. doi:10.1300/J463v03n01_07

Balsam, K.F. \& Mohr, J.J. (2007). Adaptation to sexual orientation stigma: A comparison of bisexual and lesbian/gay adults. Journal of Counseling Psychology, 54(3), 306319. doi:10.1037/0022-0167.54.3.306

Bandura, A. (1997). Social Learning Theory. Englewood Cliffs, NJ: Prentice Hall.

Barritt, L., Beekman, T., Bleeker, H., \& Mulderij, K. (1984). Analyzing phenomenological descriptions. Phenomenology \& Pedagogy, 2(1), 1-17.

Beech, I. (1999). Bracketing in phenomenological research. Nurse Researcher, 6(3), 3550. doi: $10.7748 / \mathrm{nr} 1999.04 \cdot 6.3 .35 . \mathrm{c} 6086$ 
Benzies, K.M. \& Allen, M.N. (2001). Symbolic interactionism as a theoretical perspective for multiple method research. Journal of Advanced Nursing, 33(4), 541-547. doi:10.1046/j.1365-2648.2001.01680.x

Blumer, H. (1969). Symbolic interactionism: Perspective and method. Englewood Cliffs, NJ: Prentice Hall.

Bower, J., Gurevich, M., \& Mathieson, C. (2002). (Con)tested identities: Bisexual women reorient sexuality. Journal of Bisexuality, 2(2/3), 23-52. doi:10.1300/J159v02n02_03

Bontempo, D.E. \& D'Augelli, A.R. (2002). Effects of at-school victimization and sexual orientation on lesbian, gay, or bisexual youths' health risk behavior. Journal of Adolescent Health, 30, 364-374. doi:10.1016/S1054-139X(01)00415-3

Bornstein, B.H., \& Miller, M.K. (2009) God in the courtroom: Religion's role at trial. New York, NY: Oxford University Press.

Bradford, M. (2011). Reflections on the bisexual experience. Journal of Bisexuality, 11, 509-512. doi:10.1080/15299716.2011.620856

Bradford, M. (2004). The bisexual experience: Living in a dichotomous culture. Journal of Bisexuality, 4(1/2), 7-23. doi:10.1300/J159v04n01_02

Brendtro, L.K., Brokenleg, M., \& van Bockern, S. (1990). Reclaiming youth at risk: Our hope for the future. Bloomington, IN: Solution Tree.

Brewster, M.F. \& Moradi, B. (2010). Personal, relational and community aspects of bisexual identity in emerging, early and middle adult cohorts. Journal of Bisexuality, 10, 404-428. doi:10.1080/15299716.2010.521056 
Burleson, W.E. (2005). Bi America: Myths, truths, and struggles of an invisible community. Binghamton, NY: Harrington Park Press.

Callis, A.S. (2009). Playing with Butler and Foucault: Bisexuality and queer theory. Journal of Bisexuality, 9, 213-233. doi:10.1080/15299710903316513

Callis, A.S. (2013). The black sheep of the pink flock: Labels, stigma, and bisexual identity. Journal of Bisexuality, 13(1), 82-105. doi:10.1080/15299716.2013.755730

Cass, V. (1979). Homosexual identity formation: A theoretical model. Journal of Homosexuality, 4, 219-235. doi:10.1300/J082v04n03_01

Chmielewski, J.F., \& Yost, M.R. (2013). Pyschosocial influences on bisexual women's body image: Negotiating gender and sexuality. Psychology of Women Quarterly, 37, 224-241. doi: $10.1177 / 0361684311426126$

Christina, G. (1995). Bi sexuality. In Bisexual politics: Theories, queries, and visions. N. Tucker (Ed.). New York, NY: Harrington Park Press.

Cohen, S. \& Wills, T.A. (1985). Stress, social support, and the buffering hypothesis. Psychological Bulletin, 98(2), 310-357. doi:10.1037/0033-2909.98.2.310

Cohler, B.J. \& Hammack, P.L. (2007). The psychological world of the gay teenager: Social change, narrative, and "normality". Journal of Youth and Adolescence, 36, 47-59. doi:10.1007/s10964-006-9110-1

Cover, R. (2013). Conditions of living: Queer youth suicide, homonormative tolerance, and relative misery. Journal of LGBT Youth, 10(4), 328-350. doi:10.1080/19361653.2013.824372 
Cox, S., Bimbi, D.S., Parsons, J.T. (2013). Examination of social contact on binegativity among lesbians and gay men. Journal of Bisexuality, 13(2), 215-228. doi:10.1080/15299716.2013.782596

Dahlberg, H. \& Dahlberg, K. (2003). To not make definite what is indefinite. A phenomenological analysis of perception and its epistemological consequences. The Humanistic Psychologist, 31(4), 34-50. doi:10.1080/08873267.2003.9986933

Dahlberg, K., Dahlberg, H., Nyström, M. (2008). Reflective Lifeworld Research. Lund, Sweden: Studentlitteratur.

Darby-Mullins, P. \& Murdock, T.B. (2007). The influence of family environment factors on self-acceptance and emotional adjustment among gay, lesbian, and bisexual adolescents. Journal of GLBT Family Studies, 3(1), 75- 91. doi:10.1300/J461v03n01_04

D'Augelli, A.R. (2002). Mental health problems among lesbian, gay, and bisexual youth ages 14-21. Clinical Child Psychology, 7, 439-462.

D’Augelli, A.R., Hershberger, S.L., \& Pilkington, N.M. (2001). Suicidality patterns and sexual orientation-related factors among lesbian, gay, and bisexual youth. Suicide and Life-Threatening Behaviors, 31(3), 250-265. doi:10.1521/suli.31.3.250.24246

Davis, T.S., Saltzburg, S., \& Locke, C.R. (2009). Supporting the emotional and psychological well being of sexual minority youth: Youth ideas for action. Children and Youth Services Review, 31, 1030-1041. doi:10.1016/j.childyouth.2009.05.003 
SOCIAL INTERACTIONS

DeCrescenzo, T. (Ed.). (1994). Helping Gay and Lesbian Youth. Binghamton, NY: Harrington Park Press.

Denzin, N.K. \& Lincoln, Y.S. (Eds.) (2005). The Sage handbook of qualitative research, Thousand Oaks, CA: Sage.

Detrie, P.M. \& Lease, S.H. (2007). The relation of social support, connectedness, and collective self-esteem to the psychological well-being of lesbian, gay, and bisexual youth. Journal of Homosexuality, 53(4), 173 - 199. doi:10.1080/00918360802103449

DiFulvio, G.T. (2011). Sexual minority youth, social connection and resilience: From personal struggle to collective identity. Social Science and Medicine, 72, 16111617. doi:10.1016/j.socscimed.2011.02.045

DiPlacido, J. (1998). Minority stress among lesbians, gay men, and bisexuals: A consequence of heterosexism, homophobia, and stigmatization. In G.M. Herek (Ed.), Psychological perspectives on lesbian and gay issues: Vol. 4. Stigma and sexual orientation: Understanding prejudice against lesbians, gay men, and bisexuals (pp. 138-159). Thousand Oaks, CA: Sage.

Doty, N. D., Willoughby, B. L. B., Lindahl, K. M., \& Malik, N. M. (2010). Sexuality related social support among lesbian, gay, and bisexual youth. Journal of Youth and Adolescence 39(10), 1134-1147. doi:10.1007/s10964-010-9566-x

Dworkin, S. H. (2001). Treating the bisexual client. Journal of Clinical Psychology, 57(5), 671-680. doi: 10.1002/jclp.1036 
Eisenberg, M.E., Ackard, D.M., \&Resnick, M.D. (2007). Protective factors and suicide risk in adolescents with a history of sexual abuse. Journal of Pediatrics, 151, 482487. doi:10.1016/j.jpeds.2007.04.033

Eisenberg, M.E. \& Resnick, M.D. (2006). Suicidality among gay, lesbian, and bisexual youth: The role of protective factors. Journal of Adolescent Health, 39(5), 662668. doi:10.1016/j.jadohealth.2006.04.024

Elia, J.P. (2010). Bisexuality and school culture: School as a prime site for biintervention. Journal of Bisexuality, 10, 452-471. doi:10.1080/15299716.2010.521060

Espelage, D.L., Aragon, S.R., Birkett, M., \& Koenig, B.W. (2008). Homophobic teasing, psychological outcomes, and sexual orientation among high school students: What influence do parents and schools have? School Psychology Review, 37(2), 202-216.

Finlay, L. (2011). Phenomenology for therapists: Researching the lived world. West Sussex, UK: Wiley - Blackwell.

Fisher, E.S., Komosa-Hawkins, K., Saldana, E, Thomas, G.M., Hsaio, C., Rauld, M., et al. (2008). Promoting school success for lesbian, gay, bisexual, transgendered, and questioning students: Primary, secondary, and tertiary prevention and intervention strategies. The California School Psychologist, 13, 79-91.

Friedman, M.S., Silvestre, A.J., Gold, M.A., Markovic, N., Savin-Williams, R.C., Huggins, J., \& Sell, R.L. (2004). Adolescents define sexual orientation and 
SOCIAL INTERACTIONS

suggest ways to measure it. Journal of Adolescence, 27, 303-317.

doi:10.1016/j.adolescence.2004.03.006

Gelber, S. (2012). The bullying crisis: Have our children lost their humanity? Buffalo Examiner. Retrieved from http://buffalo.legalexaminer.com/miscellaneous/thebullying-crisis-have-our-children-lost-their-humanity.aspx?googleid=303434

Glover, J.A., Galliher, R.V., \& Lamere, T.G. (2009). Identity development and exploration among sexual minority adolescents: Examination of a multidimensional model. Journal of Homosexuality, 56, 77-101. doi:10.1080/00918360802551555

Goodenow, C., Szalacha, L., \& Westheimer, K. (2006). School support groups, other school factors and the safety of sexual minority adolescents. Psychology in the Schools, 43(5), 573-589. doi:10.1002/pits.20173

Griffin, P., Lee, C., Waugh, J., \& Beyer, C. (2004). Describing roles the gay-straight alliances play in schools: from individual support to school change. Journal of Gay \& Lesbian Issues in Education, 1(3), 7-22. doi:10.1300/J367v01n03_03

Hall-Lande, J.A., Eisenberg, M.E., Christenson, S.L., \& Neumark-Sztainer, D. (2007). Social isolation, psychological health, and protective factors in adolescence. Adolescence, 42(166), 265-286.

Hammack, P.L., Thompson, E.M., \& Pilecki, A. (2009). Configurations of identity among sexual minority youth: Context, desire, and narrative. Journal of Youth and Adolescence, 38, 867-883. doi:10.1007/s10964-008-9342-3 
Hanson, A.L. (2007). School-based support for GLBT students: A review of three levels of research. Psychology in the Schools, 44(8), 839-848. doi: 10.1002/pits.20269

Hatzenbuhler, M.L. (2011). The social environment and suicide attempts in lesbian, gay, and bisexual youth. Pediatrics, 127(5), 896-903. doi: 10.1542/peds.2010_3020

Heck, N.C., Flentje, A., \& Cochran, B.N. (2011). Offsetting risks: High school gaystraight alliances and lesbian, gay, bisexual, and transgender (LGBT) youth. School Psychology Quarterly, 26(2), 161-174. doi:10.1037/a0023226

Hershberger, S.L., Pilkington, N.W., \& D’Augelli, A.R. (1997). Predictors of suicide attempts among gay, lesbian, and bisexual youth. Journal of Adolescent Research, 12, 477-497. doi:10.1177/0743554897124004

Horowitz, J. L. \& Newcomb, M.D. (2001). A multidimensional approach to homosexual identity. Journal of Homosexuality, 42(2), 1-17. doi:10.1300/J082v42n02_01

Huba, G. J., Melchior, L. A., Greenberg, B., Trevithick, L., Feudo, R., Tierney, S., et al. (2000). Predicting substance abuse among youth with, or at high risk for, HIV. Psychology of Addictive Behaviors, 14(2), 197-205. doi:10.1037/0893-164X.14.2.197

Husserl, E. (1970). Logical investigations II. Translated by J.N. Finday. Amherst,NY: Humanity Books.

Husserl, E. (1927). Phenomenology. For Encyclopedia Britannica (R. Palmer, Trans. and revised). Available at: http://www.hfu.tw/ huangkm/phenom/husserlbritanica.htm 
Husserl, E. (1913/82). Ideas pertaining to a pure phenomenology and to a phenomenological philosophy: General introduction to a pure phenomenology. The Hague: Martinus Nijhoff.

Israel, T. (2010). Bisexuality and youth: Introduction to the special issue. Journal of Bisexuality, 10, 359-365. doi:10.1080/15299716.2010.521038

Israel, T. \& Mohr, J.J. (2004). Attitudes toward bisexual women and men - current research, future directions. Journal of Bisexuality, 4, 117-134. doi: 10.1300/J159v04n01_09

Kaminski, J.W., Puddy, R.W., Hall, D.H., Cashman, S.Y., Crosby, A.E., \& Ortega, A.A.G. (2010). The relative influence of different domains of social connectedness on self-directed violence in adolescence. Journal of Youth and Adolescence, 39, 460-473. doi:10.1007/s10964-009-9472-2

Kennedy, K.G. \& Fisher, E.S. (2010). Bisexual students in secondary schools: Understanding unique experiences and developing responsive practices. Journal of Bisexuality, 10, 472-485. doi:10.1080/15299716.2010.521061

Kleese, C. (2011). Shady characters, untrustworthy partners, and promiscuous sluts: Creating bisexual intimacies in the face of heteronormativity and biphobia. Journal of Bisexuality, 11(2/3), 227-244. doi:10.1080/15299716.2011.571987

Kosciw, J.G., Greytak, E.A., Bartkiewicz, M.J., Boesen, M.J., \& Palmer, N.A. (2012). The 2011 National school climate survey: The experiences of lesbian, gay, bisexual and transgender youths in our nation's schools. Glsen.org. 
SOCIAL INTERACTIONS

LaFromboise, T.D. \& Lewis, H.A. (2008). Zuni life skills development program: A school/community-based suicide prevention intervention. Suicide and LifeThreatening Behaviors, 38(3), 343-353. doi:10.1521/suli.2008.38.3.343

Lapinski, J. \& McKirnan, D. (2013). Forgive me father for I have sinned: The role of a Christian upbringing on lesbian, gay, and bisexual identity development. Journal of Homosexuality, 60, 853-872. doi:10.1080/00918369.2013.774844

Larkin, M., Watts, S., \& Clifton, E. (2006). Giving voice and making sense in interpretative phenomenological analysis. Qualitative Research in Psychology, 3, 102-120. doi:10.1191/1478088706qp062oa

Lasser, J. \& Tharinger, D. (2003). Visibility management in school and beyond: A qualitative study of gay, lesbian, and bisexual youth. Journal of Adolescence, 26, 233-244. doi: 10.1016/S0140-1971(02)0031-X

Lewis, R.J., Derlega, V.J., Brown, D., Rose, S., \& Henson, J.M. (2009). Sexual minority stress, depressive symptoms, and sexual orientation conflict: Focus on the experiences of bisexuals. Journal of Social and Clinical Psychology, 28(8), 971992. doi:10.1521/jscp.2009.28.8.971

Lietz, C.A., Langer, C.L., \& Furman, R.F. (2006) Establishing trustworthiness in qualitative research in social work implications from a study regarding spirituality. Qualitative Social Work, 5(4), 441-458. doi: $10.1177 / 1473325006070288$

Mann, S.A. \& Kelley, L.R. (1997). Standing at the crossroads of modernist thought. Gender \& Society, 11(4), 391-408. doi:10.1177/089124397011004002 
McDermott, E., Roen, K., \& Scourfield, J. (2008). Avoiding shame: Young LGBT people, homophobia and self-destructive behaviors. Culture, Health \& Sexuality, 10(8), 815-829. doi:10.1080/13691050802380974

McLean, K. (2001). Living life in the double closet: Bisexual youth speak out. Hecate, 27(1), 109-118.

McLean, K. (2008). Inside, outside, nowhere: Bisexual men and women in the gay and lesbian community. Journal of Bisexuality, 8, 63-80. doi:10.1080/15299710802143174

McNicholas, S.L. (2002). Social support and positive health practices. Western Journal of Nursing Research, 27(7), 772-787. doi:10.1177/019394502237387

Merrell, K.W., Gueldner, B.A., Ross, S.W., \& Isava, D.M. (2008). How effective are school bullying intervention programs? A meta-analysis of intervention research. School Psychology Quarterly, 23(1), 26-42. doi:10.1037/1045-3830.23.1.26

Meyer, I.H. (2003). Prejudice, social stress, and mental health in lesbian, gay, and bisexual populations: Conceptual issues and research evidence. Psychological Bulletin, 129(5), 674-697. doi:10.1037/0033-2909.129.5.674

Morrow, D.F. (2004). Social work practice with gay, lesbian, bisexual, and transgender adolescents. Families in Society, (85)1, 91-99. doi:10.1606/1044-3894.246

Needham, B.L, \& Austin, E.L. (2010). Sexual orientation, parental support, and health during the transition to young adulthood. Journal of Youth and Adolescence, 39, 1189-1198. doi:10.1007/s10964-010-9533-6 
Newheiser, A.-K., \& Barreto, M. (2014). Hidden costs of hiding stigma: Ironic interpersonal consequences of concealing a stigmatized identity in social interactions. Journal of Experimental Social Psychology, 52, 58-70. doi:10.1016/j.jesp.2014.01.002

Ochs, R. (1996). Biphobia: It goes more than two ways. In B.A. Firestein (Ed.), Bisexuality: The Psychology and Politics of an Invisible Minority. Thousand Oaks: Sage Publications.

Orenstein, A. (2001). Substance abuse among gay and lesbian adolescents. Journal of Homosexuality, 41(2), 1-15. doi:10.1300/J082v41n02_01

Pallotta-Chiarolli, M. (2006). On the borders of sexuality research: Young people who have sex with both males and females. Journal of Gay \& Lesbian Issues in Education, 3(2/3), 70-86. doi:10.1300/J367v03n02_07

Pallotta-Chiarolli, M. \& Martin, E. (2009). “Which sexuality? Which service?”: Bisexual young people's experiences with youth, queer, and mental health services in Australia. Journal of LGBT Youth, 6, 199-222. doi:10.1080/19361650902927719

Poteat, V.P., Espelage, D.L., \& Koenig, B.W. (2009) Willingness to remain friends and attend school with lesbian and gay peers: Relational expressions of prejudice among heterosexual youth. Journal of Youth and Adolescence, 38(7), 952-962. doi:10.1007/s10964-009-9416-x

Remafedi, G., French, S. Story, M., Resnick, M.D., \& Blum, R. (1998). The relationship between suicide risk and sexual orientation: Results of a population-based study. American Journal of Public Health, 88, 57-60. doi:10.2105/AJPH.88.1.57 
Robins, S.P., Chatterjee, P., \& Canda, E.R. (2012) Contemporary Human Behavior Theory. Boston: Allyn \& Bacon.

Robinson, J.P. \& Espelage, D.L. (2011). Inequities in educational and psychological outcomes between LGBTQ and straight students in middle and high school. Educational Researcher, 40(7), 315-330. doi:10.3102/0013189X11422112

Rofes, E. (1983). I thought people like that killed themselves: lesbians, gay men, and suicide. San Francisco: Grey Fox Press.

Rogers, A.T. (2010). Human behavior in the social environment. NY: Routledge. Rostosky, S.S., Riggle, E.D.B., Horne, S.G., \& Miller, A.D. (2009). Marriage amendments and psychological distress in lesbian, gay, and bisexual (LGB) adults. Journal of Counseling Psychology, 56, 56-66. doi: $10.1037 / \mathrm{a} 0013609$

Rubinstein, T., Makov, S., Sarel, A. (2013) Don't bi-negative: reduction of negative attitudes toward bisexuals by blurring the gender dichotomy. Journal of Bisexuality, 13(3), 356-373. doi: 10.1080/15299716.2013.813419

Russell, S.T. (2011). Bisexuality and adolescence. Journal of Bisexuality, 11, 434-438. doi:10.1080/15299716.2011.620470

Russell, S.T., Clarke, T.J., \& Clary, J. (2009). Are teens “post-gay”? Contemporary adolescents' sexual identity labels. Journal of Youth and Adolescence, 38, 884890. doi: $10.1007 / \mathrm{s} 10964-008-9388-2$

Russell, S.T. \& Seif, H. (2010). Bisexual female adolescents: A critical analysis of past research, and results from a national survey. Journal of Bisexuality, 10, 492-509. doi:10.1080/15299716.2010.521065 
Rust, P.C. (2000). Bisexuality: A contemporary paradox for women. Journal of Social Issues, 56(2), 205-221.

Sadowski, M., Chow, S., \& Scanlon, C.P. (2009). Meeting the needs of LGBTQ youth: A relational assets approach. Journal of LGBT Youth, 6, 174-198.

doi:10.1080/19361650903013493

Saewyc, E. (2011). Research on adolescent sexual orientation: Development, health disparities, stigma, and resilience. Journal of Research on Adolescence, 21(1), 256-272. doi:10.1111/j.1532-7795.2010.00727.x

Saewyc, E.M., Homma, Y., Skay, C.L., Bearinger, L.H., Resnick, M.D., \& Reis, E. (2009). Protective factors in the lives of bisexual adolescents in North America. American Journal of Public Health, 99(1), 110-117. doi:10.2105/AJPH.2007.123109

Saewyc, E.M., Skay, C.L., Hynds, P., Pettingell, S., Bearinger, L.H., Resnick, M.D., \& Reis, E. (2007). Suicidal ideation and attempts in North American school-based surveys: Are bisexual youth at increased risk? Journal of LGBT Health Research, 3(2), 25-36. doi:10.1300/J463v03n02_04

Saewyc, E.M., Skay, C.L., Pettingell, S., Reis, E., Bearinger, L.H., Resnick, M.D., et al. (2006). Hazards of stigma: The sexual and physical abuse of gay, lesbian, and bisexual adolescents in the United States and Canada. Child Welfare, 85(2), 195213.

Savin-Williams, R.C. (2005). The new gay teenager. Cambridge, MA: Harvard University Press. 
Savin-Williams, R. C., \& Joyner, K. (2004). The dubious assessment of gay, lesbian, and bisexual adolescents of Add Health. Archives of Sexual Behavior, 43, 413-422. doi: $10.1077 / \mathrm{s} 10508-013-0219-5$

Savin-Williams, R.C. (1998). The disclosure to families of same-sex attraction by lesbian, gay, and bisexual youths. Journal of Research on Adolescence, 8, 49-68. doi:10.1207/s15327795jra0801_3

Savin-Williams, R.C. (2005). The New Gay Teenager. Cambridge, MA: Harvard University Press.

Sedgwick, E. (2003). Touching, feeling: Affect, pedagogy, performativity. Durham, NC: Duke University Press.

Sheets, R.L. \& Mohr, J.J. (2009). Perceived social support from friends and family and psychosocial functioning in bisexual young adult college students. Journal of Counseling Psychology, 56(1), 152-163. doi:10.1037/0022-0167.56.1.152

Smith, J.A. (1996). Beyond the divide between cognition and discourse: Using interpretative phenomenological analysis in health psychology. Psychology and Health, 11, 261-271. doi:10.1080/08870449608400256

Smith, J.A. (2004). Reflecting on the development of interpretative phenomenological analysis and its contribution to qualitative research in psychology. Qualitative Research in Psychology, 1, 39-54.doi: 10.1191/1478088704qp004oa

Smith, J.A., Flowers, P., \& Larkin, M. (2009). Interpretative phenomenological analysis. Los Angeles: Sage. 
Smith, J.A. \& Osborn, M. (2003). Interpretative phenomenological analysis. In J.A. Smith (Ed.), Qualitative psychology: A practical guide to methods. London: Sage. Substance Abuse and Mental Health Services Administration (2014). A practitioner's resource guide: Strengthening families to support LGBT children. Retrieved from http://store.samhsa.gov/.

Szalacha, L.A (2003). Safer sexual diversity climates: Lessons learned from an evaluation of Massachusetts Safe Schools Program for gay and lesbian students. American Journal of Education, 110(1), 58-88. doi: 10.1086/377673

Teasdale, B, \& Bradley-Engen, M.S. (2010). Adolescent same-sex attraction and mental health: The role of stress and support. Journal of Homosexuality, 57, 287-309. doi:10.1080/00918360903489127

Ueno, K. (2005). Sexual orientation and psychological distress in adolescence: Examining interpersonal stressors and social support processes. Social Psychology Quarterly, 68(3), 258-277. doi:10.1177/019027250506800305

Udry, J.R., \& Chantala, K. (2005). Risk factors differ according to same-sex and opposite-sex interest. Journal of Biosocial Science, 37(4), 481-497. doi:10.1017/S0021932004006765

van Manen, M. (1990). Researching lived experience: Human science for an action sensitive pedagogy. Albany: The State of New York University Press.

Wright, E.R. \& Perry, B.L. (2006). Sexual identity distress, social support, and the health of gay, lesbian, and bisexual youth. Journal of Homosexuality, 51(1), 81-110. doi:10.1300/J082v51n01_05 
Yardley, L. (2008). Demonstrating validity in qualitative psychology. In J.A. Smith (Ed.), Qualitative Psychology: A Practical Guide to Methods (2 $2^{\text {nd }}$ ed.). London: Sage. 


\section{Appendix A}

\section{Consent for participation in: An Interpretative Phenomenological Analysis of Bisexual young adults' experiences of social interactions in high school}

You have been invited to participate in a research study conducted by Del Quest, a doctoral candidate from Portland State University, School of Social Work. The researcher hopes to learn about the experiences of social interactions of bisexual young adults. This research is being conducted by a student researcher under the supervision of Dr. Ben Anderson-Nathe (dissertation chair) from Portland State University School of Social Work.

You were selected as a possible participant in the study because of your experience as young adult who identifies as bisexual. If you agree to take part in the study, you will be asked to participate in one or more interviews about your experiences of social interactions during your high school years. Interviews may be audio-taped. Participation in this study may cause you to feel uncomfortable or become upset because of one or more of the interview questions. You have the right to decline to answer any question or end your involvement in this study at any time. Participants will receive a \$20 gift card as a thank you for your time and participation. You may not receive any additional benefit from participating in this study, but the study may help increase knowledge which may help others in the future.

When reporting the findings of this study, real names will not be used and every effort will be made to protect the identity and confidentiality of you and your family. However, there is a small possibility that you or your story will be identifiable through details contained in the report. You will have the opportunity to review any material in the report referring to or provided by you prior to publication or dissemination of the findings. Findings from this study may be published in the form of a paper, dissertation, journal article, book, or conference presentation. Names of participants and all field notes, transcripts, audio-recordings, or any other materials will be kept confidential by storage in a locked file cabinet or in password-protected computer files at the researcher's office for five years.

Participation in this study is voluntary. You do not have to take part in this study, and your decision will not affect any services you are receiving. You may also discontinue your participation in this study without affecting your relationship with the agency referring you to the study. 
If you have concerns about your participation in this study, or your rights as a research subject, please contact the Human Subjects Research Review Committee, Research and Strategic Partnerships (http://www.rsp.pdx.edu), $1600 \mathrm{SW} 4^{\text {th }}$ Ave, Suite 620, Portland State University, (503) 725-3423/ 1-800-547-8887. If you have questions about the study itself, contact Del Quest at School of Social Work, Portland State University, P.O. Box 751, Portland, OR., 97207; or by phone at (970)749.9726. Your signature indicates you have read and understand the above information and agree to participate in this study. Please understand you may withdraw your consent at any time without penalty, and, that, by signing, you are not waiving any legal claims, rights, or remedies. The researcher will provide you with a copy of this form for your records.

Participant's Name (printed)

Participant's signature

Date 


\section{Appendix B}

Interview Guide

Project: An Interpretative Phenomenological Analysis of the Experiences of Bisexual Young Adults of Social Interactions during Their High School Years

Remind participant about phenomenological interviewing:

"In these interviews, I'm trying to understand what social interactions are like for bisexually attracted young people in high school. I'm really interested in hearing specific stories about your social interactions, because these stories will help me make sense of what was happening for you in those interactions."

Explain that I am really interested in understanding the experience:

"Sometimes, people find the interview format a little irritating, because I may interrupt you to ask a question about something you said and it may feel a little like you are telling me the same thing over and over. Remember that I am only asking another question so I can be sure I really understand your story."

Start Interview:

"So, given what I talked about a minute ago, think back to a time in high school when you had an interaction with a peer and you became really aware of how your attraction for both boys and girls was influencing how the interaction went. Tell me that story (try to include as many details as you can - what were you thinking, feeling, what did the space feel like). I may interrupt you to ask more questions but let's start from here and see where we get."

\section{Potential prompts:}

- "I want to make sure I understand. Can you tell me more about what felt like?"

- "Tell me more about ..."

- "I know what I would mean if I said , but can you tell me more about what that was like for you?"

- "When you say , think about another time when you felt that. Describe that to me."

- "Can you tell me about a time when you felt "in" because of your attractions? A time when you felt "out" because of them?" 
- "Tell me about your peers' behaviors told you you were in or out? How did you know?"

- "What about the school environment told you you were in or out?" 


\section{Appendix C}

\section{What will happen to the information that I give you?}

It will be typed up, word for word, and examined closely so that we can identify, firstly, the things that are important to you about your experience, and secondly, so that we can see what connections there are between your experience and other people's.

In the final report, which will be publicly available, but mainly read by scientists and health professionals, we will quote from your interview, and from other interviews that we have conducted. People will be able to see what you said, but they won't know that it was you who said it. We will give you a false name, and will change any references that you make to other people's real names or other potentially identifying details.

Furthermore, if we think that there is a risk that readers of the work might be able to identify you from any of the quotes that we wish to use, we will check them with you before using them. 


\section{Appendix D}

I. Investigator's Assurance: See attached form.

\section{Project Title and Prospectus:}

An Interpretative Phenomenological Analysis of Bisexual Young Adults' Experiences of Social Interactions during their High School Years

Despite increases in research with sexual minorities over the past decade, little is known about how youth/young adults identifying as something other than exclusively heterosexual or gay/lesbian experience their social interactions. Recent studies examining health/behavior outcomes for this population found that bisexual youth struggle more in school compared to heterosexual and gay/lesbian peers. In an effort to understand the experiences of this group more fully, the proposed study asks the following research question: how do young adults (18-24) describe their experiences of social interactions (with peers/teachers/ institutions) when they were in high school?

The study has significance for social work because no prior studies have used a sample consisting solely of bisexual youth/young adults to examine their experiences of social interactions as unique from those of other sexual minorities. Using descriptions provided by these youth/young adults to gain a clearer understanding of how they experience social interactions can inform practice with bisexual youth and guide further research with sexual minority youth.

Interpretative Phenomenological Analysis is "a qualitative approach committed to the examination of how people make sense of their major life experiences" (Smith, Flowers, Larkin, 2009, p. 1) which allows the investigator to collect, analyze, and report rich and detailed descriptions from study participants. A sample of eight to ten young adults (18-24) identifying as something other than exclusively heterosexual or gay/lesbian will be recruited from Portland area agencies offering services to this population. Participants will be selected purposively for their ability to offer access to the particular perspective of the experience of social interactions as a bisexual youth.

Participants providing active consent will meet with the investigator for one or two semistructured interviews. These interviews will be digitally audio-recorded and transcribed for analysis. Thematic analysis strategies will be used to identify patterns and commonalities or differences among participant experiences.

III. Type of Review: Full committee

IV. Subject recruitment: Subjects will be young adults (18-24) who identify as bisexual or something other than exclusively heterosexual/gay/lesbian. Eight to ten participants will be recruited who meet the following criteria: subjects will be male/female/transgender young adults of any ethnicity between the ages of 18 and 24 who identify their sexual orientation as something other than exclusively heterosexual or exclusively gay/lesbian. Participants will be recruited at the Queer Resource Center of PSU campus, Cascade AIDS Project, SMYRC, PFLAG, and by word of mouth participant referring another participant. Exclusion criteria include if potential subjects are outside the age range of 18-24, if they identify as exclusively heterosexual or gay/lesbian, if they cannot recall events which happened during high school age years, or if they are concerned about being "outed". This age range is chosen because subjects will 
have self-awareness about choice of sexual orientation, are still close enough to high school age to have clear recall of events that occurred during that time, and because they will potentially be more open to discussing their sexuality.

V. Informed Consent: Active consent of the adult subjects will be obtained by investigator in face-to-face orientation sessions explaining the project and the potential risks and benefits of participation. See attached form.

VI: First-person scenario: "I saw a flyer at QRC about a research project that was looking for people my age who are bisexual to talk about their experiences when they were in high school. I wanted to know more about the project so I called the number on the flyer and was told my story could possibly help people who work with sexual minority young adults provide better support for those who don't just identify as het or gay/lesbian. I set up a time to meet with the investigator to get more information. We met in a private room at $\mathrm{QRC}$ where she explained the project to me completely. I agreed to participate so we made an appointment for an interview. At the interview, the investigator asked me several questions and then once I got going telling my story, she asked me questions about what I was telling her. When we were all done meeting she gave me \$20 for taking the time to meet with her and I felt happy to have been able to tell someone my story."

VII. Potential risks and safeguards: Risks from participation in proposed study are anticipated to be minimal and include the following: some discomfort at recall of experiences in high school, concern about potential "outing" of chosen sexuality, recall of painful events, and embarrassment at sharing intimate stories with investigator. The safeguards which will be taken to mitigate these risks include the following: the investigator is a licensed clinical social worker experienced in counseling youth and young adults who will be able to provide emotional support if needed; investigator will also provide participants with a list of resources for additional support if requested or if the investigator feels the subject was distressed in anyway by the interview.

VIII. Potential Benefits: Participants may benefit from the opportunity to share their story and from the knowledge that they may be helping to improve supports for other sexual minority youth. A one-time gift of a $\$ 20$ gift card will be given to participants as a token of appreciation.

IX. Confidentiality, Records, and Distribution: Identities of participants will be concealed with the use of pseudonyms or code names both during the course of the research process and in subsequent journal articles, conference presentations, and the dissertation. All data collected, including digital voice recordings, written accounts from participants, field notes or investigator's journal, and transcripts of interviews will be kept in a locked file in the investigator's office or in password protected computer files accessible only to investigator for up to a period of five years. Interviews will be audio recorded by the investigator for the purposes of data analysis. Recordings will be shared with one transcriptionist only after she has signed a confidentiality agreement (see attached form). The digital recording device will be transported only to interviews and to the transcriptionist. When it is necessary to transport the device, it will be secured in a locked box or pouch. When not in transit, the device will be kept in a locked file cabinet at the investigator's office. At the end of five years, typed transcripts will be shredded, 
digital files will be deleted from the recording device, and all consent forms signed by participants will be shredded.

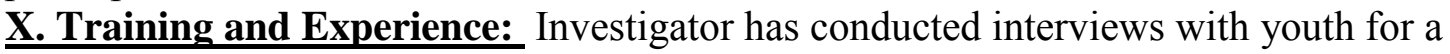
qualitative research project conducted through RRI. Investigator will be advised by Ben Anderson-Nathe during the course of the study. Investigator has completed NIH Human Subjects training (see attached certificate)

\section{Appendices}

I: Recruitment flyer

II: Interview questions

III: Introductory telephone script

IV: Informed Consent form

V: Transcriptionist confidentiality form

VI: Human subjects certificate 


\section{Appendix E}

Screening protocol

(Collect this information in initial phone or in person contact with potential participants)

Age

Identifier

This study is interested in the experiences of bisexually attracted young people when they were in high school. If you meet the criteria for inclusion in the study, and you choose to participate, you will receive a \$20 gift card as a thank you for your time. There are several options for the type of gift card you would receive such as iTunes, Starbucks, Subway, Fred Meyer, or a Visa gift card. If you are chosen to participate, you will be asked which card you'd prefer.

Thinking back to when you were in high school, which of the following statements BEST describes your attractions:

Only attracted to opposite sex (no attraction to same sex)

Mostly attracted to opposite sex (some attraction to same sex)

Equally attracted to both same and opposite sex

Mostly attracted to same sex (some attraction to opposite sex)

Only attracted to same sex (no attraction to opposite sex) 


\section{Appendix F}

Research Study

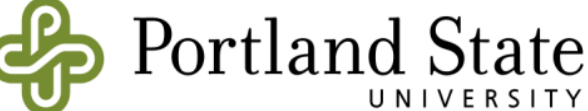

Are you:

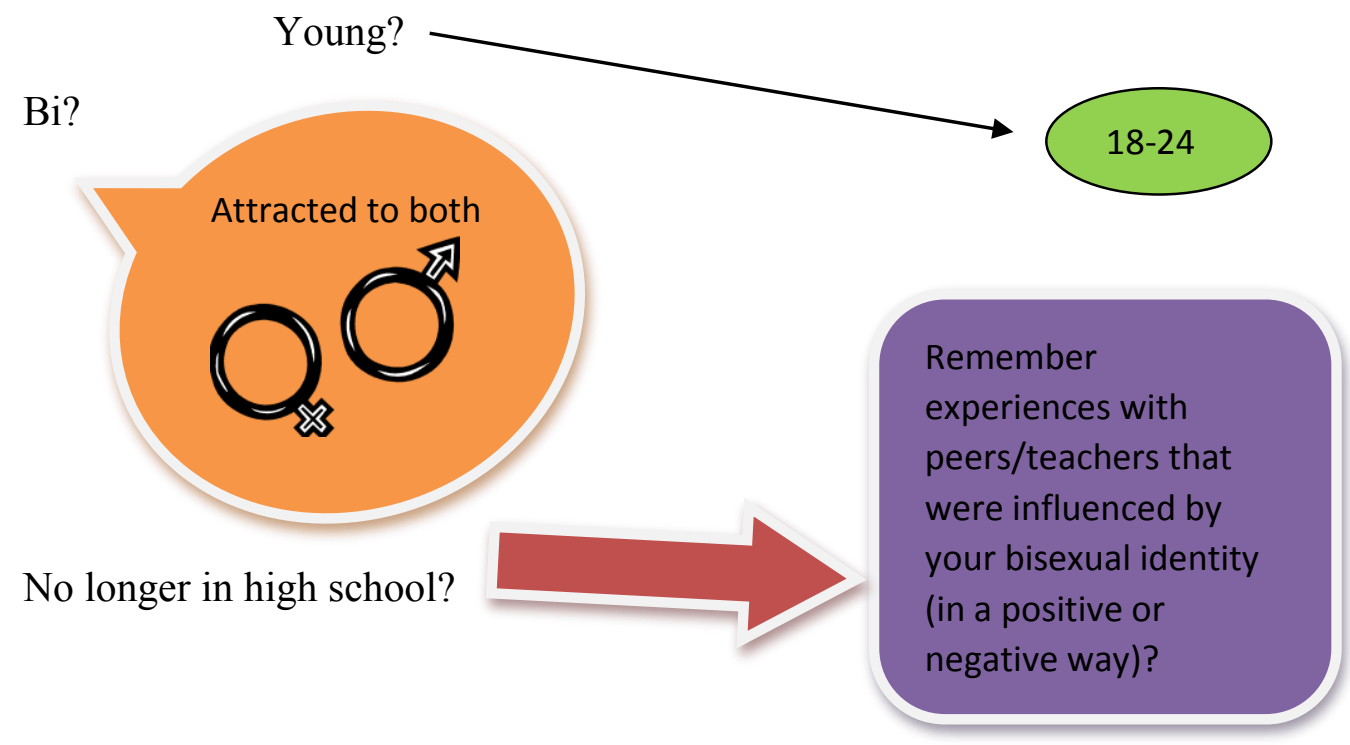

Then I want to hear your story!

I am a doctoral student at Portland State University and your experiences may be included as part of my dissertation. The purpose of the study is to better understand what kinds of social interactions young bisexual people have when they are in high school. If you agree to participate, I will ask you several questions about what you remember from high school and your social interactions. These interviews will take place in a location of your choosing. All information you provide will be kept confidential. You will receive a $\$ 20$ gift card in appreciation for your time.

Del Quest

Call me at 970.749.9726 or email me at adq@pdx.edu 


\section{Appendix G}

Participant bios

Amelia-Amelia was a 22 year old college student; moved to Portland to attend college from a large urban area in the southwest. She had a positive and supportive relationship with her parents; she adopted a role in high school of questioning teachers' and peers' assumptions about sexuality, marriage, gender, and religion as her way of working to educate others about these issues. She described some of her school experiences as painfully surprising in the way that she had to learn of the discriminatory attitudes of others for the first time. She talked about the open-minded and accepting attitudes of her parents and their friends and the surprise she felt when she experienced bias for the first time at her conservative Catholic high school. She learned by listening to those around her the things she would need to be careful about sharing about herself. An experience she had at high school that had the most profound impact on her in terms of how she engaged with others was the firing of two teachers for being gay and the rumor that the dean of students had disowned his son for being gay. She knew because of these things she would not be safe in her school so she learned to monitor what she said. This also raised her awareness of discrimination and taught her to engage in discussions about these things in a way that didn't implicate her but allowed her to teach others a little bit.

Aythn - was a 24 year old college student; lived in Portland all her life; raised by her grandparents because her mother experienced mental health issues and was declared unfit to raise her. Grandfather was verbally and emotionally abusive to her and she thought through the process of seeking help. She decided she wanted to stay in her grandparents' home because she at least knew what to expect and she was nervous about the unknown aspect of foster care and imagined she might be just as likely to get abused in that situation. She had a supportive relationship with someone she referred to as a sister who was not biologically related but who provided her with that kind of support. This person provided a sense of safety. Aythn's recollections about school seemed to be very emotionally based and she talked quite a bit about negative things that happened to her friends and how those things influenced the ways in which she sought out and engaged in peer relationships in school. She took the observations she got by watching the things that happened around her and modified the things she did at school and who she talked to and who she avoided.

Brittany - first interview done by phone; was a 20 year old, working, mother of a newborn baby. She was in foster care most of her life. Both of her parents used and sold drugs, and both were in prison. For a time she lived with a biological grandmother but the grandmother was frequently abusive to Brittany's brother so she ran away because she could noy stand to watch it. Her brother followed her a short time after she ran. She lived in several homes but talked about the experiences she had in one of them during the interview as having a profound impact on her self-esteem and her feelings about her 
attractions to more than one gender. She had imbued the foster mother in this home with a great deal of importance because she was seeking a mother figure and when this mother betrayed her trust and belittled her and ridiculed her in front of her foster sisters, she was devastated. Her experiences in high school were positive in terms of how others viewed her and her attractions. She witnessed her brother get bullied extensively because he was gay and she frequently jumped into these fights and protected him because he was her younger brother. The stories that had the greatest emotion as she shared them were all related to him and the abuse he had experienced.

CS - 22 years old; college student; from a large metropolitan area in the Pacific Northwest; all-girls Catholic high school; she had attended a public middle school and was experiencing attractions to more than one gender at that school; when she went to high school and was with all girls, she didn't feel attractions to them and was confused by the this - she thought if she had these attractions like she thought she did, why wasn't she attracted to any of her peers in the school; she shut down her thinking about sexuality at that time and didn't think about it again until college when she again felt attractions to more than one gender; she felt guilty for not talking with her family about it sooner because she was used to being honest with them and she felt like she was keeping something from them but it was related to her questioning and not that she thought they wouldn't accept her;

Emerald - 20 year old college student from small urban area in the Pacific Northwest; attended an alternative high school; this interview took place in a small agency serving LGBTQ youth where she said she spent a lot of her time because she felt comfortable there and had friends there who accepted her; she was out to her mother because her mother made her come out; she identified her mother as queer and said she thought she took advantage of the man she was married to and straight privilege

Emily - from a large metropolitan area in the intermountain west; attended Catholic high school; reported her school as being supportive and school years as the happiest of her life: she felt like an outsider on several levels: Catholic in a Mormon town and bi attracted in a catholic school; she talked about her mother as being open-minded but not necessarily about her; she came out to a sister with whom she fought all the time in hopes this sister would out her to her mother and then she could gauge her mother's reaction and say her sister was not telling the truth if her mother reacted badly; at the time of our interview she was not sure if her mother knew - she had not discussed it with her; she talked about her attractions in very concrete binary terms and intimated that when she chose a partner, that would decide if she was straight or lesbian

Jane - one of the interviews done by phone; mother died while she was in high school, raised by father; religion very important to her and this was one of the biggest obstacles she identified in terms of reaching an understanding of her attractions to both males and females: this was muddy for her as she was currently in a relationship with a trans* 
person; the loss of her connection to her church felt like losing her mother a second time as this church was something important to her mother and it remained a connection for Jane after her mother passed away; there was one adult in her life that supported her and offered her a sense of safety; she felt cared for by her father but knew he did not understand her making it difficult to be close to him

Kina - last interview; interviewed by phone; 18 year old; "unschooled" during high school; attended middle school until it became too stressful for her; she felt targeted in public school for a number of reasons and began to experience some depression so her parents agreed to let her home school. At the time of the interview she was attending a small liberal arts college; she had experienced support from her family who she characterized as open-minded and accepting; despite what she knew about them, she anticipated the coming out conversation with anxiety because she didn't want to tell them she was different than they thought she was and different from them; her father was happy she was in a relationship with a woman because he thought it meant he wouldn't have to worry about her getting pregnant and he thought it meant there was less chance of a partner hurting her; her struggles were with males who sexualized her relationships with women and she felt creeped on by males

Kylie -22 year old; identified as female when recruited for the study and male at the time of the interview. At the time of the interview he was living in a youth shelter in Portland after deciding to leave his parents' home in California because of their non-acceptance of him. He was attending college and looking for work. The important relationships he identified in his life as supportive of him were a librarian at his high school and his current case worker who was helping him access services. These two people were the only ones he identified as positive and supporting of his identity.

TD - 20 year old college student; relationships with family members were experienced as dismissive (her mother laughed when she told her she was attracted to males and females) and negative (she did not come out to her father based on an interaction she witnessed between him and her stepsister where he was hateful about the fact that she was trans*; told her he didn't understand how she could be like that and he just didn't like people like her because he had gotten hit on by males when he was younger and it bothered him so much); she didn't out herself to her father because she didn't want to experience something similar; she talked a lot about the concept of wanting a road map and how examples are there for hets and gays - there are role models who can provide examples of how to be gay or straight but there weren't the same things for those who were attracted to both males and females and she didn't know if what she was feeling were actually attractions since she was experiencing them in different ways - not having a role model left her confused and unsure of herself. She did not identify anyone in her life as a support 